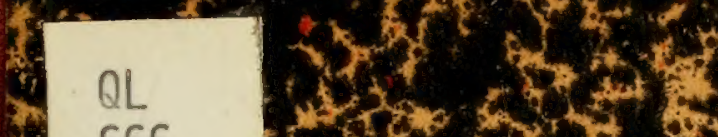

666

C5K96

REPT。

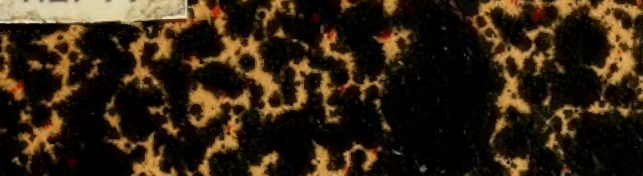

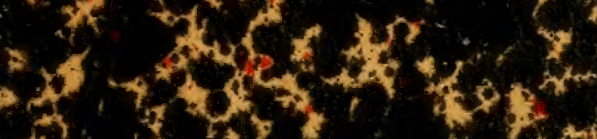

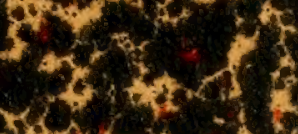

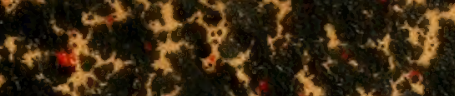

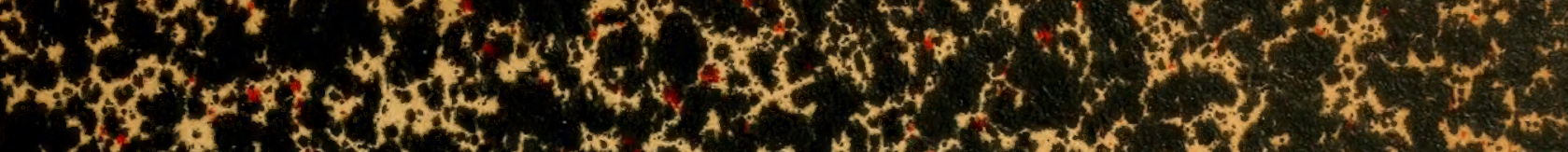

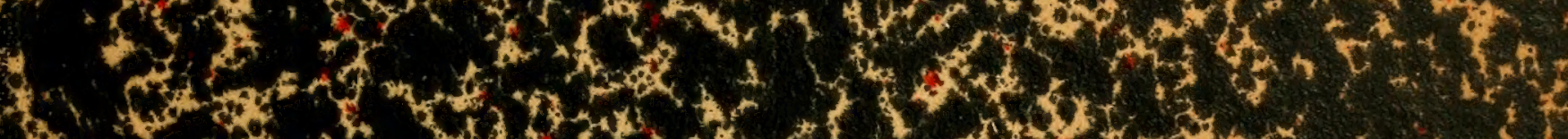

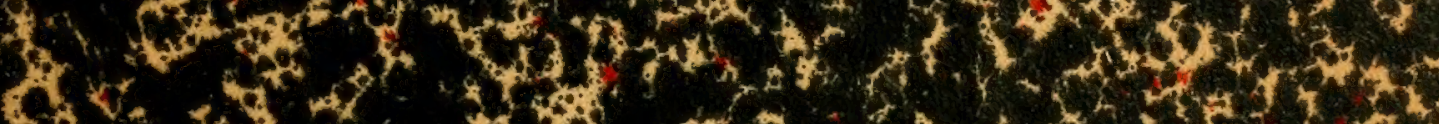

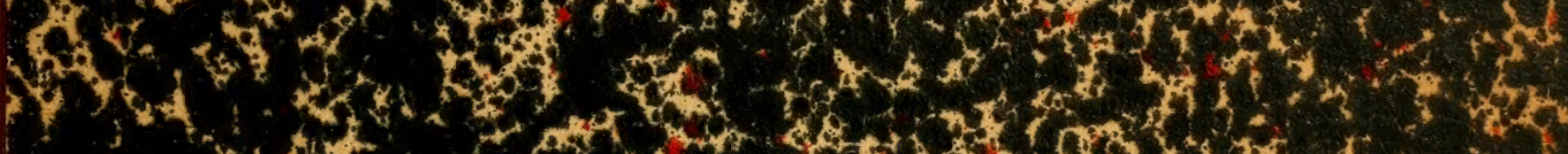

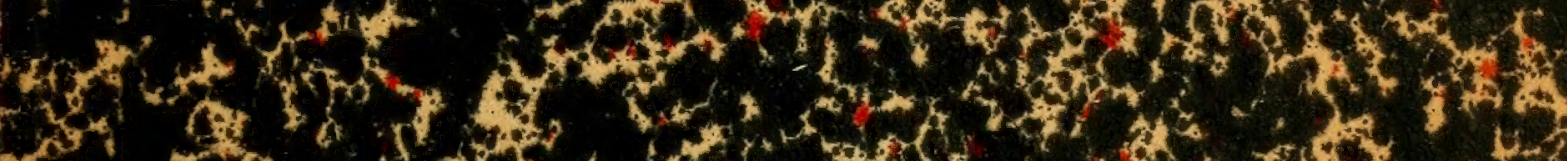

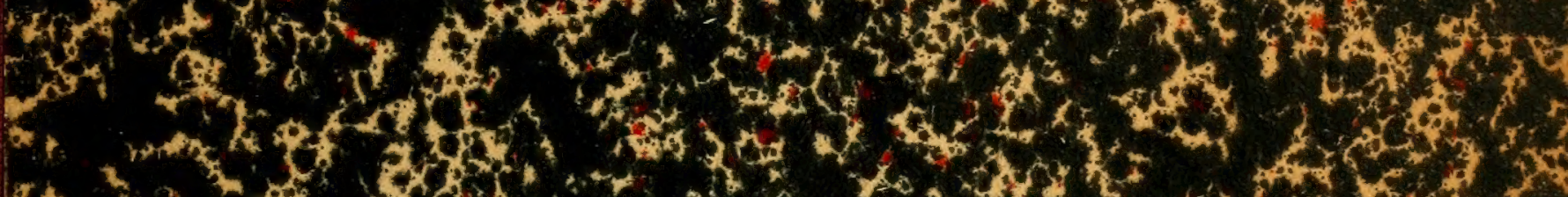

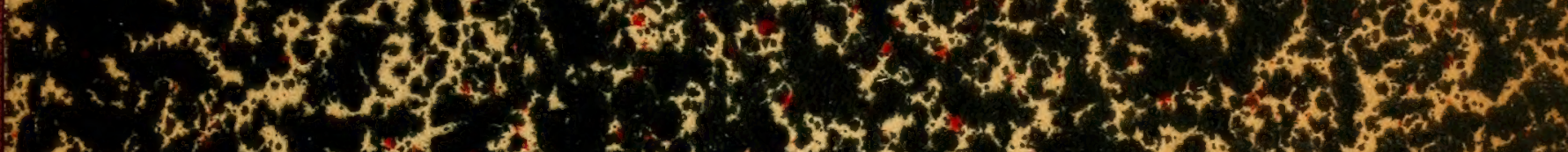

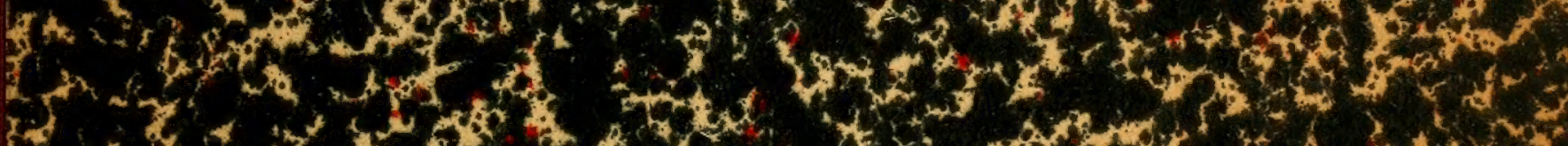

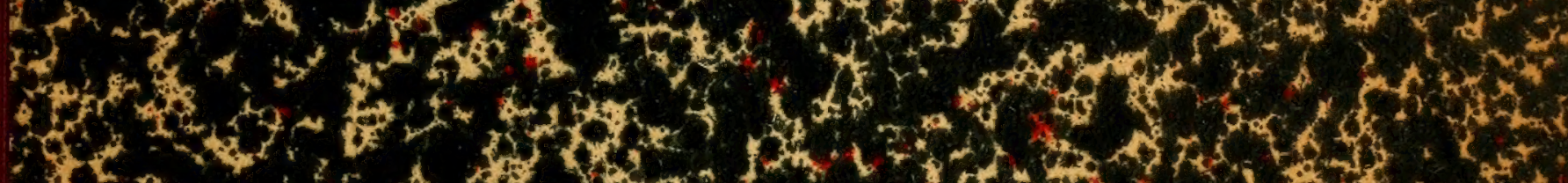

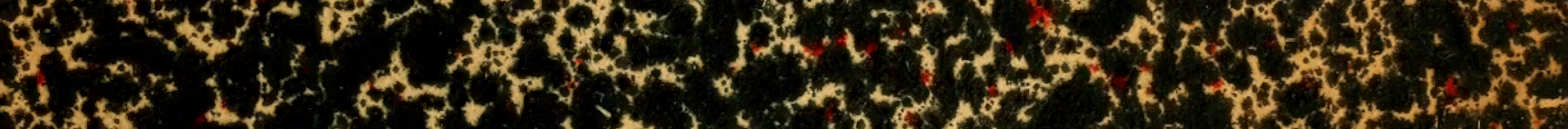

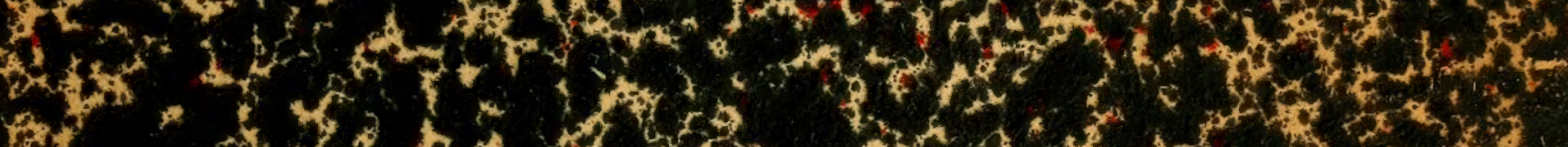

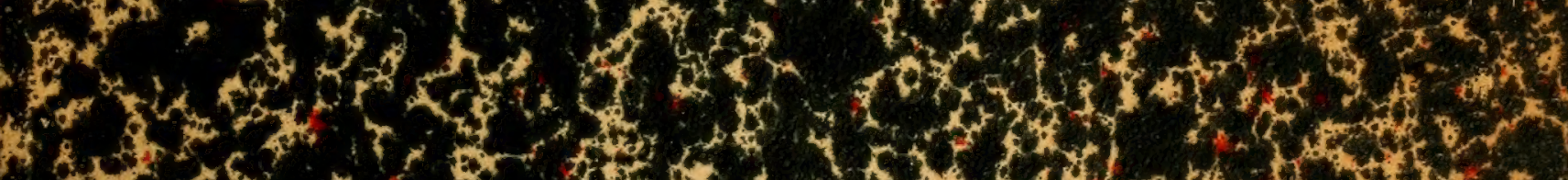

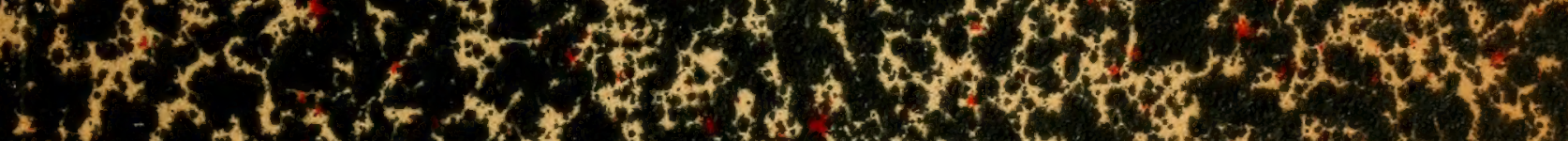

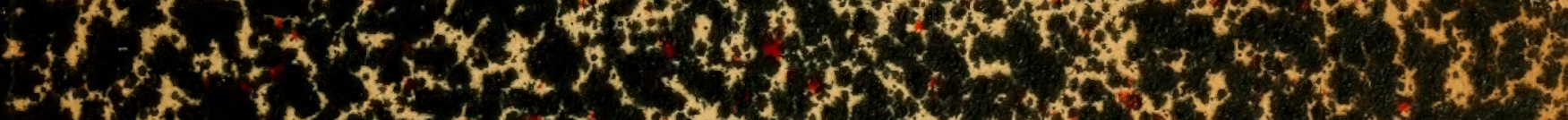

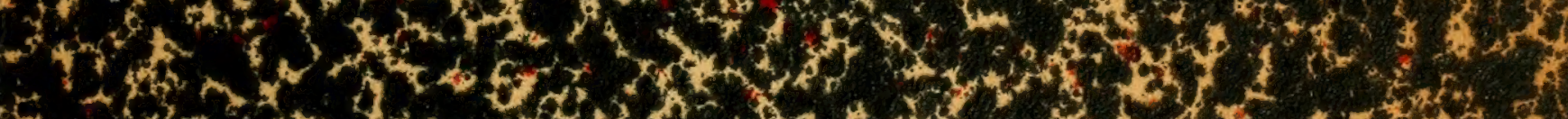

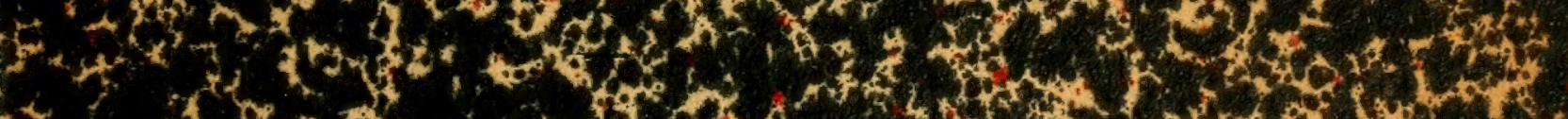

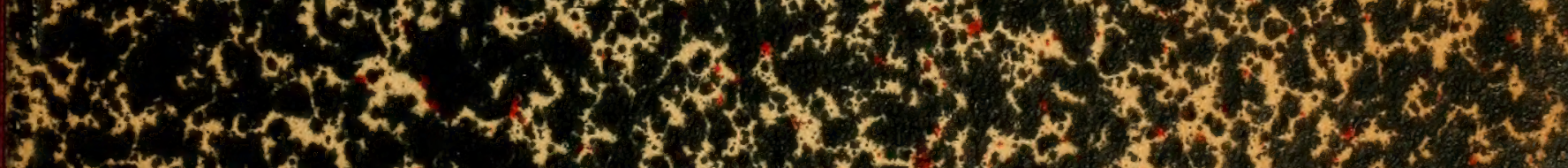

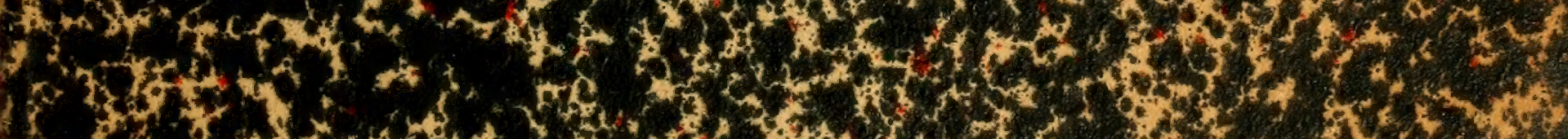

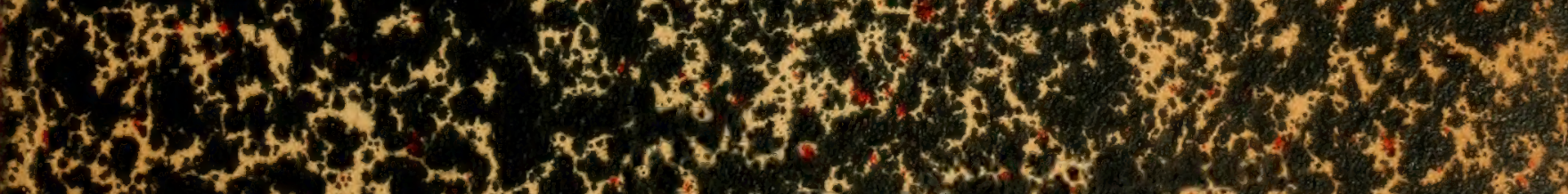

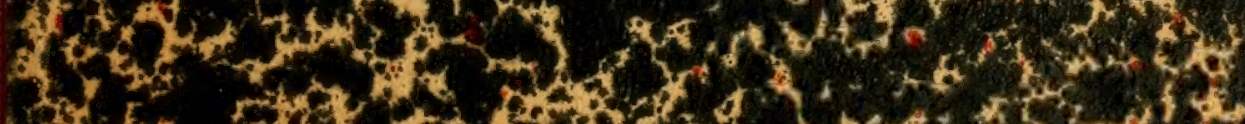
(5)

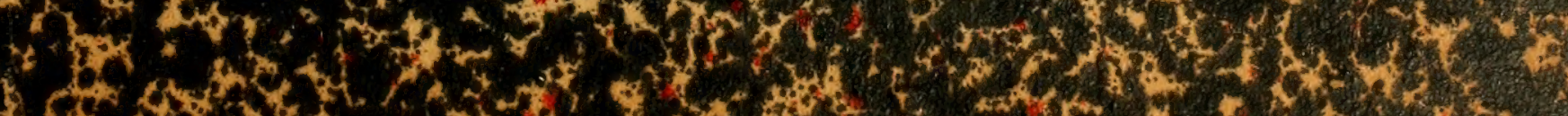
(1)

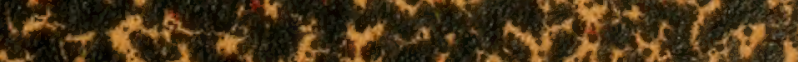





\section{The Development of the Skull of Emys Lutaria}

B. W. KUNKEL

From the Anatomisches Institut, Freiburg, 1. B., and the Sheffield Biological Laboratory of Yale University New Haven

RECV

CAT

Reprinted from JodRnal of MorphoLogy, Vol. 23, No. 4 , December, 1912 



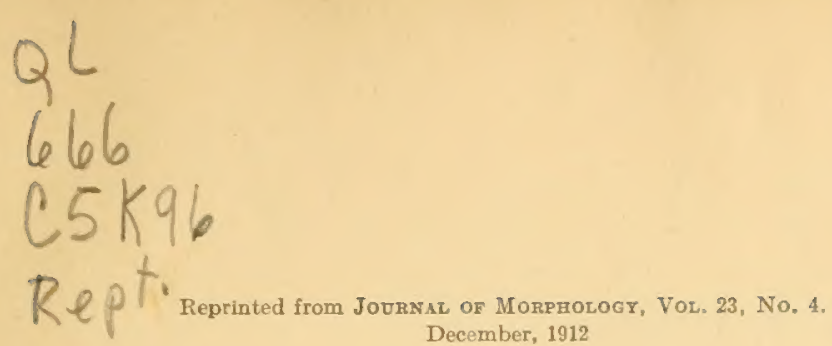

December, 1912

\section{THE DEVELOPMENT OF THE SKULL OF EMYS LUTARIA/}

B. W. KUNKEL

From the Anatomisches Institul, Freiburg iे. B., and the Sheffeld Biological Laboratory of Yale University, New Haven

THIRTY-ONE FIGURES

\section{CONTENTS}

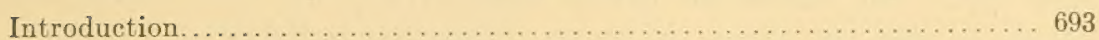

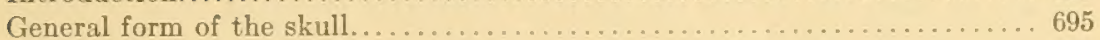

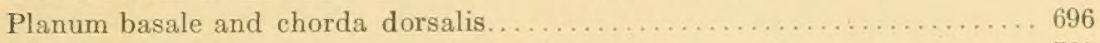

Regio oecipitalis............................................ 702

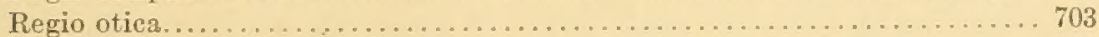

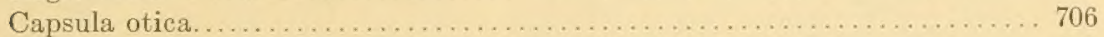

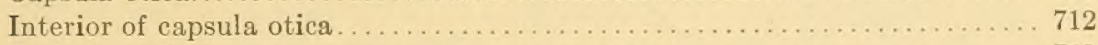

Tectum posterius. . . . . . . . . . . . . . . . . . . . . . . . . . . 719

Crista parotica. . . . . . . . . . . . . . . . . . . . . . . . . . . . . 719

Relation of the nerves in the regio otica...................... 720

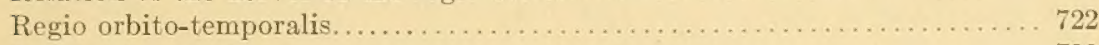

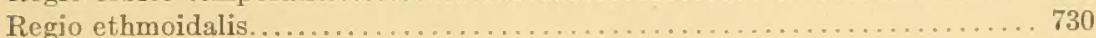

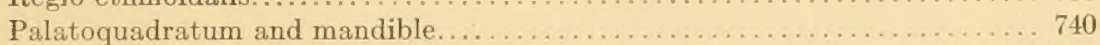

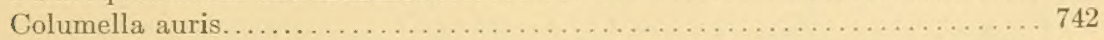

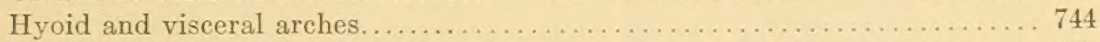

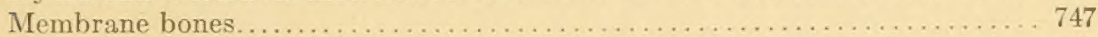

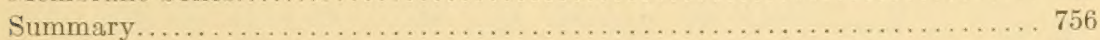

Bibliography. . . . . . . . . . . . . 761

\section{INTRODUCTION}

Although certain parts of the chondrocranium of the chelonia have already been studied to some extent, the only previous work which has aimed to furnish a picture of the skull and its development in its entirety has been that of Parker ('80) on the development of the skull of Chelone viridis. His results are of great value, but on account of imperfect methods, many details of structure and development escaped him and several errors occur. A preliminary account of the present work has already appeared (Kunkel '11).

693

JOURNAL OF MORPHOZOGT, vót. 23 , No. 4

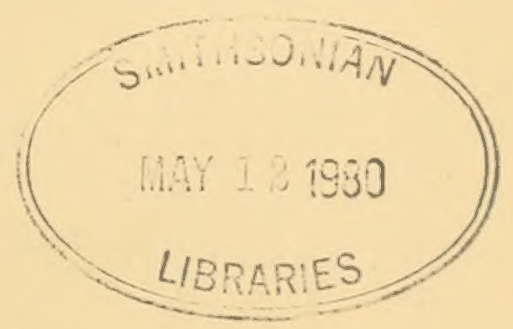


Of recent papers which deal with the chelonian chondrocranium especial reference should be made to that of Ogushi ('11) on Trionyx japonicus in which the cartilaginous as well as the bony elements of the adult skull are carefully described, and to the extensive paper of Nick ('12) on Dermochelys coriacea.' Neither of these deals with the embryonic condition of the skull. Several papers on the development of special regions may be referred to briefly. Seydel's ('96) conclusions regarding the development of the nasal capsules are confirmed, but several new facts which throw light on the significance of some of the characters of this region are set forth here for the first time. Noack's ('07) conclusion that the columella arises solely from the otic capsule is faulty in that my series shows the columella to be in reality made up of a stapes which arises external to the capsule and an extracolumella as has been described by Fuchs ('07) and Bender ('11). $\mathrm{My}$ own results accord with those of these investigators regarding the independence of columella and otic capsule. As to the significance of the stapes and extracolumella my results confirm Bender's as opposed to Fuchs's. The latter's conclusions regarding the development of the visceral skeleton I am able to confirm. Filatoff ('06) has called attention to the presence of a processus ascendens of the palatoquadratum in Emys.

Besides these papers may be mentioned also Filatoff's ('07) on the metamerism of the head of Emys, Fuchs's ('07) on the development of the roof of the mouth, and Thäter's ('10) on the same subject. Hitherto a complete account of the embryonic chondrocranium of the turtle and its development has been lacking so that comparisons have been possible only on the insecure basis of the adult condition.

In order to obtain a clear representation of the form relationships of the embryonic skull, a model was made by the Born wax

\footnotetext{
${ }^{1}$ In addition to these, should be mentioned a preliminary report by Fuchs (Ueber einige Ergebnisse meiner Untersuchungen über die Entwickelung des Kopfskelettes von Chelone imbricata. Verhandl. anat. Gesellsch., 26. Versamml. 1912, pp. 81-106.) Unfortunately further reference to it is impossible at this time. Of special importance is his demonstration of the derivation of the tropibasic skull from the platybasic type.
} 
plate method of an embryo of Emys lutaria in which the carapace measured $11 \mathrm{~mm}$. in length. The model represents the cartilaginous skull magnified fifty times with the membrane bones of the left side removed. At this stage the cartilage is well developed and ossification has not proceeded far enough to alter materially the original form of the chondrocranium. The membrane bones are fairly well developed although the parasphenoideum and quadratojugale as well as the complementare of the lower jaw appear first in older embryos than that modelled. The present study undertakes to determine the course of development of the chelonian skull from its early prechondral stage. A series of embryos and young with carapace lengths ranging from $4.7 \mathrm{~mm}$. to 28 $\mathrm{mm}$. forms the basis of the work.

It gives me pleasure to make the following acknowledgments: to Herr Professor Gaupp for the suggestion of the problem in the first place as well as for his constant valuable criticism and suggestions, and for the generous loan of many series of sections of Lacerta and Chelone embryos and of many papers from his private library; to Herr Professor Keibel who furnished me with a large number of embryos of Emys lutaria which were collected by Mehnert; and to Herr Geheime Rat Wiedersheim for the courtesies and facilities of the Anatomisches Institut of Freiburg i. B. where most of the work was done during the college year of 1910 11. To my father I am under obligation for material aid without which the present investigation could hardly have been undertaken.

GENERAL FORM OF THE SKULL

The cartilaginous skull of Emys lutaria resembles rather closely in its essential features that of Lacerta which has been so fully described by means of models by Gaupp ('00). The Chelonian skull is less elongated than that of Lacerta, especially in the anterior half, as is shown by the relatively anterior position of the fenestra hypophyseos. This is due principally to the fact that the septum interorbitale of the turtle is much shorter than in the lizards and the olfactory capsule, as will be shown later, is bent ventrally so that it comes to lie to a greater extent ventral rather than anterior to the orbital portion of the skull. Besides being 
of more compact form on account of the shortening of the space between the olfactory and otic capsules, the numerous fenestrae of the lizard skull are reduced both in number and size. At the same time also, the slender rods of the lizard's skull are to a great extent replaced by broad, more or less continuous, plates. In this respect the chelonian chondrocranium resembles more nearly that of Sphenodon as described by Schauinsland ('00) and Howes and Swinnerton ('01) and that of the crocodile described by Parker ('83) than it does that of the lizards (Gaupp '00) and snakes (Parker '78). 'The greater strength of the jaws of the adult chelonian and crocodilian seems to be early foreshadowed in the embryo by the greater solidity of the skull, especially in the portions more intimately associated with the jaws. Notwithstanding, however, this greater solidity of the chelonian chondrocranium, in one respect it seems to be weaker in that it lacks the taenia marginalis which couples the orbital region with the otic capsule dorsally. In Emys the orbital and temporal regions are discontinuous except for the trabeculae which lie near the mid-ventral line, and the temporal and otic regions are discontinuous except ventrally because of the absence of the taenia marginalis. More detailed comparisons of the reptilian chondrocrania will be made below, under the respective parts of the skull.

\section{PLANUM BASALE AND CHORDA DORSALIS}

The basal plate forms the entire floor of the parachordal portion of the chondrocranium (fig. 25) extending forward from the occipital condyle through the occipital and otic regions. It is simple and continuous as far forward as the anterior half of the otic capsule where the hexagonal fenestra basicranialis posterior is situated. In front of this space the floor of the skull is represented by a heavy, transverse bar, the crista sellaris, which forms the hinder boundary of the fenestra hypophyseos $(f . h$.$) .$

There can be but little doubt that the part of the skull here $\checkmark$ referred to as basal plate is made up in part, in the otic region, from the floor of the otic capsule. In a much younger stage (carapace length, $4.7 \mathrm{~mm}$.) the boundary between the blastema of the basal plate and that of the otic capsule is quite distinct. 
From this embryo it is seen that the blastema of the otic capsule extends medially slightly beyond the median wall of the membranous labyrinth, so that the basal plate proper is greatly reduced in width, and its lateral margins are slightly concave antero-posteriorly because of the position of the floor of the otic capsule. The fusion between the floor of the otic capsule and basal plate is complete in the stage modelled so that no line of demarcation is visible.

In general form the basal plate in the stage modelled may be regarded as hexagonal, exhibiting short anterior and posterior sides extending transversely, and antero-lateral and posterolateral sides. Extending along the mid-ventral line from in front of the occipital condyle to the fenestra basicranialis posterior is a low, rounded crest formed by the chorda dorsalis which in Emys lies in the same plane with and enclosed by the basal plate and at this stage is so large as to cause the latter to bulge both dorsally and ventrally in the regions where the basal plate is quite thin. Immediately behind the fenestra basicranialis posterior, the basal plate on each side of the middle line exhibits a gentle convexity on its ventral side which is caused by the extension of the pars cochlearis as will be described later. The postero-lateral and antero-lateral margins of the basal plate do not pass directly over into the lateral portions of the occipital and otic regions, as in Lacerta, but show a tendency to project freely laterally in the form of crests. The postero-lateral margin projects laterally and slightly ventrally as the crista inferior (c.i., fig. 1), whose posterior end terminates freely at the side of the base of the condylus occipitalis. This crest lies ventral to the anterior end of the fissura metotica and foramina spiro-occipitalia which thereby come to open into a groove between the crista inferior and the lateral portion of the occipital region. This groove, lateral to which the ganglia vagi and spino-occipitalia lie, may be called the 'sulcus supracristularis' (s.s., fig. 1). Laterally the margins of the basal plate project beyond the otic capsule, except in the posterior portion of the latter, to form a crista substapedialis (c.st., fig. 4), a horizontal shelf which is continuous anteriorly with the crista basipterygoidea and on which the foot plate of 
the columella auris rests ventrally, and under which the ramus communicans $\mathrm{n}$. facialis cum glossopharyngeo lies. The anterolateral margin of the basal plate projects as a long ridge which passes directly into the trabecula cranii in front. This is the crista basipterygoidea ( $p r . b .$, fig. 7 ) and represents the processus basipterygoideus of Lacertá, as will be shown later. It is inclined slightly ventrally so that a shallow groove is formed along the margin of the ventral surface of the basal plate in which lie the ramus palatinus $n$. facialis and arteria carotis interna (fig. 7). Accordingly it corresponds to the sulcus cavernosus of the adult pterygoideum (s.c., fig. 25).

The dorsal surface of the basal plate exhibits a longitudinal ridge in the middle line which becomes less conspicuous posteriorly, disappearing completely in the condylar region. It is produced by the chorda dorsalis whose diameter is greater than the vertical thickness of the basal plate along the middle line. The thickness of the basal plate varies, decreasing markedly from the posterior end.

The fenestra basicranialis posterior (f.b.p., fig. 25) is of a broad, hexagonal form with anterior and posterior margins extending transversely and with lateral angles. It lies in the anterior half of the basal plate between the anterior portions of the two otic capsules, with its anterior margin formed by the crista sellaris. At the stage modelled it is closed by a membrane of dense connective tissue beneath which the chorda dorsalis extends.

The crista sellaris (c.s., fig. 25) forms a heavy transverse bar between the fenestra basicranialis posterior behind and the fenestra hypophyseos in front. In the mid-ventral line it exhibits a pronounced longitudinal ridge, separating two longitudinal grooves, while its lateral margin projects freely ventro-laterally continuous with the crista basipterygoidea. Within the groove thus formed, between the median crest of the crista sellaris and the projecting lateral crests, lie ramus palatinus $\mathrm{n}$. facialis and arteria carotis interna.

Between the crista inferior and the pars lateralis of the occipital region extends the sulcus supracristularis, a wide groove facing laterally. In front it is limited by the posterior wall of the otic 
capsule. Along the dorso-median wall of the sulcus open the three foramina spino-occipitalia and at its anterior end opens the ductus perilymphaticus. The ganglia vagi and spino-occipitalia are situated lateral to the groove.

The foramina spino-occipitalia and facialis lie rather in the lateral portion of the cranium than in the basal plate, but they may be conveniently described at this time. There is some variation in the number and relations of the foramina spino-occipitalia in the series of embryos studied, although they always lie in two horizontal lines, which converge in front, and are ventral to the bases of the arcus occipitales and fissura metotica. They pierce the basal plate in a ventro-lateral direction and open exteriorly in the sulcus supracristularis. In the individual modelled there are three pairs of foramina, of which the anterior is the smallest and the posterior the largest. The middle foramen is equally distant from the other two. In the adult, as is well known, the first and second pairs of nerves leave the cranial cavity through the same foramen, and only two pairs of foramina spinooccipitalia are present. In two younger embryos having a carapace length of from 7 to $8 \mathrm{~mm}$. the adult condition was met with. In one embryo, older than that modelled, the first and second foramina were united at their external ends but completely separated from each other internally. On the other hand in one of the oldest individuals studied all three pairs of foramina were quite distinct as in the model.

The foramen facialis $(f, f$., fig. 6 ) lies well in front of the anterior end of the otic capsule and relatively far laterally in the side portion of the otic region. Behind this foramen the basal plate is continuous with the otic capsule for a long space. In front of it there is only a slender commissure uniting the basal plate and the cupula anterior of the capsule.

The foramen abducentis ( $f . a$. , figs. 8 and 2t) passes horizontally forward at the anterior end of the crista sellaris, as a moderately long canal opening anteriorly ventral to the pila prootica and dorsal to the crista basipterygoidea, and posteriorly on the dorsal surface of the basal plate immediately behind the proximal end of the pila prootica. 
The basal plate is separated from the cupula posterior of the otic capsule by the triangular, ventral portion of the fissura metotica; and from the cupula anterior by the fenestra prootica. Between these two foramina the basal plate is continuous with the capsule except for the formen facialis which is so situated as to leave a slender commissure uniting the basal plate and otic cepsule between itself and the fenestra prootica.

The relations of the chorda dorsalis to the basal plate are of considerable interest. In the embryo modelled the chorda passes without interruption from the anterior face of the dens epistrophei into the posterior end of the condylus in which region it is completely imbedded in cartilage. It is surrounded directly by a sheath which is continuous with the perichondrium of the basal plate in front and from which, in the region between the dens and condylus, the ligamentum apicis dentis is derived.

In front of the condyle, where the basal plate becomes gradually thimner, as far forward as the fenestra basicranialis posterior, the chorda lies in the same plane with the basal plate and tends to divide it into two symmetrical halves. The basal plate, accord- ingly, is parachordol, as has been already described in the skull of $\checkmark$ snekes, crocodilians, and Sphenodon; and not hypochordal as in Lacerta. This condition, however, is probably secondary, since in younger individuals in which the condyle is not yet developed, the basal plate immediately in front of the condylar region is hypochordal to within a short distance of the fenestra basicranialis posterior where it becomes parachordal.

The tissue immediately dorsal and ventral to the chorda in the region posterior to the fenestra basicranialis posterior is reduced to a very thin layer and is not fully chondrified in the stage modelled. In passing through the fenestra basicranialis posterior the chorda is enclosed in a membranous sheath which is continuous with that which fills the fenestra, although it comes to lie in a plane ventral to the basal plate.

The chorda dorsalis is lodged posteriorly on the dorsal surface of the crista sellaris in a deep groove whose sides gradually close together anteriorly, converting the groove into a canal which 
extends forward through the crista and opens on its anterior surface into the fenestra hypophyseos.

In passing through the crista sellaris the chorda tapers from the uniform diameter which it exhibits posteriorly to a rounded point.

As might be expected in a part undergoing rapid degeneration, the anterior end of the chorda exhibits considerable variations in its relations to the crista sellaris. In several specimens it was bent in a dorso-ventral direction within the crista so that the anterior portion lay in a plane dorsal but parallel to the posterior portion. In most of the embryos studied the crista was completely perforated by the canal for the chorda, but in one young embryo the canal terminated within the cartilage. In another embryo only slightly younger than that modelled, the anterior end of the chorda projected freely into the fenestra hypophyseos while in the model, as in most of the specimens studied, the end of the chorda was flush with the anterior surface of the crista.

At the extreme caudal end of the condylus in the embryo modelled, the chorda is completely surrounded by cartilage, but in a very slightly younger embryo the condylus at its extreme caudal end exhibits a U-shape in cross section quite similar to that of Lacerta; that is, the chorda was surrounded only ventrally and on. the two sides with cartilage (fig. 15). Later, however, the chorda is completely surrounded. Immediately surrounding the chorda the cartilage becomes excavated to form a cup-like depression, the central cavity, into which the dens epistrophei fits. The chorda passes from the anterior face of the epistropheus into the posterior face of the condyle, forming a condylus anularis characteristic of the Chelonia. The ventral surface of the condyle articulates with the atlas which projects ventrally to it.

In contrast with the condyle of Lacerta, as Gaupp has shown, that of Emys does not exhibit the two processes, one on each side of the chorda dorsalis, but rather a single ring-like process around the chorda dorsalis. In view, then, of the embryonic condition in Lacerta, the derivation of the mammalian condyles from those of reptiles is not improbable. In Chelone, according to Gaupp, the chorda enters the condyle from the ventral side so that, 
even in the adult of this form, the central cavity of the condyle, in which the ligamentum apicis dentis is inserted, lies near the ventral margin of the posterior surface of the condyle.

\section{REGIO OCCIPITALIS}

The occipital region, like that of Lacerta, may be differentiated into a basal and two lateral parts. A dorsal region is lacking, although the tectum posterius, which is continuous with the otic capsules, and hence properly belongs to the otic region, projects caudally with its strongly developed processus posterior and closes in the foramen occipitale magnum dorsally.

The basal portion is represented by the basal plate including the condylus and cristae inferiores (fig. 1), and the lateral parts by the arcus occipitales, which are continuous ventrally with the basal plate and extend freely dorsally, separated from the otic capsules in front by the fissura metotica and not united distally with the tectum posterius. Because of the separation distally of the arcus occipitales from the tectum, it is evident that at this stage the fissura metotica and formen occipitale magnum are not completely separated from one another.

The condylus occipitalis projects posteriorly as a cylindrical process with convex ventral surface and flat, or even slightly concave, dorsal surface so that a cross section is reniform. Its free distal surface is flat except for a slight depression which extends dorsally from the canal in which the chorda lies and gradually deepens toward the dorsal surface of the condyle. The free end of the condylus is embraced, except for a short space on the dorsal side, by the atlas, which has the form of an incomplete ring and projects forivard ventral to the condyle as a stout process.

In later stages the ossification of the condylus is seen to proceed from three centers, one ventral to the chorda and one on each side of it; corresponding to the basioccipitale and two pleuroccipitalia respectively.

The lateral portions of the occipital region are represented by the arcus occipitales which arise from the dorsal surface of the basal plate in the region of the foramina spino-occipitalia. The arcus occipitales are stout, curved, sightly tapering prismatic 
rods which recall strikingly the neural arches of the vertebrae. Their medial margins are curved regularly to enclose the foramen occipitale magnum laterally; their external margins, however, exhibit a more angular contour because of a marked thickening midway between their base and apex against which the otic capsule rests posteriorly. The fissura metotica is accordingly greatly narrowed here but not completely obliterated. The arcus occipitales bound the foramen occipitale magnum laterally and the fissura metotica posteriorly and medially.

The foramen occipitale magnum is large and of hexagonal form, with its dorsal and ventral margins transverse and with lateral angles. Its plane is vertical and transverse. The condyle and basal plate form its ventral margin, the curving arcus occipitales its lateral margins, and the free posterior margin of the processus posterior of the tectum posterius its dorsal margin.

\section{REGIO OTICA}

In contrast to the occipital the otic region is complicated. The basal plate forms the floor, the otic capsules the lateral walls and the tectum posterius the dorsal portion. Of the basal plate there should be mentioned the large, hexagonal fenestra basicranialis posterior in the anterior part of the otic region and bounded anteriorly by the crista sellaris. The antero-lateral margins of the basal plate are extended ventro-laterally beyond the connection with the otic capsule, and form the posterior end of the crista pterygoidea. The lateral margin of the basal plate extends laterally, beyond the anterior and middle thirds of the capsule, as the crista substapedialis (c.st., fig. 4). Posterior to the level of the fenestra vestibuli the lateral margin of the basal plate passes into the lateral capsular wall; in front of this fenestra, however, the lateral extension of the basal plate becomes gradually more pronounced.

The basal plate and otic capsule are in connection with each other for a considerable space, extending from the fenestra prootica in front to the foramen jugulare behind and interrupted only by the foramen facialis which is well in front of the cochlear portion of the otic capsule and separated from the fenestra pro- 
otica by a short and comparatively slender rod, the commissura praefacialis which extends dorsally and laterally from the basal plate to the ventral aspect of the anterior cupula of the otic capsule. Behind the foramen facialis the median wall of the cochlea passes continuously into the basal plate along a curved line which is concave on the lateral side.

The prefacial commissure, together with the anterior cupula of the capsule, forms the posterior margin of the fenestra prootica in which is located, immediately below the capsule, the ganglion semilunare of the nervus trigeminus (g.s., fig. 7). Unlike the condition in Lacerta, the ganglia of the three rami are closely united so that they appear as a single ganglion wholly within the fissure, except the anterior extremity which lies external and ventral to the pila prootica; whereas in Lacerta the ganglion of the ramus ophthalmicus lies widely separated from the others, quite far in front of the slender pila prootica.

The fissura metotica $(f . m$.$) is a narrow slit, widening ventrally$ to a large triangular space, situated between the otic capsule on the one hand and the basal plate and arcus occipitalis on the other. The otic capsule forms the anterior and lateral boundary of the fissure, and the arcus occipitalis, the posterior and medial one. In its narrow dorsal portion the capsule comes to lie somewhat external to the occipital arch so that the fissure opens nearly transversely, while its extensive ventral portion faces laterally. Dorsally the fissure is continuous with the foramen occipitale magnum as already deseribed, although its dorsal portion is closed by a mass of connective tissue.

In the expanded ventral portion of the fissure are situated the nervus vagus, vena jugularis, and ductus perilymphaticus in their passage to the exterior of the skull. The ductus perilymphaticus occupies the extreme ventral corner of the fissure. Dorsal to the ductus perilymphaticus, but still within the triangular expansion of the fissure at its ventral end, are situated the jugular vein and vagus nerve which in the adult pass out of the cranium through the foramen jugulare externum (f.m., fig. 1).

Beneath the canalis perilymphaticus on the left side of figure 2 there may be seen a narrow groove which becomes wider in a pos- 
terior direction from the section figured and which becomes converted into a very fine tube anteriorly by the growing together of the walls of the groove dorsally. In the embryo modelled the tube extends through only two or three sections and ends blindly posterior to the cavum cochleae. It apparently is the canalis hypoperilymphaticus which Nick ('12) has described in Dermochelys, Chelydra, and Chelone; like that of the two latter it contains no blood vessels but only a very loose connective tissue. In an older embryo (carapace length of $13.5 \mathrm{~mm}$.) this canal has increased considerably in size so that it is one-third as large in diameter as the canalis perilymphaticus and it communicates anteriorly with the cavum cochleae at the most ventral and posterior portion of the latter. While the canalis hypoperilymphaticus apparently is not differentiated at a much earlier stage than that modelled, in an individual recently hatched of $28 \mathrm{~mm}$. in carapace length, the canal was large.

The posterior wall of the cochlea, which is perforated by the large, oval fenestra cochleae, bounds the fissura metotica in front. This fenestra opens anteriorly into the cavum cochleae along the median wall of the capsule and posteriorly into the extreme anterior end of the sulcus supracristularis. The anterior end of the sulcus supracristularis corresponds quite closely with the recessus scalae tympani, as described by Gaupp in Lacerta. This region communicates with the otic capsule by means of the fenestra cochleae, with the cranial cavity by the extreme anterior end of the fissura metotica, and opens widely throughout its extent to the exterior of the cranium. These communications represent respectively the fenestra cochleae (s. rotunda), apertura medialis recessus scalae tympani, and apertura lateralis recessus scalae tympani.

The principal differences in the relationships of these three openings in Lacerta and Emys lie in the fact that the plane of the fenestra cochleae in the latter is vertical, while that of Lacerta is horizontal, and also in that the front margin of the apertura lateralis recessus scalae tympani lies slightly behind that of the apertura medialis in Emys. These slight differences are explicable by the fact that the cochlea in Emys has developed in a pos- 
terior direction, as is also indicated by the relation of the nervus glossopharyngeus to the otic capsule. This change in relations may be imagined to have taken place by supposing that the posterior extension of the floor of the cochlea has occurred principally in front of the fenestra cochleae and has been more rapid on the antero-ventral aspect of the sac than on the postero-dorsal. In this event it is apparent that a foramen, for example, which originally lay in the floor of the capsule will be rotated to occupy the posterior wall. In the same way also, should the growth in a posterior direction be more rapid laterally than medially where the proximity to the basal plate would retard the extension, the external aperture of the recess would come to be somewhat posterior to the internal aperture.

\section{CAPSULA OTICA}

In general form the otic capsule may be compared to a triangular prism with one long edge situated ventrally and with the broadest face vertical and medial; accordingly there are an anterior and a posterior base and also a latero-dorsal and lateroventral face, as well as a median one. The two prisms lie with their axes horizontal and their median faces diverging only slightly from ventral to dorsal and from posterior to anterior. In contrist to the condition in Lacerta the lateral walls of the cranium are more fully represented by the otic capsules and the brain is confined more completely by them without exhibiting a tendency to extend laterally dorsal to the capsules. On account of the unusual extension of the sacculus and lagena in a ventral direction the height of the capsule is almost as great as the greatest length of the same. The two bases of the prismatic capsule project in its long axis as a cupula anterior and posterior, the latter of which is the more pronounced. The cupula anterior bounds the dorsal portion of the fenestra prootica posteriorly and projects freely without connection with other parts of the skull. The cupula posterior bounds the fissura metotica anteriorly and laterally, extending caudally to lie external to the occipital arch as already described. The two capsules are united dorsally by the tectum posterius whose slender lateral rods arise 
gradually from them as triangular plates. The comparatively simple prismatic form is greatly modified by a number of prominences which for the most part follow the underlying parts of the membranous labyrinth though not as closely as in Lacerta because of the greater thickness of the capsular walls.

The capsule may be differentiated into a dorsally situated vestibular portion and a smaller, ventrally situated cochlear portion which encroaches upon the basal plate, as already described. The vestibular portion exhibits prominences corresponding to the semicircular canals, with their ampullae, and the utriculus; the cochlear portion which remains simpler in its external form, exhibits a flattened, oval, pocket-like form.

The prominentia semicircularis anterior (fig. 28) forms the dorsal and antero-dorsal margins of the otic capsule. Its ventral end, situated in the cupula anterior, widens to accommodate the ampulla anterior which lies in a somewhat oblique position so that it does not produce a marked convexity in the capsular wall. The plane of the anterior semicircular canal inclines medially from ventral to dorsal and from anterior to posterior. The prominentia semicircularis posterior is continuous in front with the anterior prominence and curves along the dorsal and posterior margins of the capsule to the cupula posterior. The dorsomedian edge of this prominence is continuous for its middle third with the tectum posterius. The plane of the canal inclines medially from below and in front, so that its ventral end projects laterally much as does that of the anterior canal. The prominentia ampullaris posterior forms a marked convexity on the lateral wall of the capsule below the ventral end of the posterior semicircular canal and dorsal to the crista parotica (cr.p., fig. 28); the prominentia ampullaris posterior accordingly forms the postero-ventral margin of the capsule and bounds the anterior end of the fissura metotica. On the median wall it forms a continuous area with the gently bulging prominentia utricularis which forms an area continuous in front with the prominentia sinus superioris utriculi, ventrally with that of the sacculus, posteriorly with the prominentia ampullaris posterior, and dorsally with the prominentia.semicircularis posterior. On the median 
capsular wall the prominencos of the anterior and posterior semicircular canals unite with the dorsal end of the prominentia sinus superioris utriculi.

The prominentia semicircularis lateralis with that of its ampulla forms a horizontal ridge which is situated on the lateral surface of the capsule between the ventral ends of the anterior and posterior canals, and which broadens anteriorly to accommodate the ampulla. A decided triangular depression marks this ridge off dorsally from the other two canals. Ventrally it passes gradually into the prominentia saccularis except at its anterior end where the prominentia recessus utriculi is situated.

The prominentia recessus utriculi on the lateral aspect of the otic capsule occupies a circular space ventral to the combined prominences of the ampullae lateralis and anterior, dorsal to the foramen facialis, and antero-dorsal to the fenestra vestibuli. On the median face of the capsule it forms a gentle triangular. convexity with its posterior angle situated immediately dorsal to the foramen acusticum posterius; its antero-ventral angle dorsal to the foramen facialis and anterior to the foramen acusticum anterius. The prominentia recessus utriculi is separated above from that of the anterior semicircular canal by the shallow fossa subarcuata; it passes imperceptibly into the prominentia ampullaris anterior in front, and is bounded ventrally by a line joining the foramina facialis and acusticum posterius; it is continued posteriorly between the latter and the foramen endolymphaticum and forms a marked convexity for the ductus endolymphaticus immediately dorsal to its opening into the sacculus, and ventral to the foramen endolymphaticum.

The prominentia sinus superioris utriculi extends obliquely antero-dorsally from the foramen endolymphaticum to unite with the dorsal ends of the prominences of the two vertical semicircular canals. In front it forms the posterior boundary of the fossa subarcuata, posteriorly it is continuous with the combined prominentiae utricularis and ampullaris posterior.

The prominentia saccularis occupies the entire ventral third of the capsule. In contrast to the condition met with in most of the vertebrates, the cochlea of the chelonians extends posteriorly 
instead of anteriorly so that the unique condition is met with in that the nervus glossopharyngeus passes through the cavity of the cochlea in its passage from the cranium to the exterior, as will be described more fully later. On its lateral aspect the prominentia saccularis is semicircular with its convexity below. It is situated behind the foramen facialis and the prominentia recessus utriculi and beneath the prominentia semicircularis lateralis, and passes posteriorly beyond the foramen glossopharyngei externum. Its ventral wall is the basal plate. As already mentioned the prominentia saccularis is apparent from the ventral side of the skull as a gentle convexity of the basal plate which lies behind the level of the fenestra basicranialis posterior. On the median aspect of the otic capsule the prominence extends posteriorly from the region of the foramen acusticum anterius posteriorly as far as the anterior angle of the fissura metotica. The convexity of the prominentia saccularis medially is more pronounced in its anterior portion immediately behind the slender side piece through which the $\mathrm{n}$. facialis passes than posteriorly so that the foramen acusticum anterius, which is situated in this region, comes to face somewhat anteriorly as well as medially.

The crista parotica forms a stout prismatic structure with its ventral surface horizontal and extending forward from the ventral limits of the prominentia ampullaris posterior and projecting freely for a very short distance in front.

The fenestra vestibuli (s. ovalis) (f.v., fig. 28) is situated in the ventral part of the lateral wall of the otic capsule, in the middle of the saccular region between the foramen glossopharyngei externum and foramen facialis, slightly nearer the former than the latter. It is of equilateral triangular form to accommodate the foot plate of the columella auris. Its ventral margin is horizontal and is formed by the basal plate which projects laterally beyond the capsule as a kind of horizontal shelf on which the foot plate of the columella rests (fig. 5).

Behind the fenestra vestibuli and separated from it by a slender rod sloping obliquely postero-ventrally, is the external opening for the n. glossopharyngeus (f.g.e., fig. 28). This is 
situated ventral to the prominentia ampullaris posterior and at the postero-dorsal angle of the prominentia saccularis.

On the median wall of the otic capsule are five or six foramina arranged in two horizontal rows. In the ventral row are the foramina acusticum anterius and posterius and the median opening for the glossopharyngeal nerve. The foramen acusticum anterius is small and is situated above and behind the foramen facialis and ventral to the prominentia recessus utriculi. Close behind the anterior foramen is the much larger, oval foramen acusticum posterius which is situated in the antero-dorsal portion of the prominentia saccularis. Posterior to and separated by a considerable space from the last is the small foramen glossopharyngei internum. It lies close in front of the fissura metotica and at the upper margin of the prominentia saccularis and below the prominentia ampullaris posterior. In the upper row of foramina are the foramen endolymphaticum, a foramen for a small blood vessel and a third foramen which may or may not be present and which has apparently no significance, being simply an unchondrified area. The foramen endolymphaticum is situated postero-dorsally from the foramen acusticum posterius and in front of the broad prominentia sinus superioris utriculi. The small foramen for a blood vessel lies in front of the foramen endolymphaticum; and on the left side only in the individual modelled between these two foramina is the insignificant unchondrified area already mentioned.

Viewed from the lateral side the otic capsule (fig. 28) exhibits the following topography. The anterior margin of the cupula anterior projects slightly laterally as a rounded ridge, the prominentia semicircularis anterior. Below the ventral end of this, in the space above the foramen facialis, is a circular convexity, the prominentia recessus utriculi, which extends behind as far as the fenestra vestibuli. Extending horizontally from the ventral end of the prominentia semicircularis anterior to the ventral end of the prominentia semicircularis posterior is the conspicuous cylindrical ridge comprising the prominentiae ampullaris lateralis and semicircularis lateralis; ventrally this prominence merges without a sharp boundary into the prominentia saccularis, 
dorsally it is separated from the prominences of the vertical semicircular canals by a deep depression. The prominentia saccularis is interrupted by the large fenestra vestibuli as well as by the foramen glossopharyngei externum at its extreme upper and posterior angle. The prominentia semicircularis posterior rounds off the capsule postero-dorsally and rests ventrally on the prominentia ampullaris posterior which is separated by a slight depression from that of the semicircular canal.

The median aspect of the capsule has a much more uniform surface than the lateral one. The prominences of the two vertical semicircular canals make a less conspicuous ridge framing the capsule above than they do on the lateral side. Ventral to the prominentia semicircularis anterior is the conspicuous depression, the fossa subarcuata, which separates it from the prominentia recessus utriculi. Posterior to the ventral end of the prominentia semicircularis anterior and ventral to the fossa subarcuata is the inconspicuous triangular prominentia recessus utriculi which is dorsal to the foramen facialis and antero-dorsal from the foramen acusticum anterius. Its posterior angle extends dorsal to the foramen acusticum posterius and ventral to the foramen endolymphaticum. Posterior to the foramen endolymphaticum the prominentia sinus superioris utriculi extends diagonally forward and upward and continues at its upper end with the prominences of the two vertical semicircular canals; posteriorly it merges imperceptibly into the prominentia utricularis and ampullaris posterior. Ventral to the line connecting the dorsal margins of the two foramina acustica and glossopharyngei internum is the semicircular prominentia saccularis which bulges suddenly immediately behind the foramen facialis and extends backward to the fissura metotica.

The posterior wall of the cochlea is perforated near its median margin by the fenestra cochleae, the anterior end of the canalis perilymphaticus, as already described. The relation of these parts is complicated in the stage modelled on account of the extension posteriorly of the lateral wall of the cochlea so that the canalis perilymphaticus opens posteriorly into a funnel-like extension of the anterior end of the sulcus supracristularis. 
In older embryos, as already described, in addition to the canalis perilymphaticus is also the canalis hypoperilymphaticus opening into the cochlear cavity from the sulcus supracristularis.

\section{INTERIOR OF CAPSULA OTICA}

The interior of the otic capsule (figs. 29 and 31) exhibits a complicated form, but in contrast to that of Lacerta it is somewhat simpler because of the absence of a septum intervestibulare and the consequent differentiation of cava vestibuli anterius and posterius. Besides this, the posterior development of the lagena tends to make the interior more compact. It is possible to distinguish a cavum vestibuli with a cavum ampullare posterius, laterale, and anterius, the three canales semicirculares, and a cavum cochleae which communicates widely with the cavum vestibuli. Of especial interest in comparison with Lacerta, in addition to the absence of a septum intervestibulare and the relation of the cavum cochleae, may be noted the sulcus in the posterior wall of the cochlea in which the $n$. glossopharyngeus is situated in its passage from the interior of the cranium to the exterior. It is slightly oblique in its course, extending slightly ventrally from the median to the lateral side on the posterior side of the cavum cochleae immediately below the recessus ampullaris posterior.

The principal part of the total cavity of the capsule is represented by that of the vestibule. Medially the carum vestibuli extends to the median wall of the capsule, but the lateral wall of the capsule forms only a part of its lateral boundary, the vertically situated septum between the vestibulum and the canalis semicircularis lateralis (septum semicirculare laterale) being interposed in the space immediately in front of the recessus ampullaris posterior and behind that of the lateral ampulla (s.s.l., fig. 4). The roof of the cavum vestibuli is incomplete because of the large foramen pro sinu superiore utriculi. The roof is formed by the septa semicircularia anterius and posterius which extend horizontally outwardly from the median wall of the otic capsule and separate the canalis semicircularis anterior and posterior respectively from the cavum vestibuli. The septum semi- 
circulare posterius extends laterally in a horizontal direction to the septum semicirculare laterale, the septum semicirculare anterius to the lateral wall of the capsule. The floor of the cavum vestibuli is very limited in extent because of the wide connection ventrally between it and the cavum cochleae which lies below it. The whole cavity of the capsule including that of the lateral semicircular canal is somewhat flattened from side to side.

The cavum vestibuli may be differentiated for clearness in description into a central portion with posterior, vertical, and anterior limbs. The posterior limb is situated ventral to the septum semicirculare posterius and encloses the ampulla posterior and the median limb of the canalis semicircularis lateralis as well as the posterior portion of the utriculus (fig. 3, left side). The vertical limb is situated between the anterior end of the septum semicirculare posterius and the posterior end of the septum semicirculare anterius, and encloses the sinus superior utriculi (fig. 4). The anterior limb is situated below the septum semicirculare anterius, and encloses the ampullae anterior and lateralis and the recessus utriculi (fig. 6, left side). The central portion of the cavity is situated medial to the septum semicirculare laterale and encloses the principal portion of the utriculus and the recessus utriculi.

The posterior limb of the cavum vestibuli is pear-shaped in a vertical cross section, the narrow end being directed laterally and dorsally to accommodate the posterior semicircular canal, while the thickened end is medial and ventral for the accommodation of the posterior ampulla. Posterior to the septum semicirculare posterius, the orificium inferius canalis semicircularis posterioris opens ventrally into the cavum vestibuli on its dorsal aspect. Immediately ventral to this septum the canalis semicircularis lateralis opens in a vertical longitudinal plane into the lateral aspect of the posterior limb of the cavum vestibuli. Dorsally the cavum vestibuli communicates with the two vertical semicircular canals by means of a common orifice situated between the septa semicircularia anterius and posterius and near the median side of the cavity. Opening into the anterior limb of the cavum vestibuli in a vertical plane facing obliquely forward and laterally 
is the orificium inferius canalis semicircularis anterioris. Behind this orifice and below the septum semicirculare anterius are the cavities of the lateral and anterior ampullae which are in the form of lateral pouches from the cavum vestibuli, that of the lateral ampulla being somewhat dorsal and posterior to that of the anterior ampulla. Ventral to the cava ampullaria anterius and lateralis is that of the recessus utriculi which forms a concavity in the lateral wall of the cavum vestibuli, so that at this point the cavum vestibuli exhibits its maximum width from side to side (fig. 6). The cavum vestibuli has a small bulging on its median side about midway between its posterior and anterior ends and at a level with the ventral end of the sinus superior utriculi for the accommodation of the ductus endolymphaticus as it proceeds ventrally from its foramen to its opening into the sacculus (fig. 4).

The cavum ampullare posterius, occupying the postero-ventral corner of the cavum vestibuli, is differentiated from the dorsally situated canalis semicircularis lateralis by a medial thickening of the lateral capsular wall on the one hand and a ventro-lateral ridge on the septum semicirculare posterius on the other (fig. 2 ); anteriorly the cavity of the posterior ampulla opens into the cavum vestibuli; and dorsally, into the posterior semicircular canal.

The cavum ampullare laterale lies lateral to the anterior end of the cavum vestibuli and opens medially into it by a wide mouth, anteriorly it opens into the cavum ampullare anterius and ventrally into that of the recessus utriculi; posteriorly it communicates with the canalis semicircularis lateralis through the wide orificium anterius canalis semicircularis lateralis. Its antero-dorsal boundary is formed by the septum semicirculare - anterius, its lateral wall is that of the capsule itself; and medially it opens by a very wide aperture into the cavum recessus utriculi and the sinus superior utriculi. At its extreme dorsal end the cavum ampullare laterale is bounded medially by the posterior end of the septum semicirculare anterius.

The cavum ampullare anterius forms a kind of antero-lateral pocket of the cavum vestibuli, being continuous with the anterior 
end of the cavum recessus utriculi. The canalis semicircularis anterior opens into it from above by the orificium inferius canalis semicircularis anterioris. The cavum ampullare anterius is differentiated from that of the recessus utriculi which lies behind it by a broad vertical ridge on the lateral capsular wall.

The cavum utriculi, which occupies the middle portion of the cavum vestibuli, is continuous dorsally with that of the sinus superior utriculi, anteriorly with the recessus utriculi and ampulla lateralis, posteriorly with the ampulla posterior and canalis semicircularis lateralis, and ventrally with the cavum sacculi. Its median wall is formed throughout by the median capsular wall; laterally it is bounded by the septum semicirculare laterale and, ventral to the septum, by the lateral wall of the capsule which is continuous with it. Anterior to the septum the cavity opens laterally into the lateral ampulla and the recessus utriculi, and posterior to the septum it is continuous with the median limb of the lateral semicircular canal. At its anterior end the cavum utriculi widens abruptly in a lateral direction to form the cavum recessus utriculi, which lies rather ventral to the lateral ampulla.

The cavum sinus superioris utriculi extends dorsally from the cavum utriculi between the septa semicircularia anterius and posterius. Opening into it from the anterior and lateral aspect are the cava recessus utriculi and ampullare laterale. Dorsally it opens into the orificia superioria canalis semicircularis anterioris and posterioris. Medially and laterally it is limited by the respective capsular walls.

The cavum recessus utriculi forms a pocket extending ventrally from the cavum ampullare laterale and anterior to the cavum utriculi. Anteriorly it opens into the cavum ampullare anterius and ventrally into that of the sacculus, but at its extreme anterior end the ventral capsular wall limits it.

The canalis semicircularis posterior curves laterally and ventrally from its union with the sinus superior utriculi, in a posterior direction to the posterior ampulla, into which it opens from above by means of the orificium inferius canalis semicircularis posterioris. The canalis semicircularis lateralis connects with the posterior portion of the posterior semicircular canal by means of 
the orificium posterius canalis semicircularis lateralis which is situated immediately ventral to the septum semicirculare posterius and somewhat lateral to the posterior semicircular canal.

The canalis semicircularis anterior curves from its posterior end, first in an antero-lateral direction, then ventrally, and at its extreme antero-ventral portion, somewhat medially, so that its entrance into the cavum ampullare anterius through the orificium inferius canalis semicircularis anterioris is from above and laterally. It is bounded dorsally, medially, anteriorly, and in part laterally by the corresponding walls of the capsule; ventrally it is bounded by the septum semicirculare anterius which also lies somewhat lateral to the canal at its posterior end. The anterolateral end of the canal is limited behind by a medial thickening of the lateral capsular wall which separates the cavities of the anterior and lateral ampullae.

The canalis semicircularis lateralis has two quite distinct portions, a median limb and a lateral one. The cavity of the median limb is confluent with that of the utriculus, the posterior,ampulla and the inferior end of the posterior canal. It lies lateral and dorsal to the utriculus and posterior ampulla and anterior to the posterior semicircular canal. The cavity of the median limb is bounded laterally by the septum semicirculare laterale and dorsally by the septum semicirculare posterius. The lateral limb is separated, except at its posterior end, from the median limb by the septum semicirculare laterale. The canal is horizontal in position and is continuous in front with the lateral ampulla through the large orificium anterius canalis semicircularis. Posteriorly the lateral limb of the lateral semicircular canal is continuous with the median limb immediately behind the septum semicirculare laterale and also with the ventral and posterior end of the posterior semicircular canal.

The cavum sacculi (c.sac., fig. 29) exhibits several features of great morphological interest on account of the relations of the ductus perilymphaticus and the development of the ductus cochlearis in a posterior direction. It has the general form of a flattened pocket which is rather shallow in front and increases quite regularly in depth posteriorly so that the posterior wall is 
high and vertical in position. Dorsally the cavum sacculi stands in wide open connection with that of the vestibulum. Its boundaries are the capsular walls laterally, medially, posteriorly, and anteriorly; and ventrally the basal plate which bulges ventrally as already noted because of the great extension of the lagena in a ventral direction. In its ventral portion the cavum sacculi exhibits an antero-lateral and a postero-medial lobe which stand in wide open communication with each other; the boundary between the two extending from the median wall at the level of the foramen acusticum posterius in a postero-lateral direction. The antero-lateral lobe extends on the outer aspect posteriorly beyond the fenestra vestibuli which interrupts its lateral wall; on its median aspect it extends posteriorly only as far as the foramen acusticum posterius. In it is situated the sacculus. The posteromedial lobe is somewhat deeper than the previous one so that its ventral end projects slightly below the level of the lateral lobe. It is somewhat triangular in form with the posterior side in a vertical plane. This encloses the lagena, the ductus perilymphaticus and the n. glossopharyngeus in its course between the external and internal foramina of that nerve. Accordingly this cavity exhibits two small but very important extensions; namely, the sulcus glossopharyngeus $\left(s . g_{\circ}\right)$ and the canalis perilymphaticus (c.per.). The sulcus glossopharyngeus is situated on the posterior cochlear wall ventral to the cavum ampullare posterius and extends transversely from the foramen glossopharyngei internum in a lateral and ventral direction to the foramen glossopharyngei externum. It is in the form of a cylindrical groove of uniform size which opens into the cavum sacculi as already indicated. Near its median extremity it intersects the ventral wall of the cavum ampullare posterius so that it shows communication with this part as well. It is completely filled by the nerve which thus comes to lie with its anterior half projecting freely into the cavum sacculi. The canalis perilymphaticus extends in an anterior direction from the fenestra cochleae horizontally through the posterior cochlear wall. It opens into the sacculus at a point half way between the dorsal and ventral ends of that part and somewhat medial to the middle plane of the cavity. 
The canal opens at its anterior end in an oblique plane along the median wall of the cochlea a short distance in front of its extreme posterior end (fig. 3, left side). The ductus perilymphaticus fills the canal completely.

The septum semicirculare posterius is in the form of a horizontal plate which extends laterally from the median to the lateral capsular wall and septum semicirculare laterale. It passes dorsal to the cavum ampullare posterius and ventral to the canalis semicircularis posterior as has been already noted. The septum begins at its posterior end as a ridge which extends laterally. from the median capsular wall and differentiates the canalis semicircularis posterior from its ampulla. It terminates abruptly anteriorily behind the sinus superior utriculi. Dorsal to the septum is situated the canalis semicircularis posterior while ventral to it are the ampulla posterior, the utriculus, and the median limb of the lateral semicircular canal. The two latter are differentiated from each other by a broad ridge on the under side of the septum.

The septum semicirculare laterale is a vertical plate situated in a longitudinal plane separating the ampulla posterior, the cavum vestibuli, and median limb of the lateral semicircular canal on the one hand from the lateral limb and ampulla on the outer side. At its posterior end the lateral margin of the septum semicirculare posterius and the lateral capsular wall unite.

The septum semcirculare anterius is a plate which extends between the lateral and median capsular walls in an oblique position, its anterior end lying somewhat higher than its posterior. It lies dorsal and medial to the ampullae lateralis and anterior, and ventro-lateral as well as posterior to the canalis semicircularis anterior. The septum is slightly twisted; at its posterior end its lateral margin lies at a higher level than its median margin, while at its anterior end the lateral margin is lower than the median margin. In front the septum arises from the median capsular wall as a ridge which projects laterally and differentiates the anterior semicircular canal from its ampulla. Posteriorly the septum arises from the lateral capsular wall as a ridge which demarcates the cavum sinus superioris utriculi from that of the lateral ampulla. 


\section{TECTUA POSTERIUS}

The tectum posterius, which is the only part of the chondrocranium roofing in the central nervous system dorsally, is continuous ventro-laterally with the otic capsules, and so may properly be described with the otic region notwithstanding the fact that it extends posteriorly to close in the foramen occipitale magnum above. The tectum posterius may be differentiated into a median and two lateral portions. The latter are slender cylindrical rods which slant medially and dorsally from the upper margin of the otic capsule in order to support with their distal median ends the large median portion which is of rhomboidal form with its long axis in the sagittal plane. This median portion accordingly exhibits a long, slender triangular processus ascendens which slants upward in an anterior direction and a stouter processus posterior which is more nearly semicircular in form and extends with its postero-ventral extremity to limit the foramen occipitale magnum above. In cross section the processus ascendens becomes crescentic toward its apex, with the convexity directed dorsally, while that of the processus posterior is more nearly oval. The tectum is slightly curved in the sagittal plane, thus exhibiting a postero-dorsal convexity and an antero-ventral concavity. The saccus endolymphaticus is situated close below and in front of the slender lateral portion.

\section{CRISTA PAROTICA}

The crista parotica (cr.p., fig. 28) forms a short, longitudinal crest, extending in an anterior direction from the ventro-lateral aspect of the prominentia ampullaris posterior slightly beyond the foramen glossopharyngei externum, dorsal to which it ends freely in a vertical, transverse face (cr.p., fig. 2). It is triangular in cross section exhibiting a ventral and a median surface, the latter attached to the otic capsule except at its extreme anterior end which projects freely. There is accordingly a dorso-lateral face which makes a broad, shallow groove with the part of the external wall of the otic capsule lying dorsal to it in which the postero-ventral portion of the quadratum rests. 
Ventral to the crest runs the vena capitis lateralis which joins the $v$. jugularis interna immediately posterior to the crista parotica a short distance anterior to the fenestra metotica and continues obliquely upward and forward over the lateral wall of the capsule ventral to the prominentia semicircularis lateralis.

A separate processus paroticus articulating with the crista parotica, and which Gaupp has described in Lacerta, is not present at any stage of Emys in the series studied.

\section{RELATION OF THE NERVES IN THE REGIO OTICA}

The relations of the nerves in the otic region of the skull exhibit several points of considerable interest. As described by Bojanus the $\mathrm{n}$. glossopharyngeus passes directly through the cavity of the ossebus labyrinth of the ear in Emys. In the stage modelled both the median and lateral walls of the cochlea are perforated near their posterior ends and immediately ventral to the vestibular portion of the capsule by the foramina glossopharyngei internum and externum respectively. The $\mathrm{n}$. glossopharyngeus passes from the inner foramen to the outer one in a ventrolateral direction. Between the two foramina the posterior wall of the cochlea is excavated, as has been already described, to form a deep groove, the sulcus glossopharyngeus, in which the nerve lies with its anterior surface freely exposed in the cochlear cavity. The dorsal wall of the groove is incomplete at its median end because of the intersection of the cavum vestibuli with the sulcus glossopharyngeus, so that the nerve has its dorsal as well as its anterior surface for a short space exposed freely in the cavity of the capsule.

With reference to the nervus glossopharyngeus, the lagena extends much further ventrally and posteriorly than it does in Lacerta in which form the $n$. glossopharyngeus leaves the skull together with the vagus through the fissura metotica which extends quite far forwards ventral to the pars cochlearis.

From the foramen glossopharyngei externum the nerve extends in a ventro-lateral direction to the ganglion petrosum (s. glossopharyngei) which lies ventral to the external fenestra and lateral to the sulcus supracristularis. 
The nervus acusticus exhibits a ramus vestibularis and a ramus cochlearis. The former is the smaller of the two and is situated slightly dorsal and somewhat anterior to the latter. They enter the capsule through the foramina acustica anterius and posterius respectively. The anterior foramen is situated at the extreme anterior end of the pars cochlearis immediately ventral to the recessus utriculi; the posterior foramen is situated nearer the middle of the pars cochlearis, immediately in front of the posteromedial lobe of the cochlear cavity and ventral to the cavum utriculi.

The nervus facialis finds its exit from the cranial cavity through the foramen facialis which is situated a short distance dorsal to the basal plate and in front of the anterior wall of the cochlea. The ganglion facialis (s. geniculi) lies external to the chondrocranium, separated from it by a thin layer of connective tissue, in front of the foramen and dorsal to the lateral extension of the basal plate already mentioned. The ganglion, accordingly, rests in a broad groove between the basal plate on the ventral side and the prefacial commissure, which unites the basal plate and otic capsule, on the dorsal side. This groove is apparently the homo$\log$ of the fovea genicularis of the rabbit, as described by Voit ('08, p. 448).

The ramus palatinus nervi facialis arises from the lateral aspect of the ganglion facialis and passes in a ventro-medial direction around the free edge of the crista substapedialis and then turns in an anterior direction in the sulcus palatinus which is medial to the rudimentary processus basipterygoideus on the ventral side of the basal plate.

The ramus hyomandibularis arises from the posterior end of the ganglion geniculi and runs posteriorly in the fovea genicularis and comes to lie further laterally and dorsally as it proceeds and passes dorsal to the columella auris. At the level of the latter the ramus hyomandibularis gives off the chorda tympani which extends in a lateral direction along the dorsal margin of the columella and then turns sharply forward and ventrally to reach the mandible, as Noack ('06) has already described. The main 
portion of the hyomandibular branch continues in a posterior direction in the space between the quadratum and the otic capsule.

At the point at which the palatine branch reaches the sulcus palatinus there is given off in a posterior direction the ramus communicans $\mathrm{n}$. facialis cum $\mathrm{n}$. glossopharyngeo which extends postero-laterally along the ventral surface of the chondrocranium beneath the pars cochlearis of the otic capsule, the crista substapedialis, and the planum basale to unite finally with the anterior end of the ganglion glossopharyngei.

\section{REGIO ORBITO-TEAIPORALIS}

The orbito-temporal region shows the same general configuration as that of Lacerta except that it is of much heavier and more compact structure, being made up of broader plates instead of slender rods. The fenestrae are also less numerous and relatively smaller than in Lacerta, in which respect the chelonian skull resembles more closely the primitive condition of Sphenodon. The whole region has the form of a shallow longitudinal trough, within which the anterior end of the brain is supported on its ventral side. Ventral to the trough, the septum interorbitale (s.i., fig. 9) lies in a sagittal plane and increases in height from the posterior to the anterior end. 'The sides of the trough are formed by the pila prootica, the subiculum infundibuli, the pila metoptica, and the planum supraseptale. These walls are perforated by the fenestrae prootica, metoptica, optica, and foramen ophthalmicum, besides a small perforation in the subiculum infundibuli, present only on the right side of the embryo modelled which represents the beginning of the absorption of the cartilage at this point.

As in all the Sauropsida, the orbito-temporal region is differentiated into a posterior temporal and an anterior orbital portion. The temporal portion is continuous behind with the otic region and exhibits a basal and two lateral parts. The orbital region is characterized by the high septum interorbitale which forms a continuous wall between the two orbits. This septum is a thin vertical plate, as will be described later; in the stage modelled it is thin, but in younger embryos it is relatively thicker and made 
up of two parallel plates which are united to each other only along the ventral margin by a high commissure (figs. 22 and 23), a condition which apparently may be referred to a primitive form in which the skull was platybasic. Anteriorly the septum interorbitale passes without interruption into the septum nasi, which in my youngest stages is apparently of unpaired origin.

The temporal region is made up of the trabeculae and pilae prooticae, both arising from the anterior aspect of the crista sellaris, the latter from the dorsal side, the former from the ventral side. The bases of these two structures are separated from each other by the nervus abducens which, as already mentioned, penetrates the crista sellaris ventral to the base of the pila prootica (VI, fig. 8).

The trabeculae project horizontally forward in the plane of the basal plate as triangular rods which converge in the median line and enclose the semicircular fenestra hypophyseos in front and on the two sides. They continue further forward as the thickened ventral margin of the septum interorbitale and fuse so that no trace of the paired nature of the septum remains. Posteriorly the trabeculae are continuous with the antero-lateral margins of the basal plate which represent the crista basipterygoidea, as already described.

At the level of the posterior margin of the fenestra hypophyseos a separate cartilago articularis, described by Gaupp in Lacerta, is represented by a rudimentary, imperfectly chondrified mass of tissue which is attached to the ventral edge of the crista basipterygoidea (c.a., fig. 8). This cartilage forms a small, roundish knob, about two-thirds as broad as long, which projects downward from the crest with its free end directed anteriorly and ventrally. It extends lateral to the ramus palatinus $\mathrm{n}$. facialis and its free end is embraced laterally as well as ventrally by the pterygoideum. In older embryos the crista basipterygoidea becomes relatively more prominent and is partly surrounded by the dorsomedian portion of the pterygoideum, and the cartilago articularis disappears as a distinct piece, probably fusing with the crest (c.pt., fig. 20). 
The pila prootica which forms the lateral portion of the temporal region may be described in general as a broad U-shaped plate of nearly uniform width, with its convex side anterior and its concave side posterior, and exhibiting accordingly a median and a lateral limb. It is attached to the basal plate by the median limb, while the external limb of the $U$ is somewhat dorsal to the former and ends freely close to and medial to the anterior cupula of the otic capsule. The plane of the whole plate is so curved that while it is nearly horizontal in a transverse direction at its attachment to the basal plate, the free lateral limb is nearly vertical in its position. The median limb is inclined antero-dorsally from its proximal end where it is attached to the front surface of the crista sellaris. The lateral limb of the pila exhibits a small, anteriorly directed process which approaches a posteriorly directed process from the postero-lateral angle of the planum supraseptale. These two processes narrow the fenestra metoptica dorso-laterally without closing it in completely, and suggest, in their position, an incomplete taenia marginalis. In another embryo, slightly younger than that modelled, this anteriorly directed process of the lateral limb is greatly enlarged and is perforated by a large foramen, the significance of which is still undetermined.

In the embryo modelled, the pila prootica grows very thin toward its dorso-lateral margin and passes gradually into a thin layer of dense connective tissue which extends dorsally and medially and encloses the cranial cavity above.

A peculiarity of the individual modelled, which has not been met with in any of the other specimens studied, is the presence of a short cylindrical rod-like process from the dorsal surface of the medial limb of the pila prootica near its distal end which extends postero-laterally in a horizontal plane and ends freely in the cranial cavity medial to the anterior margin of the fenestra prootica. The nervus oculomotorius, as it passes anteriorly over the medio-dorsal surface of the pila prootica in order to leave the cranial cavity through the fenestra metoptica, lies dorsal and medial to this process, while the $n$. trochlearis, which is approximately parallel to the oculomotor, lies lateral and dorsal to this same process. Beneath the pila prootica, running horizontally 
forward from the anterior apex of the ganglion semilunare, are the nervi nasalis and frontalis of the ramus ophthalmicus.

The pila prootica bounds the fenestra prootica in front and on its two sides and forms the posterior margin of the fenestra metoptica. Immediately external to the fenestra prootica, and occluding it almost completely, is the ganglion semilunare whose anterior apex lies in front of the fenestra.

The fenestra hypophyseos is semicircular, the transverse front margin of the crista sellaris forming its posterior boundary and the two trabeculae enclosing it laterally and in front.

The arteria carotis interna enters the cranial cavity through the postero-lateral angles of the fenestra hypophyseos which are not excavated to form incisurae caroticae as in Lacerta. The ventral side of the crista sellaris, however, as already noted, bears a broad longitudinal groove on each side of the middle line, the sulcus palatinus, in which the arteria carotis interna, together with the ramus palatinus $n$. facialis, lies; so that the extreme anterior end of the sulcus where the artery turns dorsally to enter the fenestra hypophyseos might be looked upon as an indication of an incisura carotica. Posteriorly the sulcus palatinus continues as the sulcus cavernosus.

The anterior three-fourths of the fenestra hypophyseos is completely occupied by the hypophysis cerebri which has a slightly oblique position so that its anterior surface rests partly upon the subiculum infundibuli in front of the fenestra.

The subiculum infundibuli arises in front of the fenestra hypophyseos from the dorsal surface of the trabeculae as a thin plate made up evidently of two symmetrical halves which are slightly inclined toward each other in the middle line to form a shallow longitudinal trough. The infundibulum and antero-dorsal end of the hypophysis are supported by this plate. The subiculum infundibuli is triangular, with its apex directed posteriorly and its base anteriorly forming the hinder margin of the fenestra optica, and, with its antero-lateral angles prolonged to form the short pilae metopticae, and with its postero-lateral margins bounding the ventral half of the fenestra metoptica in front The whole subiculum infundibuli inclines rather sharply upward in front, 
being supported ventrally by the septum interorbitale which increases rapidly in height from its posterior end. The lateral margin as it passes over into the pila metoptica is incised by the broad sinus oculomotorius for the oculomotor nerve as it passes obliquely to the outside of the cranium through the fenestra metoptica. Near the anterior margin, the subiculum infundibuli is perforated by a pair of large oval foramina (foramen ophthalmicum, f.o., fig. 25) through which the arteria ophthalmica passes to reach the orbit. In the embryo modelled there is a small fenestra on the right side only which represents the first step in the resorption of this part of the chondrocranium. The subiculum infundibuli is much thicker anteriorly and laterally than medially and behind, and in older embryos in which the resorption has been carried farther, the entire posterior part of the subiculum has disappeared and the foramen ophthalmicum becomes a sinus, opening freely behind into the fenestra metoptica. In older embryos the interorbital septum becomes fenestrated by a long, narrow opening which extends both anterior and posterior to the subiculum infundibuli, its anterior end lying beneath the fenestra optica, so that, as in Lacerta, a cartilago hypochiasmatica is differentiated.

The pila metoptica is a short, stout rod extending antero-laterally from the antero-lateral angles of the subiculum infundibuli to the posterior margin of the planum supraseptale. The nervus oculomotorius passes ventral to the pila metoptica, leaving the cranial cavity through the sulcus oculomotorius. The nervus trochlearis passes out of the cranial cavity through the fenestra metoptica lateral and dorsal to the nervus oculomotorius, lying parallel to the latter beneath the pila metoptica.

The fenestra prootica is a large, oval opening between the anterior cupula of the otic capsule and the prefacial commissure behind and the pila prootica in front. On account of the curved form of the latter the fenestra is enclosed by it dorsally as well; the closure, however, is not complete on account of the absence of a taenia marginalis and the failure of the pila prootica to fuse with the otic capsule, a condition which resembles Sphenodon. The fenestra is completely filled by the large ganglion semilunare 
which extends with its anterior apex ventral to the pila prootica (g.s., fig. 8). In Emys the ganglia of the three branches of the n. trigeminus are consolidated into one mass unlike the condition in Lacerta where that of the ophthalmic branch is separated from that of the other two and lies quite far anteriorly.

The fenestra metoptica, through which the nn. oculomotorius and trochlearis leave the cranial cavity, is a narrow slitlike opening, having an oblique position, sloping forward and dorsally from its base. It is bounded posteriorly by the pila prootica, and anteriorly by the subiculum infundibuli, pila metoptica, and planum supraseptale. From its anterior side the fenestra is narrowed by the prolonged postero-lateral angle of the planum supraseptale and again by a short posteriorly directed process midway between this process and the lateral end of the pila metoptica. On the right side of the embryo modelled this second process is reduced in the median part of its length so that only a proximal stump remains projecting from the posterior margin of the planum supraseptale and a small isolated rod of cartilage which lies freely within the fenestra (fig, 24). In another embryo of approximately the same age, the fenestra metoptica becomes regularly wider laterally and is narrowed only by the single posteriorly directed process of the postero-lateral angle of the planum supraseptale. The fenestra metoptica is not fully closed dorsally because of the absence of a complete taenia marginalis, although, as already described, the projection from the front margin of the pila prootica and that from the hind margin of the planum supraseptale suggest together an incomplete taenia marginalis.

The fenestra optica (f.opt., fig. 24) is of irregular triangular form, somewhat broader than long. The planes of the two foramina are slightly inclined toward each other in accordance with the obtuse angle made by the two halves of the planum supraseptale. The two foramina are separated from each other in the middle line only by the free dorsal margin of the septum interorbitale. Posteriorly they are bounded by the subiculum infundibuli, and for a very short distance postero-laterally, by the pila metoptica; anteriorly they are bounded by the planum supra- 
septale. The orbital portion of the obito-temporal region is characterized by the septum interorbitale which increases in height from behind and carries the planum supraseptale with its dorsal margin so that the floor of the cranium is raised.

The septum interorbitale is a triangular plate lying in the sagittal plane, arising posteriorly from in front of the fenestra hypophyseos and rapidly increasing in height anteriorly almost to its extreme anterior end where the dorsal margin inclines rapidly ventrally to pass into the septum nasi. The ventral margin is thickened throughout its length to a cylindrical rod which is continuous behind with the trabeculae and tapers anteriorly in the region of the olfactory capsule to a thin edge. Its dorsal margin is continuous with the subiculum infundibuli and planum supraseptale except in the region of the fenestra optica where it is free. The septum forms a continuous plate throughout with no fenestrae such as Lacerta exhibits, although at a later stage, as already mentioned, a long slit in the posterior portion of the septum ventral to the fenestra optica causes a cartilago hypochiasmatica to be differentiated.

Of especial interest in the stage modelled is the structure of the extreme anterior dorsal corner of the septum where it passes over in to the planum supraseptale posteriorly and the commissurae spheno-ethmoidales anteriorly. At this point the septum is very clearly paired, the right and left halves being separated from each other by a shallow groove which is continuous postero-dorsally with the troughlike planum supraseptale. By a comparison with younger stages the significance of this peculiarity becomes clear. In an embryo having a carapace length of $7 \mathrm{~mm}$. the portion of the septum lying in front of the fenestra optica is represented by two vertical plates, parallel to each other which are fused together along their ventral edges (fig. 23). Dorsally these plates diverge rapidly from each other along a line corresponding approximately to the dorsal margin of the septum in the older embryo. In the region of the fenestra optica, and for a short distance in front of the fenestra, the septum is thick so that its ventral cylindrical margin is not differentiated from the rest 
of the septum. In this young stage, accordingly, the cavum cranii extends ventrally between the two plates of the septum in the region between the eyes as a deep, narrow cleft.

The planum supraseptale forms a broad shallow trough in which the cerebral hemispheres and olfactory lobes rest. Its plane rises obliquely from behind, on account of the increasing height of the septum interorbitale, but at its extreme anterior end its plane falls rapidly ventrally so that it is almost vertical, a condition associated with the rotation ventralwards of the olfactory capsule as will be described later under the ethmoidal region. In general, it is broadly oval in form, somewhat wider than long, with its anterior and lateral margins evenly rounded, but its posterior margin irregularly indented as has been described above. Medially its posterior margin forms the front boundary of the fenestrae opticae and further laterally the front boundary of the fenestra metoptica; between these two fenestrae is the pila metoptica. The postero-lateral angle of the planum supraseptale is produced behind as a slender rod-like process which approaches the front edge of the pila prootica. The postero-lateral portion of the planum supraseptale, corresponding somewhat in position to that of the fenestra epioptica of Lacerta, is perforated by numerous small foramina which represent the first stages in the absorption of the cartilage in this part of the cranium.

At its anterior end, the planum supraseptale becomes very narrow and passes into the anterior end of the septum interorbitale. At the same time the two halves of the planum supraseptale, which form an obtuse angle with each other throughout most of their length, come to lie at the extreme anterior portion with their median surfaces almost parallel and separated from each other by a narrow cleft.

The commissurae spheno-ethmoidales, diverging from each other, extend in an antero-ventral direction from the extreme anterior margin of the planum supraseptale and serve to connect the walls of the olfactory capsule with the orbital region. They enclose the fenestrae olfactoriae laterally. 


\section{REGIO ETHMOIDALIS}

The ethmoidal region of Emys exhibits greater differences from that of Lacerta than does any other region of the chondrocranium. It has been carefully described by means of models by Seydel ('96), whose results are in the main confirmed by the present study, and by Nick ('12) in Chelydra serpentina, Chelone midas, and Dermochelys coriacea. The homologies of certain parts, however, which were not discussed by Seydel, have been determined by study of a more complete series of embryos. To Seydel's observations there are only a few details to be added.

In striking contrast to the condition in Lacerta, the capsule is more compact and is made up of continuous plates of cartilage interrupted only to a limited extent by fenestrae and not modified by alar processes and a complicated concha; besides this, the whole capsule has undergone a bending in a ventral direction. The differences in general form of this region in Lacerta and Emys are to be correlated with the greater strength of the jaws of chelonians, which condition requires that the bones against which the lower jaw impinges (premaxillare, maxillare, vomer, palatinum) have a more solid foundation to rest against than in such forms as the snakes and lizards. Gaupp ('06, p. 45) has already called attention to the fact that the form of the olfactory capsule is controlled as well by the structure of the jaws as by the form of the olfactory sac itself.

The olfactory capsule is divided into two symmetrical halves by the septum nasi which continues in an anterior direction from the septum interorbitale. The postero-dorsal wall of the capsule accordingly forms the anterior boundary of the orbit and the anterior wall forms the anterior limit of the head. On account of its position relatively far ventral to the other portions of the skull, its ventral wall projects below the level of the lower edge of the septum interorbitale to afford a prominent, and at the same time solid, support for the upper jaw. Besides the septum nasi which forms the median wall of each half, the cartilages making up the walls of the capsule may be differentiated into the tectum nasi dorsally, the paries nasi laterally, the solum nasi and 
the cartilago paraseptalis ventrally, and the planum antorbitale forming the postero-dorsal wall which separates the olfactory sac from the orbit. These regions for the most part pass ovel into each other by even transitions.

The entire dorsal and posterior portion of the capsule, as Seydel has already shown, is free from the septum as is also the case in Lacerta; that is, the planum antorbitale terminates freely above and behind. Besides the connection between the septum nasi and the walls of the capsule there is a further connection of the capsule with the rest of the skull by means of the commissura spheno-ethmoidalis, a cartilaginous rod extending posteriorly from the tectum nasi on each side to the anterior extremity of the planum supraseptale, where the latter passes into the septum supraseptale, and enclosing the two fenestrae olfactoriae on the sides, and thus separating the fenestra olfactoria from the fissura orbitonasalis.

The capsule opens in front to accommodate the apertura nasalis externa, by the fenestra narina, and posteriorly by the fenestrae basales for the choanae. There is a longitudinal slit in the floor of the capsule which Seydel has called the foramen praepalatinum. The capsule is perforated dorsally by the fenestrae olfactoriae, ventral to which on each side is the fissura orbitonasalis, through the most dorsal part of which the ethmoidal branch of the ramus ophthalmicus $n$. trigemini passes in its course from the orbit to the olfactory sac. Besides these openings there is also a small foramen epiphaniale for the passage of the $\mathrm{n}$. lateralis nasi rami ophthalmici from the capsule to the exterior. A foramen apicale is lacking in all stages studied.

In contrast to Lacerta the entire capsule is shifted ventrally and so rotated that the anterior end is slightly ventral to the posterior end. This change in position is indicated partly by the fact that the plane of the fenestra olfactoria is inclined from the horizontal, as in Lacerta, so that its ventral end is below the posterior. Besides this, the capsule is somewhat compressed laterally so that its floor is pressed ventrally and extends well below the lower margin of the septum nasi. The two halves of the capsule are thus separated on the under side by a groove which 
becomes shallower in front; and the fenestra basalis is brought well below the ventral margin of the septum, the upper side of the fenestra standing at the level of the ventral margin of the septum (figs. 9 and 27 ).

The contour of the walls of the capsule follows closely that of the underlying olfactory sac. Accordingly the capsule may be differentiated into two distinct regions, a relatively high, somewhat conical pars olfactoria situated dorsally, and a broader cylindrical pars respiratoria, opening in front by the fenestra narina and behind by the fenestra basalis. These two regions are separated by a shallow groove which extends diagonally posteriorly and ventrally and becomes more pronounced at its posterior end. The depression causes the interior wall of the capsule to be thrown up into a corresponding ridge which supports the lateral 'Grenzfalte' of Seydel.

Above the groove just described is a second depression in the lateral wall of the capsule. It is somewhat shallower than the first and appears only along the middle third of the capsule. It is the external manifestation of a corresponding ridge in the interior of the capsule. The accompanying prominent fold of the nasal epithelium supported by the thickening of the lateral wall, is evidently a rudimentary concha. It extends posteriorly as far as the recessus ducti naso-pharyngei, which is immediately ventral to it. In older embryos than that modelled, the concha becomes much more prominent on the inner side of the paries nasi (fig. 19).

The planum antorbitale is a thin curved plate making up the posterior and postero-dorsal wall of the capsule. It slopes rapidly ventrally from its antero-dorsal end and passes with an even curvature laterally and anteriorly into the paries nasi. In the stage modelled it is separated medially from the septum nasi by the fissura orbitonasalis so that it has a free margin which is rolled inwardly to project into the cavity of the capsule, parallel to the septum (fig. 12). The infolded margin is broadest in front; behind it disappears entirely in the region of the fenestra basalis.

The tectum nasi is short in an antero-posterior direction and comparatively narrow from side to side. In front it falls sud- 
denly ventrally to form the front wall of the capsule dorsal to the fenestra narina. Posteriorly it passes into the planum antorbitale and is continuous with the septum nasi and commissura spheno-ethmoidalis. Between the septum nasi and the anterior extremities of the commissurae spheno-ethmoidales accordingly, the tectum bounds the fenestra olfactoria in front. Laterally the tectum nasi bends smoothly ventrally to form the paries nasi. Anteriorly it slopes abruptly ventrally and almost vertically to enclose the pars olfactoria in front. On account of the rounded form of this part, the tectum nasi exhibits in this region two gentle convexities separated from each other by a groove marking the position of the front margin of the septum nasi with which it is in perfect continuity. Below each of these cupulas, immediately above the fenestra narina, there is a short blunt, anteriorly directed process which, in later stages, becomes more conspicuous. To this process may be given the name processus supranarinus ( $p r . s .$, fig. 25).

The paries nasi forms a practically continuous plate of cartilage of slightly convex form limiting the olfactory capsule laterally. It is continuous medially and dorsally with the tectum nasi as well as with the planum antorbitale; ventrally throughout its entire length it is continuous with the solum nasi. Its anterior end passes into the tectum nasi dorsally and ends freely ventrally as the lateral margin of the fenestra narina. This free margin is incised to form a very broad shallow sinus (sinus externus) for the accommodation of the duct of the glandula nasi externa which empties into the entrance passage of the olfactory sac (figs. 14 and 27). Posteriorly the paries nasi continues with the solum nasi to form the cartilago ectochoanalis (c.e., fig. 9) which bounds the fenestra basalis ventro-laterally. Above the cartilago ectochoanalis the posterior margin is deeply incised to form a rounded sinus in which the recessus ducti nasopharyngei lies and which I would call the sinus nasalis posterior. The paries may be differentiated into a dorsally situated pars olfactoria and a ventrally situated pars respiratoria corresponding to the respective parts of the olfactory sac lying within. These two regions are separated from each other by a broad, shallow groove, which extends 
horizontally backwards from the level of the upper margin of the fenestra narina to the apex of the sinus nasalis posterior and at the same time grows shallower. The paries nasi is of uniform thickness throughout except in the region immediately posterior to the groove on the exterior, which marks the position of the concha. Here the wall of the capsule is thickened to form a more prominent, rounded ridge on the inner surface. In front of this thickening the paries nasi exhibits on its medial surface a ridge (corresponding to the groove already mentioned on the external surface) which supports a fold of the epithelium of the olfactory șac representing a rudimentary concha (fig. 11).

The floor of the nasal capsule offers the most striking differences from the conditions met with in other reptiles. The solum nasi projects in front ventral to the fenestra narina to form the processus infranarinus, which thus limits the sinus externus below and medially. Behind the fenestra narina the solum nasi is continuous with the septum for a short space, and laterally bends upward to unite with the paries nasi with an even curvature. This portion of the solum nasi represents the lamina transversalis anterior of Lacerta. Posterior to this portion the solum nasi is separated from the septum by an elongated slit to which Seydel has given the name foramen praepalatinum (f.p. fig. 25). Behind this foramen the floor of the capsule again unites with the septum. In this region the ventral margin of the septum inclines strongly dorsally in a posterior direction. From the posterior margin of the solum there projects posteriorly a short cartilago paraseptalis which bounds the fenestra basalis medio-ventrally and is separated from the septum by a narrow sinus paraseptalis. Laterally the solum nasi at its transition to the paries nasi is prolonged, as already mentioned, to form a short spout-like process extending for a short distance posteriorly and supporting the ductus naso-pharyngeus ventrally and laterally, which may accordingly be called the cartilago ectochoanalis. The lateral margin of this limits the sinus posterior below.

The significance of that portion of the solum nasi which is continuous with the septum between the foramen praepalatinum in front and the fenestra basalis behind is difficult to understand. 
In a younger embryo than that modelled (fig. 30 ) the solum nasi is separated from the septum completely behind a slender lamina transversalis anterior so that the entire posterior half of the solum nasi is free from the septum much as in Lacerta, as Gaupp has shown. Accordingly the foramen praepalatinum of Emys corresponds to the anterior portion of the cleft separating the septum from the cartilago paraseptalis, and the portion of the solum nasi which is continuous with the septum behind the foramen praepalatinum represents a portion of the cartilago paraseptalis which has become extended medially and fused with the septum. The solum nasi exhibits in the region lateral to the cartilago paraseptalis in the younger embryos several foramina which in the embryo modelled have become occluded but which are still manifest as thinner spots in the floor of the capsule.

The cartilago paraseptalis of Emys is relatively much shorter than that of Lacerta and does not unite in the stage modelled with the planum antorbitale by its posterior end. At a later stage there is such a fusion similar to that in Lacerta. But, unlike the condition in Lacerta, the choanae of Emys lie well posterior to the cartilago paraseptalis instead of anterior to the posterior end of the cartilage.

The relationship of parts of the floor of the capsule of Emys may be derived from that of Lacerta by a widening in a median direction of the cartilago ectochoanalis so that the fenestra basalis is moved posteriorly by an obliteration from in front, and at the same time by a broadening of the cartilago paraseptalis in its posterior half so that it fuses with the septum. That these changes may actually have taken place is indicated by the nasal capsule of the younger embryos in which, as has already been noted, the cartilago paraseptalis is separated from the septum for its entire length, and by the fact that, lateral to the cartilago paraseptalis, the floor of the capsule is perforated by a series of fenestrae arranged in a longitudinal row.

Anteriorly, the solum nasi projects forward as a short process ventral to the apertura nasalis externa; it passes over smoothly into the paries nasi on the two sides. While the floor of the capsule is nearly horizontal, except for a ventral crest along the lower 
margin of the septum, which Parker ('80) termed the 'prenasal cartilage,' farther posteriorly the capsules extend much farther ventrally so that there is a fairly deep median groove between the two bulging capsules. The solum nasi projects posteriorly as the cartilago ectochoanalis. Throughout the greater part of its length the solum nasi is continuous with the septum, the foramen praepalatinum and the slit separating the cartilago paraseptalis and septum being the only points at which the floor is incomplete.

The septum interorbitale continues into the septum nasi interrupted only by a small circular perforation situated near the dorsal margin immediately in front of and between the bases of the commissurae spheno-ethmoidales, so that there is formed a very high ventral commissure and a slender, rodlike one between the septum interorbitale and septum nasi.

The septum nasi is a thin vertical plate with a longitudinal ridge on each side, the crista longitudinalis septi, which extends from in front at the level of the upper margin of the fenestra narina posteriorly and ventrally to the point at which the cartilago paraseptalis becomes separate from the septum (figs. 13 and 18). The septum is much shorter along its dorsal than along its ventral margin, and is continuous anteriorly with the tectum nasi, but posteriorly, in the region of the fenestra olfactoria, it ends freely dorsally. The upper margin slopes downward in front. The ventral margin is continuous with the floor of the capsule except in the region of the foramen praepalatinum and that of the short cartilago paraseptalis. Like the upper margin it slopes downward in front, but more rapidly than the upper margin so that the septum nasi is much higher in front than behind. Especially in the region of the anterior half of the foramen praepalatinum the septum projects below the level of the floor of the capsule to form a slight ventral crest along the mid-ventral line, the prenasal cartilage of Parker. The front margin of the septum is continuous in its dorsal half with the transverse vertical front wall of the capsule and rounds off gradually into the dorsal margin; in its ventral half the septum ends freely between the two fenestrae narinae to separate them completely from each other. In a somewhat older stage of Emys than that modelled, Seyde] 
describes the septum as not extending as far forward as I have found it, so that the two fenestrae narinae are less perfectly separated from each other.

Of special interest in connection with the septum nasi is a long rodlike cartilage which, at its posterior end, is continuous with the septum by the crista longitudinalis septi; it extends anteriorly, parallel to the crest and separated from it by a narrow space, and ends freely a short distance behind the anterior margin of the septum. The glandula nasalis media is medial and ventral to this rod while lateral to it and supported by it is the median fold of the olfactory sac which separates the pars olfactoria from the pars respiratoria. To this rod I would give the name pila supraglandularis (p.sg.; fig. 13).

In an embryo of $13.5 \mathrm{~mm}$. carapace length the pila supraglandularis is continuous at its posterior end with the floor of the capsule immediately in front of the foramen praepalatinum (figs. 16 to 18). From this relation it follows, as Seydel has shown, that the foramen praepalatinum opens into the olfactory capsule directly in a dorsal direction behind and in a lateral direction further forward beneath the pila supraglandularis. Later in embryonic development (16 mm. carapace length) the pila supraglandularis fuses along its whole length with the crista longitudinalis septi and forms a sloping roof extending ventro-laterally from the septum dorsal to the glandula nasalis media.

The glandula nasalis media lies with its posterior end in the anterior half of the foramen praepalatinum and extends obliquely forward and dorsally, parallel to the septum, beneath the pila supraglandularis. The gland opens at its anterior end into the olfactory sac ventral to the anterior end of the crista longitudinalis septi.

The cartilago paraseptalis is a short plate forming the ventromedian boundary of the fenestra basalis. It is continuous in front with the floor of the capsule which exhibits ventrally in its posterior part a moderately deep groove between its two halves. The cartilago paraseptalis accordingly exhibits a ventro-median and a dorso-lateral face at its anterior end, but toward its posterior free end it is rotated slightly so that the faces are directed 
medially and laterally and the cartilages of the two sides are nearly parallel. The dorsal margin of the cartilago paraseptalis lies slightly above the level of the ventral margin of the septum; further anteriorly, where it is more nearly horizontal, its mediodorsal margin is at the level of the lower margin of the septum. The postero-dorsal angle of the paraseptal cartilage comes to lie in contact with the planum antorbitale for a very short space so that the fenestra basalis is almost completely surrounded by cartilage. It fails, however, to fuse with the planum antorbitale, as in Lacerta until a much later stage (c.p., fig. 10).

The cartilago ectochoanalis is a posterior prolongation of the solum nasi which forms a short process ventral and lateral to the choana, with its dorsal surface concave and ventral surface convex, forming thus a trough-like projection. It is differentiated from the cartilago paraseptalis only by a shallow incision at its posterior end.

The fenestra basalis through which the choana passes posteriorly is vertical and transverse in position and is situated below the level of the ventral margin of the septum interorbitale. In the stage modelled the fenestra is not completely separated by cartilage from the fissura orbitonasalis because of the failure of the cartilago paraseptalis and planum antorbitale to fuse dorsally. The ventro-lateral margin of the fenestra projects posteriorly as the short cartilago ectochoanalis, above which the lateral margin of the fenestra is incised to form the broad sinus nasalis posterior. The medio-ventral margin is likewise incised to form the sinus paraseptalis. The fenestra is oval with the long axis oblique from dorso-medial to ventro-lateral, and with its dorsal end more acute than the ventral. In the Emys embryo modelled the dorsal end of the fenestra is not closed by cartilage but by a mass of dense connective tissue between the planum antorbitale and cartilago paraseptalis.

The two fenestrae narinae together form a large round foramen which, as it were, truncates the nasal capsule anteriorly. Unlike that of Lacerta, which faces ventrally and laterally, that of Emys is directed anteriorly in a vertical transverse plane. Dorsally 
and ventrally from each foramen the capsular wall is produced in an anterior direction into a short process, the dorsal orie of which is slightly stronger than the ventral. Laterally the margin of the foramen is incised to accommodate the duct of the glandula nasalis externa which passes medially to open into the nasal sac. The fenestra narina lies in the ventral half of the capsule so that the entire front wall of the pars respiratoria is lacking. The septum nasi ends freely in front on a level with the lateral margins of the fenestra so that the two fenestrae are completely separated from each other.

A small fenestra epiphaniale in the antero-dorsal portion of the paries nasi, near the point at which the latter passes over into the tectum nasi, is the only perforation of the paries nasi in the stage modelled. Through this fenestra the nervus lateralis nasi of the ophthalmic branch of the trigeminus passes to the exterior of the capsule.

The foramen praepalatinum is an elongated slit separating the solum nasi from the septum nasi for a space posterior to the lamina transversalis anterior. It is divided by a projection of its lateral margin into a smaller anterior and larger posterior lobe. The indentation of its lateral margin is produced by the posterior end of the pila supraglandularis which is attached at this point to the solum nasi as already described.

The fenestra olfactoria (f.ol., fig. 24) as already mentioned, slopes ventrally in front from the antero-ventral margin of the planum supraseptale to the tectum nasi. It is a long oval, bounded medially by the free margin of the septum nasi and laterally by the commissura spheno-ethmoidalis. The planes of the two fenestrae are slightly inclined toward each other because the septum does not extend dorsally as far as the level of the commissurae spheno-ethmoidales.

The fissura orbitonasalis is continuous ventrally and anteriorly with the sinus paraseptalis. Dorsally it is separated from the fenestra olfactoria by only the slender commissura sphenoethmoidalis. The nervus ethmoidalis rami ophthalmici trigemini gains access to the nasal capsule from the orbit through it. 


\section{PALATOQUADRATUM AND MANDIBLE}

The palatoquadratum of Emys is of special interest since it has a distinct pars palatina, or processus pterygoideus; a condition which recalls the primitive one of the skull of Sphenodon and the Anamnia in general. It is entirely disconnected from the rest of the skull. The pars quadrata lies close alongside of the lateral wall of the otic capsule and the pars palatina alongside of the crista basipterygoidea, both parts, however, are separated from the median portion of the skull by at least a thin layer of non-cartilaginous tissue. The form of the pars quadrata has been very aptly compared to that of the external ear of man with the convex margin directed anteriorly and the concave margin posteriorly; accordingly the anterior portion of the pars quadrata is much higher dorso-ventrally than the posterior portion. It is of about the same size as the otic capsule so that it conceals the latter somewhat when viewed from the side. Its ventral portion, the pars articularis, lies well below the level of the basal plate so that its dorsal margin lies also somewhat below that of the otic capsule. In its posterior portion, the pars quadrata, fits into the broad, shallow groove formed on the lateral wall of the otic capsule by the crista parotica and the portion of the prominentia canalis semicircularis lateralis which lies dorsal to it. The median wall of the pars quadrata has a nearly vertical position so that it is much further removed from the capsule ventrally than dorsally where the lateral semicircular canal projects. In the comparatively narrow space between the quadratum and the otic capsule are situated the arteria carotis interna and vena capitis lateralis which extend, parallel to each other, obliquely from postero-ventral to antero-dorsal, as has already been described by Noack.

The pars quadrata may be differentiated into two distinct portions, a postero-dorsal one which encloses an extension of the tympanic cavity, regarded by Hasse as the homologue of the antrum mastoideum of human anatomy (pars mastoidea), and an antero-ventral portion which lacks the outer wall of the former and so exhibits an imperfect cup shape (pars articularis). The pars mastoidea of the quadratum forms a hollow cone, flattened from side to side, with its apex directed posteriorly and its base 
directed anteriorly. The lateral wall of this region exhibits an irregular fenestra. which indicates simply the beginning of the $a b$ sorption of the cartilage under the influence of the adjacent squamosum. 'The base of this portion of the quadratum opens freely into the postero-dorsal portion of the pars articularis dorsal to the incisura coltumellae. The pars articularis is continuous with the pars mastoidea by means of the median wall and the dorsal margin of the latter which is rolled over laterally and ventrally to a slight extent to enclose partially the concavity of this region from above. The anterior and ventral margins of the anterior half of the quadratum are rolled over laterally to form a rim enclosing the tympanic cavity in front and below. Ventrally this rim becomes somewhat heavier and higher to form the processus articularis. The anterior half of the pars quadrata is much higher than the posterior, so that the processus articularis projects well below the ventral margin of the posterior part. Between the latter and the ventrally projecting processus articularis in front is a broad triangular sinus (incisura columellae) for the stalk of the columella.

The processus articularis bears a saddle-shaped articular surface for the articulation of the lower jaw. The axis of the surface is slightly oblique, sloping ventrally and posteriorly from the medial to the lateral side.

The pars palatina arises from the anterior end of the median aspect of the pars quadrata near its ventral angle and extends anteriorly and ventrally as a gradually tapering rod, its distal end bending latero-ventrally at a right angle. Of especial interest in relation to the pars palatina is the processus ascendens. This is a slender, laterally compressed process which arises from the processus pterygoideus, about midway between its origin from the pars quadrata and its sharp lateral bend. The processus ascendens extends lateral to the foramen prooticum, but somewhat removed from it. Its free distal end is close to the ventral end of the processus descendens of the parietale. Judged by its relations to the nervus trigeminus and to the palatoquadratum, it is the homologue of the 'columella' of the kionocraniate lizards, as has been pointed out by Filatoff ('06). It extends 
medial to the rami maxillaris and mandibularis of the nervus trigeminus and lateral to the ramus ophthalmicus. As development proceeds this process is reduced in size, becoming replaced by the very variable epipterygoideum of the adult.

The quadratum stands in very close relationship topographically with the columella auris as has already been shown, the posterior margin being deeply incised for the accommodation of the slender stalk of the columella as it passes horizontally from the otic capsule as far laterally as the outer wall of the quadratum where it is expanded to form a mushroom like plate which partially fills the cup-like ventral half of the quadratum.

\section{COLUTELLA AURIS}

The columella auris in the embryo modelled consists of a single cartilaginous rod in which only a trace of its origin from two centers is preserved in the fact that the chondrification of the external end is very distinctly less advanced than of the rest. In earlier stages, however, the stapes and extracolumella, which together form the columella auris, are very evidently distinct. Topographically are to be distinguished the foot plate, stalk, and insertion piece, of which the first two belong to the stapes and the last to the extracolumella.

The foot plate is triangular and fits closely into the fenestra vestibuli, resting with its ventral margin upon the planum basale. The stalk arises from near the anterior angle of the foot plate, gradually assuming its slender, cylindrical form and extending at right angles to it in a lateral direction. It is slightly sigmoid, with its lateral extremity further forward than its median extremity. It extends laterally across the cavum tympanicum ventral to the vena capitis lateralis and nervus facialis and resting in the incisura columellae of the quadratum as already described. It passes into the median surface of the insertion piece somewhat dorsal to the center of the latter. The insertion piece is mushroom-shaped with its medial surface flat and lateral aspect convex. Its plane is vertical and continuous with the lateral wall of the quadratum. It aids in closing the cavum tympanicum laterally. 
Of especial interest in connection with the extracolumella is the processus interhyalis described by Bender ('11) in Testudo and the present writer (Kunkel '12) in Emys, extending from the postero-ventral corner medially and ventrally. From the apex of the processus interhyalis a strand of dense connective tissue extends ventro-medially towards the lateral aspect of the pars retroarticularis of Meckel's cartilage as Fuchs ('07) has described. This process, in earlier stages, is distinct from the extracolumella as the interhyale.

The origin of the columella auris from two separate centers is also clearly shown in an embryo of $7 \mathrm{~mm}$. carapace length. As I have shown in an earlier paper (Kunkel '12) in this embryo the insertion piece, corresponding to the extracolumella, is distinot from the stalk, which, together with the foot plate, represents the stapes (col., fig. 21). Noack's conclusion ('07) that the columella of chelonians is a derivative of the capsular wall is not confirmed by my observations. In one of my earlier stages (carapace length, $5.2 \mathrm{~mm}$.) the blastema of the columella is distinctly in the prechondrial stage while that of the capsule has not proceeded so far. In this embryo the stapes extends medially as far as the lateral wall of the otic sac and is represented by a mass of prechondrium far in advance in development of any in its immediate neighborhood.

The relation of the nervus facialis to the columella, I find is essentially as Noack has described. The ramus hyomandibularis extends caudally in a straight line from the ganglion geniculi, dorsal to the stem of the columella, to the muscles which it innervates. Almost immediately behind the columella it gives off laterally the chorda tympani which passes first in a lateral direction as far as the quadratum and then curves forward, crossing the columella on its dorsal side, and then turns ventrally in front of the Eustachian tube eventually to reach the mandible.

Meckel's cartilage is of strong form, tapering regularly from the condyle anteriorly. In cross section in front of the condyle it is elliptical with the long axis of the ellipse oblique from dorsolateral to ventro-medial. At the condyle the rami of the mandible are flattened considerably as if by pressure from above so 
that each one flares out laterally to form a distinet flange. The upper surface of the condylus mandibularis is saddle-shaped to fit into the processus articularis of the palatoquadratum. The processus retroarticularis is very poorly developed, extending only a very short distance behind the condyle as a somewhat laterally compressed keel. The distal ends of the two rami of the mandible are united by a strong symphysis in the form of a moderately thin horizontal plate of triangular form which extends behind the anterior ends of the rami and fills up the angle made by the two. An independent 'basimandibular' element, such as Parker ('80) describes in Chelone, is not present. In earlier stages than that modelled, the symphysis is much shorter, although sections in this region show the rami to be widening medially just behind their union to fuse finally and increase the strength of the symphysis.

In the stage modelled, the proximal end of Meckel's cartilage has not yet begun to ossify to form an articulare. This ossification becomes evident for the first time in an embryo having a carapace length of $13.5 \mathrm{~mm}$.

In the earliest stage which I have studied (carapace length, $4.7 \mathrm{~mm}$.) Meckel's cartilage is present as a cylindrical rod of prechondrium which tapers gradually as it proceeds from its articulation to its distal (anterior) end. At this stage the rami do not meet in a symphysis. The processus retroarticularis is relatively longer than at a later stage, possibly because the condylus, in becoming larger, usurps a portion of the original pars retroarticularis.

\section{HYOID AND VISCERAL ARCHES}

The development of the hyoid and visceral arches of Emys has already been described by Fuchs ('10) to whose account I can add from my own study of this region only a few points.

The corpus hyale in the stage modelled is simple and of the pentagonal form usual in the adult chelonians. The apex is directed, anteriorly and from its lateral margins project three pairs of processes. It is somewhat concave dorsally and convex ventrally to form a shallow cup with a thickened rim in which the 
larynx rests. The anterior apex of the corpus is produced anteriorly to form a conical processus lingualis which exhibits on its dorsal surface at its proximal end a shallow longitudinal groove representing the original space between the pair of processes of the corpus from which the processus lingualis has developed. The two antero-lateral angles of the corpus (processus lateralis anterior) are continuous laterally and posteriorly with the very short cornua hyalia. The processus lateralis intermedius is small and separated from the cornu branchiale primum. The processus lateralis posterior is continuous at this stage with the stout cornu branchiale secundum. The cornua hyalia may be differentiated from the processus lateralis anterior by a deep cleft which extends anteriorly from behind so that the cornu itself is represented by a broad, flat, stump which projects posteriorly and is thicker at its distal than at its proximal end.

The cornua branchialia prima are the longest of all the cornua and are long cylindrical rods, tapering very gradually toward their distal ends, and curved at first slightly in a postero-lateral direction and then toward their distal ends in simply a dorsal one. At their extreme distal ends they bend sharply in a medial direction and anteriorly to form short hooks whose free ends are directed forwards. These rods are in close relationship to, but are not continuous with, the processes of the corpus by their proximal ends. The cornua branchialia secunda are at this stage continuous with the processus laterales posteriores. They are heavy rods of ellipitical cross section, rather thicker than the cornua branchialia prima. They are parallel in general with the last mentioned and terminate with their distal ends slightly upturned some distance ventral and medial to the extremity of the cornu branchiale primum. The second pair of cornua are considerably shorter than the first and so do not extend so far posteriorly.

No trace of an entoglossum occurs in the embryo modelled, but in an older individual (carapace length, $28 \mathrm{~mm}$.) I find a thin plate of cartilage just ventral to the anterior end of the corpus hyale. It extends beyond the processus lingualis and is separated from it by only a thin layer of connective tissue. It is 
somewhat triangular, with the base posterior and apex in front. This cartilago entoglossalis is imbedded in a much larger mass of fibrous tissue in which some scattered cartilage cells are present. In the adult, this surrounding mass of fibrous tissue forms a conspicuous heart-shaped plate beneath the anterior end of the corpus hyale.

In the adult of Emys, as already known, the three pairs of cornua are distinct from the corpus hyale and are connected with it by connective tissue. Already in a young individual with a carapace length of $28 \mathrm{~mm}$. the three pairs of cornua are distinct from the corpus although the cornu branchiale primum is the only part of the hyobranchial arches which exhibits an ossification. The cornu hyale becomes segmented from the corpus hyale slightly earlier than does the cornu branchiale secundum; for example, in an embryo with carapace length of $13.5 \mathrm{~mm}$. the separation of the cornu hyale is complete while the cornu branchiale secundum is only partially separated.

A separate epibranchiale primum (Siebenrock '99) is present as a separate triangular cartilage lying dorsal to the extreme distal end of the cornu branchiale primum in an embryo having a carapace $13.5 \mathrm{~mm}$. long. It remains as a distinct cartilaginous element in the adult.

In the fully grown Emys the cornua and corpus hyale are ossified and only the processus lingualis, a small oval foramen in the anterior part of the corpus, the extreme distal ends of the cornua branchialia primum and secundum, and the epibranchiale primum remain chondrified.

The earliest portion of the hyobranchial apparatus to be laid down in cartilage is the cornu branchiale primum which is already chondrified in an embryo having a carapace length of $7 \mathrm{~mm}$. It likewise is the earliest to show signs of ossification. In the embryo modelled, ossification has already begun in its middle portion, a short distance behind the posterior margin of the corpus hyale. The cornu hyale chondrifies later than the corpus hyale and at essentially the same time as the cornu branchiale secundum; so that in the stage modelled, although the body is completely chondrified, the cornu hyale is represented by: a sepa- 
rate cartilaginous center at some distance from the corpus and is surrounded by a mass of chondroblasts which is continuous with it.

The processus lingualis arises from a pair of short processes extending forward from the front margin of the corpus hyale at a short distance from each other and converging slightly toward their distal ends. In the stage modelled it is present as a single median rod of cartilage with only a slight indication on its dorsal surface, in the form of a shallow longitudinal groove, of its paired origin. Cross sections, however, prove its double nature even at a much later stage.

\section{MEMBRANE BONES}

The membrane bones are all laid down in the stage modelled with the exception of the parasphenoideum, quadrato-jugale, and the complementare of the lower jaw.

The squamosum (s., figs. 24,25 and 26 ) is a thin plate of bone of irregular triangular form, exhibiting a convex lateral and a concave median face. It lies parallel to the outer side of the quadratum, overlying the posterior extension of the same, and separated from it by only a narrow layer of connective tissue. Its posterior margin projects slightly beyond the quadratum while its dorsal margin shows a tendency to curve medially to embrace the quadratum more closely. The ventral angle of the bone is also bent medially below the posterior end of the quadratum.

As the embryo increases in size the squamosum comes to lie with its postero-ventral angle resting against the crista parotica while its dorsal margin extends medially above the quadratum to come in contact with the lateral wall of the otic capsule dorsal to the prominentiae canalis semicircularis lateralis and ampullaris posterior. The anterior angle of the squamosum also comes to extend relatively further forward in older embryos.

The first appearance of a squamosum is in an embryo having a carapace length of $7 \mathrm{~mm}$., at which stage it has the form of a shallow saucer in contact by its margins with the posterior extension of the quadratum. 
In its relation to the quadratum, the squamosum agrees closely with that established by Thyng ('06), as the criterion of that bone.

The quadrato-jugale is not present in the stage modelled, but appears first in my next older embryo (carapace length, 13.5 $\mathrm{mm}$. .). In this it forms a triangular plate with its ventral angle greatly prolonged in front of the pars quadratum of the palatoquadratum. Its postero-dorsal angle lies a short distance ventral to the anterior angle of the squamosum and its posteroventral margin follows closely the free anterior margin of the pars articularis of the palatoquadratum. Its anterior portion comes to lie ventral to the posterior end of the postfrontale and posterior to the posterior end of the zygomaticum. In older embryos the posterior end of the quadrato-jugale is overlapped externally by the squamosum.

It is of special interest in this connection that in such chelonians as Cistudo ornata, Chelodina longicollis, and Geoemyda spinosa, the embryonic character of the absence of a quadrato-jugale is retained through life.

The zygomaticum (z., fig. 26) in the stage modelled is in the form of a long, slender plate of bone bent so that it exhibits one limb extending horizontally forward and the other obliquely postero-dorsally. At the same time the plane of the bone is somewhat twisted on its own axis so that whereas the posterodorsal portion is sagittal, exhibiting a lateral and medial surface, the anterior portion is more nearly horizontal, exhibiting a dorsal and a ventral surface. The bone lies freely in the postorbital region quite far in front of the front margin of the pars quadrata. Together with the postfrontale, it completes the posterior margin of the orbit. Its anterior end extends forward dorsal to the hinder end of the maxillare.

The maxillare $\left(m_{0}\right)$ consists of a thin elongated plate of bone having in general a horizontal position and forming the ventrolateral margin of the anterior end of the skull. Its dorsal surface is slightly concave so that it exhibits a shallow longitudinal groove; ventrally it is strengthened by a vertical rib which grows higher toward the anterior end. The plane of the horizontal 
portion of the maxillare becomes somewhat twisted at the anterior end where the bone embraces the olfactory capsule so that the dorsal surface becomes strongly inclined toward the median plane of the head. There may be distinguished three definite regions, the processus palatinus, processus alveolaris, and processus praefrontalis. The processus palatinus is horizontal, exhibiting a dorsal and a ventral surface; it is of nearly uniform thickness throughout, but becomes slightly thicker at the anterior than at the posterior end. Near its posterior end it is perforated by a small foramen for the ramus maxillaris nervi trigemini, which passes from above through the foramen to continue forward on the ventral side of the maxillare, lateral to the processus alveolaris. This latter has a vertical position, springing from the mid-ventral line of the processus palatinus and increasing in height from posterior to anterior. For the anterior one-third of its length the maxillare is made up entirely of the processus praefrontalis which is continuous ventrally with the anterior end of the processus alveolaris and dorsally with the processus palatinus. At the junction of the processus palatinus and praefrontalis are several irregular foramina (foramina alveolaria externa superiora.)

The processus praefrontalis has a concave median and convex lateral surface and embraces the posterior two-thirds of the olfactory capsule ventro-laterally. Its antero-median margin is hollowed slightly in order to accommodate the praemaxillare. The dorsal margin of the processus praefrontalis lies in the same plane with and rather close to the ventral margin of the praefrontalis.

The processus palatinus is overlapped dorsally for a very short distance by the anterior end of the zygomaticum so that the two bones together complete the margin of the orbit posteriorly and ventrally. It lies in the same horizontal plane with the palatinum which comes to lie in close relation to it by its anterior end.

The praemaxillare $(\mathrm{prm}$.$) is of small irregular form situated$ ventral to the olfactory capsule in the region of the foramen praepalatinum and medial to the anterior end of the maxillare. Like 
the maxillare it exhibits a processus palatinus and a processus alveolaris. The former is horizontal, exhibiting a dorsal and a ventral surface, and is prolonged anteriorly at its median margin to form a short process which extends nearly as far as the anterior margin of the solum nasi and which may represent a very rudimentary processus praenasalis. Even in the adult Emys, however, the praemaxillare remains wholly ventral to the olfactory capsule and does not extend anterior to it to separate the two fenestrae narinae from each other as in Lacerta, for example. The processus alveolaris is a vertical plate extending from the ventral surface of the processus palatinus in an oblique direction from postero-lateral to antero-medial.

The postfrontale $(p s t$.$) has the form of a triangular plate with$ an apex directed forward and its upper margin horizontal; its antero-ventral margin is slightly concave and thickened by a laterally projecting flange which arises near the ventral angle of the bone and extends to the anterior apex. It lies in the space between the quadratum posteriorly and the orbit anteriorly, lateral to the parietale. It approaches the posterior extremity of the zygomaticum with its ventrally projecting angle, and the anterior margin of the quadratum in its most lateral portion with its posterior margin. It has no share whatever in the formation of the cranial wall.

The parietale (par.) and frontale $\left(f_{\text {. }}\right.$ ) have essentially the same relations to the chondrocranium that they do in Lacerta; that is, their position is wholly lateral and in the stage of Emys modelled they do not begin to roof in the cranial cavity. The parietale is large and triangular in form exhibiting long dorsal and antero-ventral margins, a short posterior one, and a lateral and a medial face. Its postero-dorsal angle is prolonged slightly to form a small processus occipitalis, extending dorsal to the otic capsule for a short distance. Ventrally the parietale is prolonged to form a processus inferior which extends downward lateral to the pila prootica to come into close relationship with the free end of the processus ascendens of the palatoquadratum. The processus inferior thus comes to enclose a space external to the primordial cranial cavity so that the latter is increased in size on the sides. This space is the cavum epiptericum. 
The antero-ventral margin of the parietale lies parallel to the free margin of the planum supraseptale at a short distance dorsal and lateral to it, while its anterior angle comes to lie medial to the posterior end of the frontale. The posterior margin of the parietale rests with its projecting processus occipitalis against the anterior cupola of the otic capsule.

The frontale is a narrow, curved plate that continues the contour of the parietale forward. Its ventral margin, like that of the parietale, lies parallel to the free margin of the planum supraseptale and completes the orbit dorsally. Its posterior end overlaps laterally the anterior end of the parietale and its extreme anterior end is embraced by the dorsal extremity of the praefrontale.

In contrast to the condition in Lacerta the frontale in Emys extends less far posteriorly so that it fails to be overlapped by the anterior extremity of the postfrontale. The frontale at this stage of development is relatively small, its place being taken to a certain extent by the extremely large praefrontale in front and the unusually large parietale behind.

The praefrontale $(p f$.$) or lacrimale is very large, completing$ the orbit anteriorly and embracing the greater part of the olfactory capsule. In form it exhibits a vertical plate which extends beyond and lateral to the antero-ventral end of the frontale, and a larger oblique portion lateral to the olfactory capsule and lying dorsal to the anterior portion (processus praefrontalis) of the maxillare. The anterior margin of the vertical limb of the praefrontale becomes very thick, so that there is a distinct anterior, as well as a lateral and a medial face. It may be that this thickening of the dorsal portion of the praefrontale stands in connection with the fact that a nasale is lacking.

The pterygoideum $(p t$. ) is strongly developed in the stage of Emys modelled, and exhibits clearly many of the characteristics of the adult form. It is a long, slender bone with ventral face exteriding horizontally and a longitudinal crest, the crista pterygoidea (c.pt., fig. 20), extending dorsally, which diminishes in height from posterior to anterior and separates the fossa suprapterygoidea, lying lateral to it, from the sulcus cavernosus on 
its median side. At its anterior end the crista pterygoidea disappears and the pterygoideum extends forward as a small horizontal process between the posterior end of the platinum laterally and the fused trabeculae medially. Near the anterior end of the lateral margin of the pterygoideum a conspicuous triangular process - the processus ectopterygoideus - projects laterally beneath the distal end of the processus palatinus of the palatoquadratum. Its posterior end lies with the crista pterygoidea between the base of the processus pterygoideus of the palatoquadratum laterally and the projecting antero-lateral margin of the planum basale, coming to lie in close relation to the rudimentary eartilago articularis (c.a., fig. 8). 'The body of the pterygoideum lies in a plane ventral to the planum basale, extending laterally beneath the processus pterygoideus of the palatoquadratum and medially beneath the processus basipterygoideus to enclose from the ventral side a space in which run the ramus palatinus $\mathrm{n}$. facialis and ramus communicans $\mathrm{n}$. facialis cum glossopharyngeo, as well as the arteria carotica interna, which lie in the sulcus cavernosus on the median side of the crista pterygoidea.

The palatinum (pal.) is a flat, triangular plate with its apex directed posteriorly and base anteriorly. It lies at the same level as the processus palatinus of the maxillare and occupies the space in the roof of the mouth between the maxillare, vomer, and pterygoideum. Its posterior end lies external to the anterior prolongation of the pterygoideum and in front of the processus ectopterygoideus. The plane of the palatinum is inclined so that its median margin is somewhat dorsal to its lateral margin.

The parasphenoideum is wanting in the stage modelled, but in an older embryo (carapace length, $13.5 \mathrm{~mm}$.) it is present as a small tripartite plate lying ventral to the region of the fenestra hypophyseos. Its anterior median process extends as far forward as the front margin of the fenestra while its postero-lateral processes extend scarcely as far laterally as the lateral margins of the fenestra. 
The parasphenoideum lies immediately in front of and partially embraces on the two sides the stalk of the hypophysis at this stage. It is also of interest that a small lamella of bone extends horizontally forward from the front margin of the crista sellaris to occlude partially the fenestra hypophyseos. In an older embryo having a carapace length of $16 \mathrm{~mm}$. this lamella from the crista sellaris has extended itself further forward and fused completely with the parasphenoideum so that only a very small opening is left between the posterior processes of the parasphenoideum and this lamella for the accommodation of the hypophysial stalk. In the meanwhile the ossification of the crista sellaris, which becomes the basisphenoideum, has set in.

The basisphenoideum of the adult Emys must therefore be composed of two parts, an anterior part not preformed in cartilage and a posterior part laid down originally in the crista sellaris as a replacing bone.

The vomer $(v$.$) in the stage modelled is an unpaired bone hav-$ ing the form of a shallow trough which lies with its dorsal concave face ventral to the anterior end of the septum interorbitale and separated from it by a thin layer of connective tissue. In form the vomer tapers slightly in a horizontal plane toward the anterior end and also grows thicker dorso-ventrally.

In an embryo having a carapace length of $8.5 \mathrm{~mm}$. the vomer shows clearly its paired nature, being represented by a pair of thin lamellae set at an angle to each other so that they fit about the ventral edge of the septum interorbitale between the posterior opening of the ductus naso-pharyngeus behind and the cartilago paraseptalis in front. In an embryo having a carapace length of $13.5 \mathrm{~mm}$. the vomer extends relatively further posteriorly than in the stage modelled and its lateral margins lie close to the median margins of the two palatina which, however, come to lie rather dorsal to the vomer.

The investing bones of the adult lower jaw are all present in the stage modelled except the complementare which appears first in an embryo having a carapace length of $13.5 \mathrm{~mm}$. They may be designated as the dentale, angulare, supra-angulare, and goniale. An operculare is lacking as in the adult. The arti- 
culare, an ossification of the proximal end of Meckel's cartilage, is not apparent in an Emys embryo having a carapace length of $11 \mathrm{~mm}$.

The dentale (d.) has the form of a long, slender plate exhibiting in general a concave medial and convex lateral surface. It is provided with flattened flanges extending both laterally and medially from the dorsal margin. It lies lateral to Meckel's cartilage for almost the entire distance from the anterior, distal end to the fovea articularis, overlapping with its posterior end the anterior end of the supra-angulare so that the latter is interposed between the dentale and Meckel's cartilage.

By reason of the medial projection of the dorsal margin of the dentale, this bone comes to arch in dorsally the sulcus primordialis which accommodates Meckel's cartilage. Beneath the lateral flange of the dentale extends the portio alveolaris inferior of the ramus mandibularis $n$. trigemini which gains access to this groove (sulcus alveolaris inferior) from the sulcus primordialis through the foramen canalis alveolaris inferioris. This foramen is situated near the posterior end of the dentale immediately ventral to the thickened dorsal margin. In older embryos the sulcus alveolaris inferior becomes converted into the closed canalis alveolaris inferior by the further rolling over of the lateral margin of the dorsal flange.

The supra-angulare ( $s a$. ) is a small elongate plate of bone which lies along the lateral aspect of Meckel's cartilage in its proximal portion. It exhibits a slender posterior projection which lies along the lateral side of the fovea articularis. The anterior third of the supra-angulare at this stage is overlapped laterally by the posterior end of the dentale. The ramus recurrens cutaneus mandibulae from the mandibular branch of the trigeminus passes obliquely backward along the dorsal margin of the supraangulare and somewhat medial to it.

The angulare $\left(a_{0}\right)$ is a long slender plate of bone lying on the ventral side of the posterior end of Meckel's cartilage in the region of the supra-angulare. It forms, accordingly, the floor of the sulcus primordialis in its posterior part. It is much shorter than the supra-angulare and extends neither as far anteriorly 
nor posteriorly as the latter. Its antero-lateral margin lies in close proximity to the ventral margin of the dentale.

The goniale $(g$.$) is a thin, elongated plate of bone situated along$ the median aspect of Meckel's cartilage, from the posterior end of the latter for one-third of its length. It exhibits a convex median and a concave lateral aspect to fit more closely about the posterior end of Meckel's cartilage medially. Its postero-dorsal angle lies along the median aspect of the fovea articularis.

Of especial interest in connection with the goniale is the relation of the chorda tympani. In the embryo modelled the nerve enters the goniale at its posterior extremity by means of the canalis gonialis which extends forward for a short distance and opens anteriorly on the lateral aspect of the goniale as a well marked sulcus so that the chorda tympani reaches the canalis primordialis and extends further forward in this canal between the goniale on the median side and Meckel's cartilage on the lateral side. In an older embryo (carapace length, $13.5 \mathrm{~mm}$.) a canalis gonialis is wanting. Instead of this the chorda tympani is lodged in a groove on the median side of the goniale. The nerve passes obliquely forward and ventrally and for a short space lies along the ventral margin of the goniale. The latter then becomes suddenly wider by a ventrally projecting extension which is lateral to the nerve. For a considerable distance the chorda tympani is thus separated from Meckel's cartilage by the goniale. A foramen finally allows the nerve to pass into the sulcus primordialis.

A third relationship of the chorda tympani and goniale was encountered in an embryo having a carapace length of $16 \mathrm{~mm}$. In this individual the nerve entered the canalis gonialis from the lateral aspect of the bone and both before and after entering the canalis gonialis it lay in a deep groove communicating with the sulcus primordialis.

The complementare is not yet laid down in the embryo modelled. In an embryo having a carapace $13.5 \mathrm{~mm}$. long, however, it is present as a triangular plate of bone lying dorsal to the goniale with its anterior end somewhat further forward than that of the goniale. It lies medially to the ramus mandibularis $\mathrm{n}$. trigemini. 


\section{SUMIMARY}

The principal points which I would emphasize in conclusion are as follows:

1. The chondrocranium of Emys resembles closely that of Dermochelys and Chelone and, in general features, is similar to that of Lacerta, but is of heavier construction.

2. The planum basale is parachordal in position, surrounding the chorda dorsalis on all sides.

3. The condylus occipitalis is annular in form, a central concavity being present around the chorda dorsalis.

4. The arcus occipitales do not reach the tectum posterius distally so that the foramen occipitale magnum is not separated completely from the fissura metotica.

5. There are three foramina spino-occipitalia present at the stage modelled, the two anterior of which fuse later.

6. The tectum posterius is strongly developed, exhibiting a processus ascendens of large size and a stout processus posterior which limits the foramen occipitale magnum dorsally.

7. The fissura metotica becomes wide at its antero-ventral end at which point the nervus vagus and vena jugularis leave the cranial cavity.

8. The planum basale projects laterally beyond the lateral portions of the occipital region as the crista inferior which thereby forms the ventral side of the sulcus supracristularis.

9. The fenestra cochleae opens into the sulcus supracristularis at its anterior end (recessus scalae tympani) immediately in front of the fissura metotica.

10. The fenestra cochleae is the posterior opening of the canalis perilymphaticus which has a horizontal direction and opens into the cavum cochleae on the median wall of the latter.

11. A canalis hypoperilymphaticus is found in embryos older than that modelled, passing parallel and ventral to the canalis perilymphaticus and communicating between the recessus scalae tympani posteriorly and the cavum cochleae anteriorly. It contains nothing but loose connective tissue. It develops anteriorly from its posterior end. 
12. The nervus glossopharyngeus passes through the cavity of the otic capsule in the sulcus glossopharyngeus which is situated on the posterior wall of the cavum cochleae immediately ventral to the cavum ampullare posterius. The nerve perforates the median capsular wall by means of the foramen glossopharyngei internum and the outer wall by the foramen glossopharyngei externum.

13. The cavum cochleae is developed in a posteriordirection so that the nervus glossopharyngeus passes through it.

14. The cavity of the otic capsule is not divided by a septum intervestibulare as in Lacerta.

15. The median capsular wall is perforated anterior to the foramen glossopharyngei internum by the foramina acustica anterius and posterius and endolymphaticum; besides these are one or two smaller foramina one of which is for a blood vessel.

16. The foramen facialis lies anterior to the otic capsule and opens laterally into a depression, the fovea geniculi.

17. The foramen abducentis passes horizontally forward through the base of the pila prootica.

18. The fenestra prootica is large and unclosed dorsally because of the absence of a taenia marginalis to unite the distal end of the pila prootica and the otic capsule.

19. The fenestra hypophyseos is large and accommodates, besides the hypophysis cerebri, the arteriae carotides internae as they pass into the cavity of the cranium.

20. The fenestra metoptica, for the accommodation of the nervi oculomotorius and trochlearis, is in the form of a narrow slit and, like the fenestra prootica, is unclosed dorsally.

21. The planum basale projects laterally in the region of the crista sellaris beyond the attachment of the otic capsule to form the crista basipterygoidea which is apparently homologous with the processus basipterygoideus and with which articulates a rudimentary imperfectly chondrified cartilago articularis. The ramus palatinus nervi facialis passes ventrally from the ganglion geniculi a short distance behind the cartilago articularis and then extends anteriorly on the median side of the cartilago articularis in the sulcus cavernosus. 
22. The septum interorbitale is imperforate and is quite evidently of double origin since in younger stages than that modelled it is seen in cross section to have a distinct $\mathrm{Y}$-form, the two limbs of the $Y$ being parallel to each other and then suddenly diverging to form the planum supraseptale.

23. The fenestra optica is large and is situated in front of the foramen ophthalmicum through which the arteria ophthalmica passes into the region of the orbit of the eye. The two foramina ophthalmica are separated from each other by the subiculum infundibuli.

24. The septum interorbitale passes without interruption forward into the septum nasi which divides the ethmoidal region into two symmetrical halves.

25. The olfactory capsule is of compact form and is composed of continuous plates of cartilage not separated by extensive foramina.

26. The capsule is bent somewhat ventrally as is indicated by the plane of the fenestra olfactoria which is not horizontal, as in Lacerta, but inclines downward in front; and also by the fact that the fenestra basalis is situated below the level of the ventral margin of the septum interorbitale.

27. The olfactory capsule is connected with the septum posteriorly only by the slender commissurae spheno-ethmoidales which bound the fenestrae olfactoriae laterally and separate them from the fissurae orbitonasales.

28. The fissura orbitonasalis extends the entire length of the posterior cupula of the capsule, as in the Lacertilia, the planum antorbitale being entirely separated from the septum.

29. The nervus ethmoidalis passes into the capsule from the orbit through the fissura orbitonasalis.

30. The plane of the fenestra narina is transverse so that the fenestra faces directly anteriorly.

31. The lamina transversalis anterior is represented by the portion of the floor of the capsule in front of the foraman praepalatinum.

32. The shortness of the cartilago paraseptalis of the stage modelled is a secondary condition, since in earlier stages the fora- 
men praepalatinum is not closed posteriorly by a fusion of the cartilago paraseptalis with the septum, but extends freely posteriorly for a considerable distance.

33. The septum nasi in the stage modelled is continuous with the solum nasi except in the region of the foramen praepalatinum.

34. The cartilago paraseptalis, limiting the fenestra basalis medially, does not fuse with the planum antorbitale dorsally so that in the stage modelled the fenestra basalis is not completely enclosed with cartilage.

35. A rudimentary concha is present in the form of a shallow longitudinal infolding of the paries nasi. In older stages this is increased in height by a thickening of the wall which projects in a medial direction.

36. The septum nasi is thickened by means of a longitudinal crest, the crista longitudinalis septi, which separates the pars respiratoria from the pars olfactoria of the olfactory sac.

37. A slender rod, the pila supraglandularis, attached posteriorly to the septum in the region of the foramen praepalatinum, extends forward parallel to the crista longitudinalis septi above the glandula nasalis media and ends freely in front a short distance behind the level of the fenestra narina.

38. The septum nasi is provided with a small fenestra very near its dorsal margin in the region of the fenestra olfactoria.

39. The prenasal cartilage is present as a median ridge on the ventral side of the anterior part of the capsule.

40. A small foramen epiphaniale is present.

41. The palatoquadratum is entirely separate from the cranium and exhibits a distinct processus pterygoideus which in turn supports a processus ascendens which is the homologue of the 'columella' of the Lacertilia.

42. The pars quadrata of the palatoquadratum may be differentiated into a large hollow pars mastoidea, enclosing an extension of the tympanic cavity, and the pars articularis.

43. The posterior margin of the quadratum is deeply incised by the incisura columellae for the accommodation of the columella auris. 
44. The columella auris originates wholly external to the otic capsule and is made up of stapes and extracolumella. The foot plate occupies the fenestra vestibuli and rests upon the crista substapedialis; the stalk of the columella is slender and slightly sinuous; the extracolumella is mushroom-shaped.

45. A distinet processus interhyalis extends medially and ventrally from the ventral angle of the extracolumella.

46. The ramus hyomandibularis nervi facialis extends posteriorly dorsal to the columella and at the level of the latter gives off the chorda tympani in a lateral direction. This nerve then curves anteriorly, crossing the columella dorsally, and bends ventrally in front of the Eustachian tube.

47. Meckel's cartilage is strongly developed. The 'two cartilages meet by a strong symphysis anteriorly. The processus retroarticularis is poorly developed.

48. The corpus hyale is pentagonal, with the apex directed anteriorly. The short cornua hyalia are not segmented from the corpus. The cornua branchialia primum and secundum are both large and segmented from the corpus. A separate epibranchiale primum is present.

49. The processus lingualis arises as a pair of anteriorly directed rods from the anterior end of the corpus hyale, but at the stage modelled the two have grown together.

50. The cartilago entoglossalis appears for the first time at a later stage than that modelled.

51. The squamosum is a thin plate of bone lying parallel to the outer side of the quadratum.

52. The quadrato-jugale is not laid down in the embryo till a later stage than that at which most of the investing bones are laid down.

53. The zygomaticum, together with the postfrontale, completes the orbit of the eye posteriorly.

54. The maxillare, as in the adult, exhibits a processus palatinus, a processus alveolaris, and a processus praefrontalis. Its posterior end is perforated by a foramen for the passage from above of the ramus maxillaris nervi trigemini which continues forward lateral to the processus alveolaris. 
55. The praemaxillare is of small size, situated entirely ventral to the olfactory capsule.

56. The parietale and frontale are wholly lateral in position and do not begin at this stage to arch in the cranial cavity dorsally. The parietale exhibits a large processus inferior which extends downward, lateral to the pila prootica, to come at length into close relation with the free end of the processus ascendens palatoquadrati. A cavum epiptericum is hereby formed.

57. The praefrontale is exceedingly large and becomes very thick at its anterior margin, dorsal to the olfactory capsule.

58. The pterygoideum exhibits a pronounced crista pterygoidea on its dorsal side which separates the fossa suprapterygoidea from the sulcus cavernosus.

59. The palatinum and vomer complete the roof of the mouth at the stage modelled although later a separate parasphenoideum is present in the region of the fenestra hypophyseos. The vomer is unpaired but is derived from a paired condition.

60. In the lower jaw all the investing bones of the adult except the complementare are present at the stage modelled.

61. Along the lateral side of the dentale is the sulcus alveolaris inferior which becomes converted into the canalis alveolaris inferior of older embryos.

62. The goniale in the stage modelled is penetrated by the canalis gonialis in which the chorda tympani passes from the posterior end of the goniale obliquely forward and laterally to attain the canalis primordialis.

\section{BIBLIOGRAPHY}

No attempt is made in this bibliography to give a complete list of the works on the morphology of the skull, as such a list is to be found in Gaupp, $1905 \mathrm{~b}$, and more specifically for the chelonian skull in Nick, 1912. Only the more recent and important works which are referred to in the body of the paper are here mentioned.

BeNDER, O. 1911 Ueber Herkunft und Entwickelung der Columella auris bei Testudo graeca. Anat. Anz., Bd. 40, pp. 161-177.

Bojanus, L. H. 1819 Anatome Testudinis Europaeae. Vilnae, 1819-1821.

Filatofr, D. 1906 Zur Frage über die Anlage des Ǩnorpelschädels bei einigen Wirbeltieren. Anat. Anz., Bd. 29, pp. 623-633. 1907 Die Metamerie des Kopfes von Emys lutaria. Zur Frage über korrelative Entwicklung. Morph. Jahrb., Bd. 37, pp. 2Sy-396. 
Focrs, H. 1906 Untersuchungen über die Entwicklung der Gehörknöchelchen, des Squamosums, und des Kiefergelenkes der Säugetiere. Arch. f. Anat. u. Physiol., Anat. Abt., Supplement-band, pp. 1-90.

1907 a Untersuchungen über Ontogenie und Phylogenie der Gaumenbildungen bei den Wirbeltieren. Erste Mitteilung. Ueber den Gaumen der Schildkröten und seine Entwickelungsgeschichte. Zeitschr. f. Morph. u. Anthrop., Bd. 10, pp. 409-163.

1907 b Ueber die Entwickelung des Operculums der Urodelen und des Distelidiums ('Columella' auris) einiger Reptilien. Verhandl. d. anatom. Gesellsch., 21 Versamml., pp. 8-31.

1907 c Ueber das Hyobranchialskelett von Emys lutaria und seine Entwickelung. Anat. Anz., Bd. 31, pp. 33-39.

1910 Ueber das Pterygoid, Palatinum und Parasphenoid der quadrupeden, insbesondere der Reptilien und Säugetiere, nebst einigen Betrachtungen über die Beziehungen zwischen Nerven und Skeletteilen. Anat. Anz., Bd. 36, pp. 33-95.

GAUPP, E. 1905 a Neue Deutungen auf dem Gebiete der Lehre vom Säugetierschädel. Anat. Anz., Bd. 27, pp. 273-310.

1905 b Die Entwickelung des Kopfskelettes. Hertwig's Handbuch der Entwickelungslehre, Bd. 3, Abt. 2, pp. 573-874.

1905 c Die Nicht-Homologie des Unterkiefers in der Wirbeltierteihe. Verhandl. d. anatom. Gesellsch., 19 Versamml., pp. 125-140.

1905 d Das Hyobranchialskelett der Wirbeltiere. Ergeb. d. Anat. u. Entwickl., Bd. 14, pp. 808-1048.

1906 Ueber allgemeine und specielle Fragen aus der Lehre vom Kopfskelett der Wirbeltiere. Verhandl. d. anat. Gesellsch., 20 Versamml., pp. 21-68.

1907 a Ueber Entwickelung und Bau der beiden ersten Wirbel und der Kopfgelenke von Echidna aculeata. Jena. Denkschr., Bd. 6, T. 2, pp. 483-538. (Semon, Zool. Forschungsreisen, Bd. 3, T. 2).

1907 b Hauptergebnisse der an dem Semonschen Echidna-Material vorgenommenen Untersuchung der Schädelentwickelung. Verhandl. d. anat. Gesellsch., 21 Versamml., pp. 129-141.

1908 Zur Entrickelungsgeschichte und vergleichenden Morphologie des Schädels von Echidna aculeata var. typica. Jena. Denkschr., Bd. 6, T. 2, pp. 541-788. (Semon, Zool. Forschungsreisen, Bd. 3, T. 2). 1910 a Das Lacrimale des Menschen und der Säuger und seine morphologische Bedeutung. Anat. Anz., Bd. 36, pp. 529-555.

$1910 \mathrm{~b}$ Säugerpterygoid und Echidnapterygoid nebst Bemerkungen über das Säuger-palatinum und den Processus basipterygoideus. Anat. Hefte, Bd. 42, pp. 311-431.

1911 a Ueber den N. trochlearis der Urodelen und über die Austrittsstellen der Gehirnnerven aus dem Schädelraum im Allgemeinen. Anat. Anz. Bd. 38, pp. 401-444.

1911 b Beiträge zur Ínntnis des Unterkiefers der Wirbeltiere. I. Der Processus anterior (Folii) des Hummers der Säuger und das Goniale der Nichtsäuger. Anat Anz., Bd. 39, pp. 97-135. II. Die Zusammensetzung des Unterkiefers der Quadrupeden. Anэt. Anz., Bd. 39, pp. $433-473$. 
Hasse, C. 1873 Das Gehörorgan der Schildkröten. Hasse's Anatomische Studien, Bd. 1, pp. 225-329.

Hoffrann, C. K. 1890 Schildkröten. Bronn's Klassen und Ordnungen, Bd. 6, Abt. 3, pp. 1-442.

Howes, G. B. And Swinnerton, H. H. 1903 On the development of the skeleton of the tuatara, Sphenodon punctatus. Trans. Zool. Soc. London, vol. 16 , pp. 1-86.

KUNKEL, B. W. 1911 Zur Entwickelungsgeschichte und vergleichenden Morphologie des Schildkrötenschädels. Anat. Anz., Bd. 39, pp. 35.1-364. 1912 On a double fenestral structure in Emys. Anat. Rec., vol. 6, pp. 267-280.

Monks, Sarak P., 1878 The columella and stapes in some North American turtles. Proc. Amer. Phil. Soc., vol. 17, pp. 335-337.

Nick, L. 1912 Das Kopfskelet von Dermochelys coriacea L. Zool. Jahrb., Abt. f. Anat., Bd. 33, pp. 1-238.

NoAcK, H. 1907 Ueber die Entwicklung des Mittelohres von Emys europaea nebst Bemerkungen zur Neurologie dieser Schildkröte. Arch. f. mikr. Anat., Bd. 69, pp. 457-490.

Ogusmi, K. 1911 Anatomische Studien an der japanischen dreikralligen Lippenschildkröte (Trionyx.japanicus). Morph. Jahrb., Bd. 43, pp. 1-106.

PARKER, W. K. 1880 On the development of the green turtle (Chelone viridis, Schneid.) 'Challenger Reports,' Zool., vol. 1, part 5, pp. 1-58.

Seydez, O. 1896 Ueber die Nasenhöhle und das Jacobson'sche Organ der Landund Sumpf-schildkröten. Festschr.z.70. Geburtstag von Carl Gegenbaur, Bd. 2, pp. 385-486.

Siebenrock, F。 1897. Das Kopfskelet der Schildkröten. Sitzungsber.d. kaiserl. Akad. d. Wissensch.Wien; math.-naturwissensch.K1., Bd. 106, Abt. 1, pp. $245-328$.

1899 Ueber den Bau und die Entwicklung des Zungenbein-Apparates der Schildkröten. Ann. d. k. k. naturhistor. Hofmuseums, Wien, Bd. 13, Heft 4, pp. 423-437.

ThYNG, F. W. 1906 The Squamosal bone in tetrapodous vertebrata. Proc. Boston Soc. Nat. Hist., vol. 32, pp. 387-425.

VAN Bemmelen, J. F。 1896 Bemerkurgen über den Schädelbau von Dermochelys coriacea. Gegenbaur's Festschrift, Bd. 2, pp. 277-286.

VersluYs, J. 1909 Ein grosses Parasphenoid bei Dermochelys coriacea, Linn. Zool. Jahrb., Bd. 28, Anat. Abt., pp. 283-294.

1910 Bemerkungen zum Parasphenoid von Dermochelys. Anat. Anz., Bd. 36 , pp. $487-495$.

Vогт, M. 1909 Das Primordialeranium des Kaninchens unter Berücksichtigung der Deckknochen. Anat. Hefte, Bd. 38, pp. 425-616. 


\section{ABBREVIATIONS}

'The following list of abbreviations is used throughout in the explanation of both text figures and plates.

a., angulare

a.c. $i_{\text {., arteria carotis interna }}$

a.o., arcus occipitalis

a.p., ampulla posterior

c.a., cartilago articularis

c.a.a., cavum ampullare anterius

c.a.l., cavum ampullare laterale

c.a.p., cavum ampullare posterius

$c . b .$, crista basipterygoidea

$c . b . p$., cornu branchiale primum

$c . b . s .$, cornu branchiale secundum

c.c., cavum cochleae

c.d., ehorda dorsalis

c.e., cartilago ectochoanalis

c.h., cartilago hypochiasmatica

c.hy., corpus hyale

$c . i$, crista inferior

c.l., crista longitudinalis septi

c.M., cartilago Meckelii

$c n . h .$, cornu hyale

c.o., condylus occipitalis

col., columella auris

c.p., cartilago paraseptalis

c.per., canalis perilymphaticus

c. pf., commissura praefacialis

c. pt., crista pterygoidea

cr.p., crista parotica

$c . s$. , crista sellaris

$c . s . \alpha$, canalis semicircularis anterior

c.sac. eavum saceuli

$c . s . l$, canalis semicircularis lateralis

c.s.p., canalis semicircularis posterior

c.sph., commissura spheno-ethmoidalis

c.s.s., cavum sinus superioris utriculi

c.st., crista substapedialis

c.t., chorda tympani

$c . v$, cavum vestibuli

d., dentale

d.e., ductus endolymphaticus

d.p., ductus perilymphaticus

ec., extracolumella

$f$., frontale

f.a., foramen abducentis f.a.a., foramen acusticum anterius

f.a.p., foramen acusticum posterius f.b., fenestra basalis

f.b.p., fenestra basicranialis posterior f.c., fenestra cochleae

f.e., foramen cndolymphaticum

f.ep., foramen epiphaniale

$f . f$., foramen facialis

$f . g .$, fovea genicularis

f.g.e., foramen glossopharyngei exter$11 \mathrm{~mm}$

$f \cdot g . i$, foramen glossopharyngei internum

f.h., fenestra hypophyseos

f.m., fissura metotica

f.mp., fenestra metoptica

f.n., fenestra narina

f.o., foramen ophthalmicum

f.ol., fenestra olfactoria

f.o.m., foramen occipitale magnum

f.opt., fenestra optica

f.orb., fissura orbitonasalis

$f . p$. , foramen praepalatinum

f.pr., fenestra prootica

f.s., fossa subarcuata

f.s.n., fenestra septi nasi

f.sp., foramen spino-occipitale

$f . v$., fenestra vestibuli

g., goniale

g.g., ganglion geniculi

g.gl., ganglion glossopharyngei

g.s., ganglion semilunare

g.v., ganglion vagi

i.c., incisura columellae

l.t.a., lamina transversalis anterior

m., maxillare

o.c., capsula otica

p., parasphenoideum

p.a., processus ascendens palatoquadrati

pal., palatinum

p.ant., planum antorbitale

p.a.p., prominentia ampullaris posterior 
par., parietale

$p . b .$, planum basale

$p f$, praefrontale

$p . i$., processus inferior

p.l., processus lingualis

p.met., pila metoptica

p.p., pila prootica

pl.s., planum supraseptale

pr.a., prominentia ampullaris lateralis

pr.b., crista basipterygoideus

pr.i., processus interhyalis

prm., praemaxillare

pr.p., processus posterior

pr.pt., processus pterygoideus

$p r . s .$, processus supranarinus

p.s.a., prominentia semicircularis anterior

p.sg., pila supraglandularis

pst., postfrontale

$p t$. pterygoideum

q., quadratum

r.c., ramus communicans $\mathrm{n}$. facialis cum glossopharyngeo

$r . h .$, ramus hyomandibularis $\mathrm{n}$. facialis r.o., ramus ophthalmicus $\mathrm{n}$. trigemini $r . p$. , ramus palatinus $\mathrm{n}$. facialis

s., squamosum

sa., supraangulare

sac., sacculus s.c., sulcus cavernosus

sep., septum nasi

s.g., sulcus glossopharyngei

$s . i$, septum interorbitale

s.o., sinus oculomotorius

s.s., sulcus supracristularis

s.s.a., septum semicirculare anterius

s.s.l., septum semicirculare laterale

s.s.p., septum semicirculare posterius sub.i., subiculun infundibuli

$t$., trabecula cranii

t.n., tectum nasi

Ł.p., tectum posterius

$u_{\text {., }}$ utriculus

$v$., vomer

v.c.l., vena capitis lateralis

$v . j$. , vena jugularis

z., zygomaticum

$I$, nervus olfactorius .

$I I, \mathrm{n}$. opticus

$I I I$, n. oculomotorius

$I V, \mathrm{n}$, trochlearis

$V$, n. trigeminus

$V I$, n. abducens

$V I I$, n. facialis

$V I I I$, n. acusticus

$I X, \mathrm{n}$. glossopharyngeus

$X$, n. vagus

$X I I$, n. snino-occipitalis 

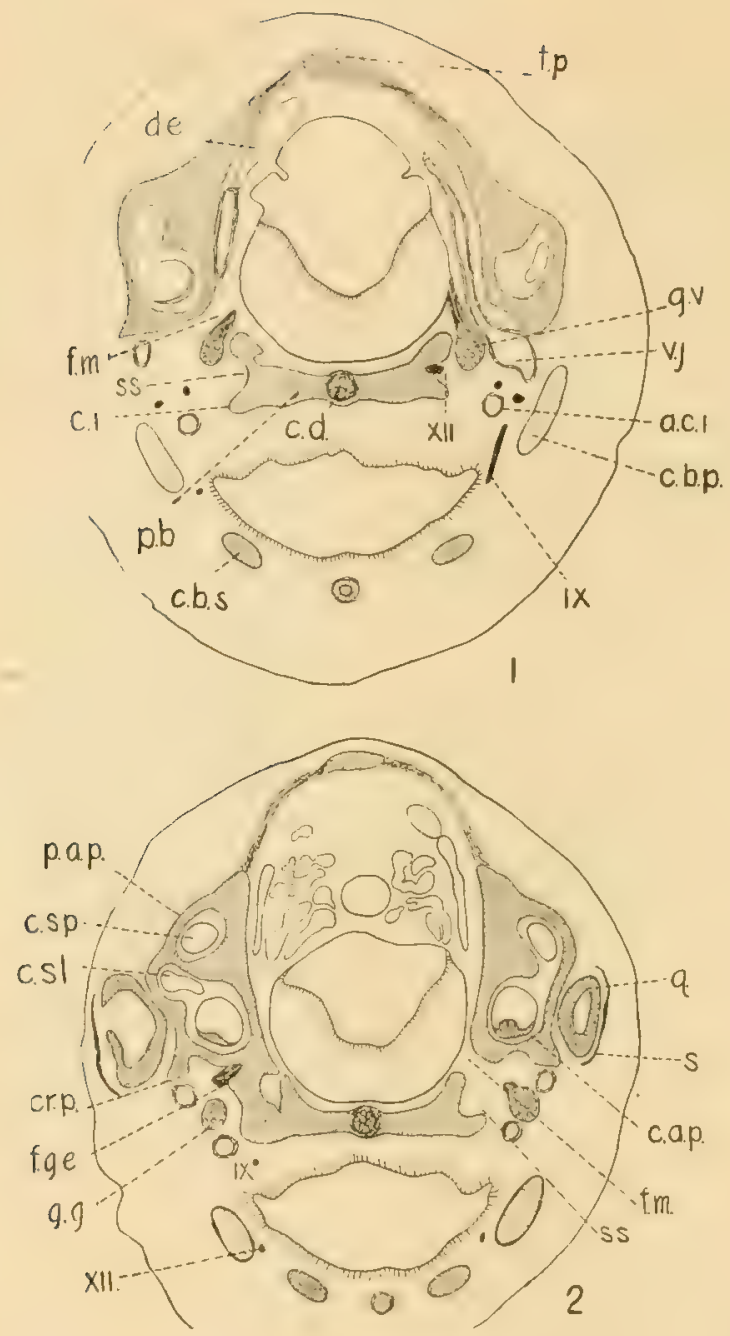

Fig. 1 Cross section through the posterior part of the otic region of an embryo having a carapace length of $11 \mathrm{~mm}$. The section is slightly oblique, the left side (reader's) being anterior to the right side. $\times 15$.

Fig. 2 Cross section through the posterior part of the otic region of the same embryo as figure 1, and slightly anterior to it. On the right side the fissura metotica $\left(f . m_{0}\right)$ and sulcus supracristularis (s.s.) are shown and on the left side the canalis perilymphaticus opens into the cranial cavity by the extreme anterior end of the fissura metotica $\times 15$. 

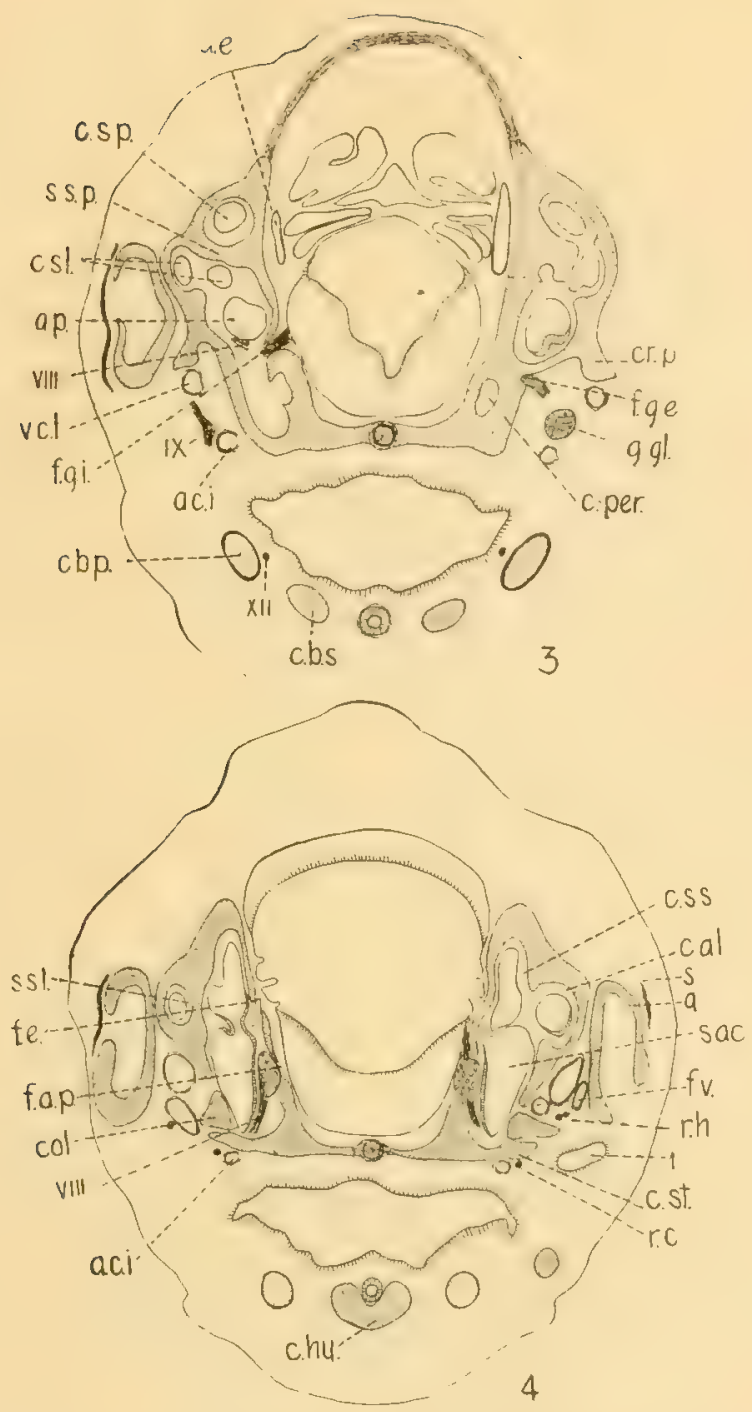

Fig. 3 Cross section through the otic region of the same embryo, showing the nervus glossopharyngeus on the right side emerging from the foramen glossopharyngei externum (f.g.e.) and on the left entering the otic capsule through the foramen glossopharyngei internum (f.g.i.). The canalis perilymphaticus (c.per.) is shown on the right side extending forward from the fissura metotica and on the left side it is opening into the carum cochleae on the median side of the latter. $\times 15$.

Fig. 4 Cross section through the same embryo, slightly in front of the previous figure. The relation of the squamosum (s.) external to the quadratum $(q$. is shown and the arteria carotis interna (a.c.i.) and ramus communicans n. facialis cum glossopharyngeo $(r . c$.$) lying ventral to the crista substapedialis. \times 15$. 

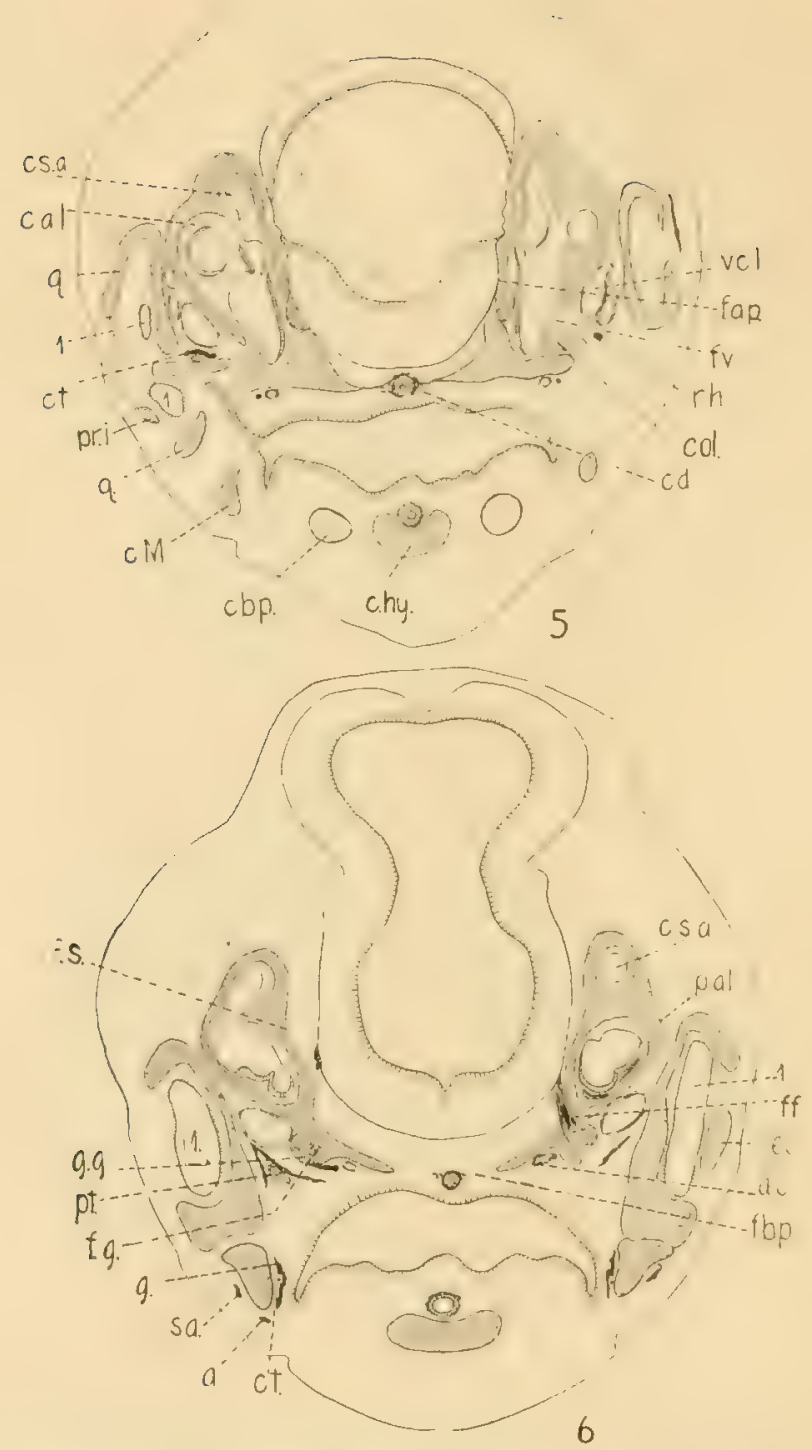

Fig. 5 Cross section of the same embryo, through the otic region, showing, on the left side, the chorda tympani (c.t.) passing from the $\mathbf{n}$. facialis laterally on the dorsal side of the columella auris. The processus interhyalis $\left(p r_{.} i_{\text {. }}\right)$ of the extrs. columella is also seen. $\times 15$.

Fig. 6 Cross section of the same embryo through the anterior part of the otic capsule showing, on the right side, the foramen facialis $\left(f . f_{.}\right)$, and on the left side the fovea geniculi $(f . g$.$) and the ramus palatinus \mathbf{n}$. facialis leaving the ganglion geniculi. The chorda tympani (c.l.) is lying in a groove on the lateral surface of the goniale. $\times 15$. 


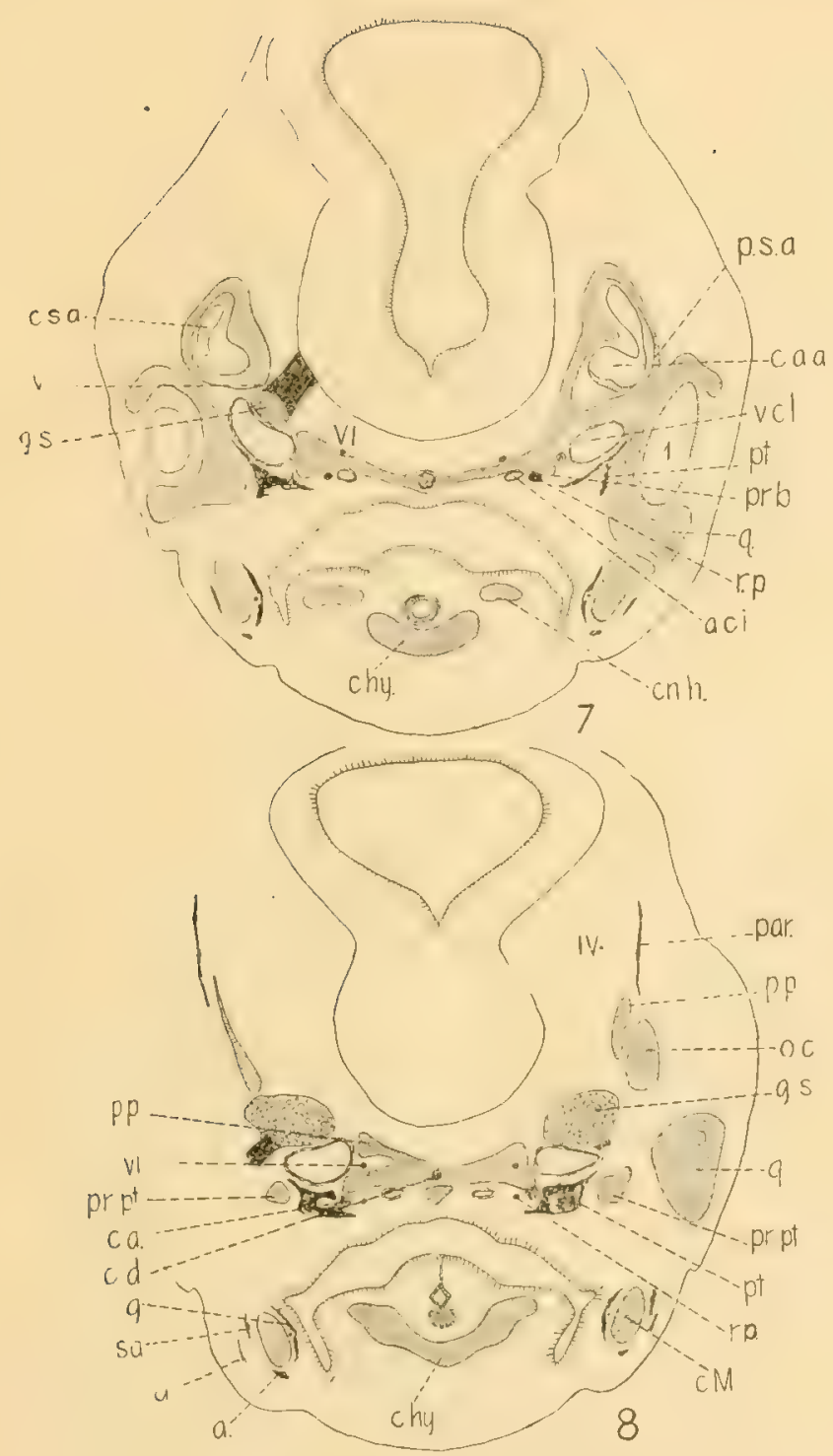

Fig. 7 Cross section of the same embryo through the anterior part of the otic region in front of the previous figure, showing the nervus abducens immediately before it enters the foramen abducentis and also the processus basipterygoideus $(p r . b.) . \times 15$.

Fig.8 Cross section of the same embryo through the posterior part of the orbitotemporal region, showing the large ganglion semilunare $(g . s$.$) lying in the fenes-$ tra prootica; the nervus abducens (VI) is seen on the right side lying in the foramen abducentis and on the left it is ventral to the base of the pila prootica (p.p.). The eartilago articularis (c.a.) is to be seen attached to the ventral surface of the processus basipterygoideus. $\times 15$. 

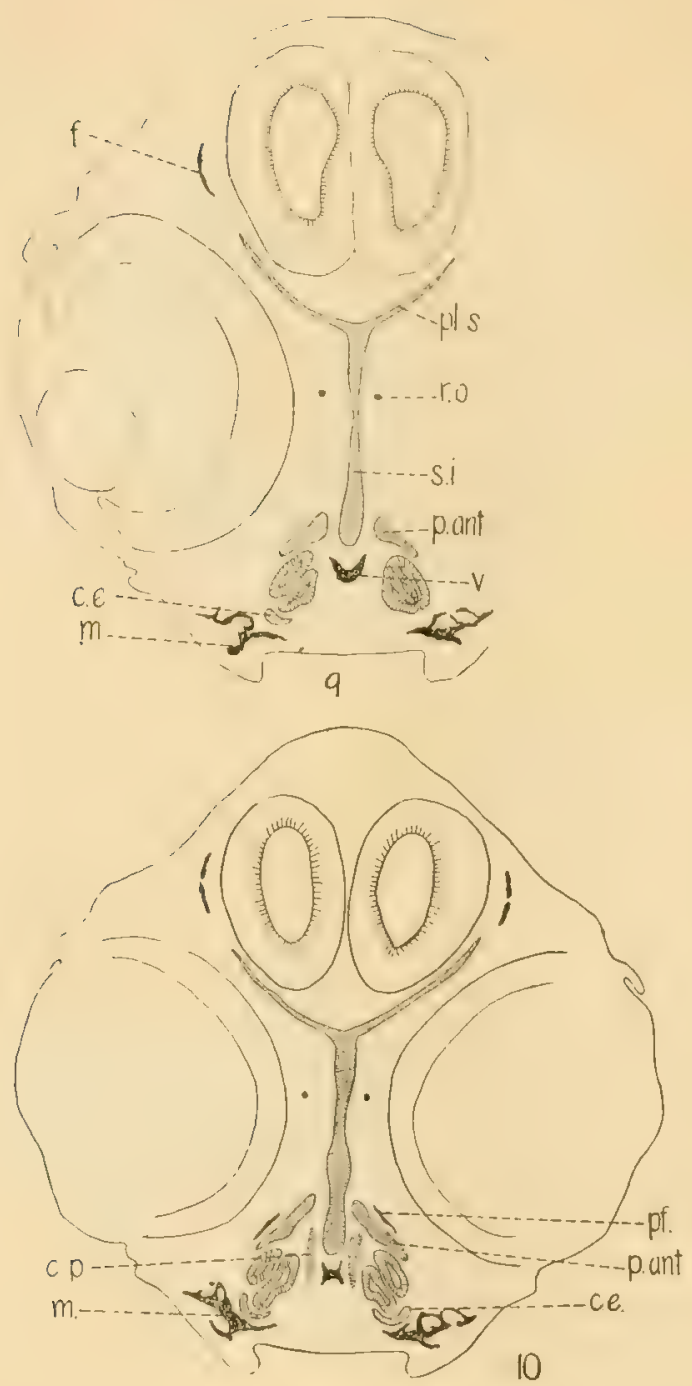

Fig. 9 Cross section through the anterior part of the orbital region of the same embryo, showing the septum interorbitale (s.i.) and the posterior part of the olfactory capsule, the planum antorbitale $(p$.ant.) and the cartilago ectochoanalis (c.e.) alone being cut. $\times 15$.

Fig. 10 Cross section through the posterior part of the ethmoidal region of the same embryo showing the lack of continuity between the olfactory capsule posteriorly and the septum interorbitale. $\times 15$. 

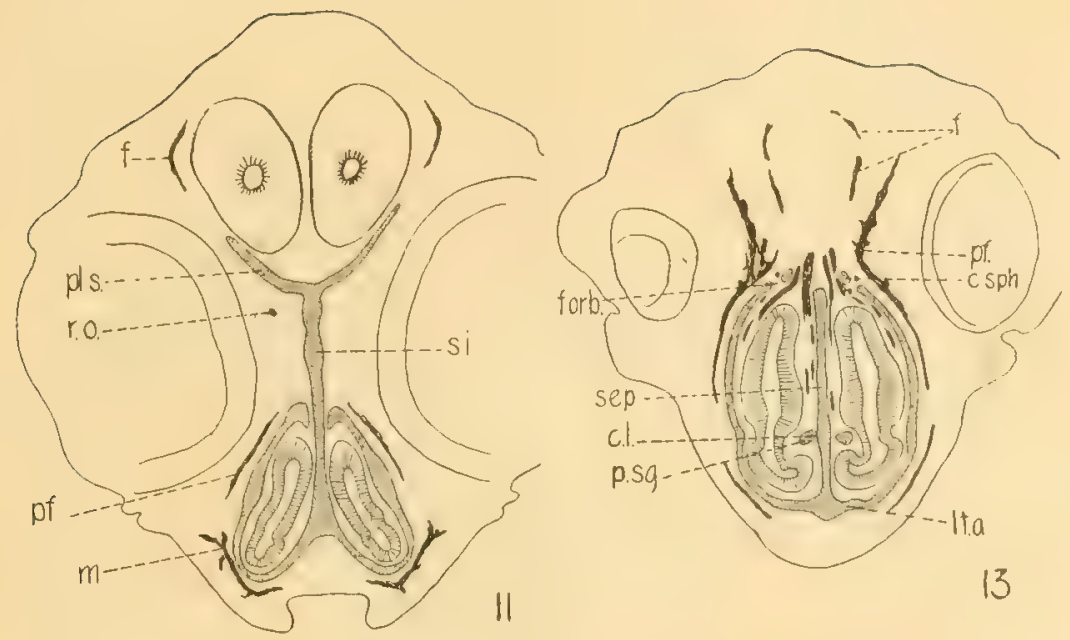

13
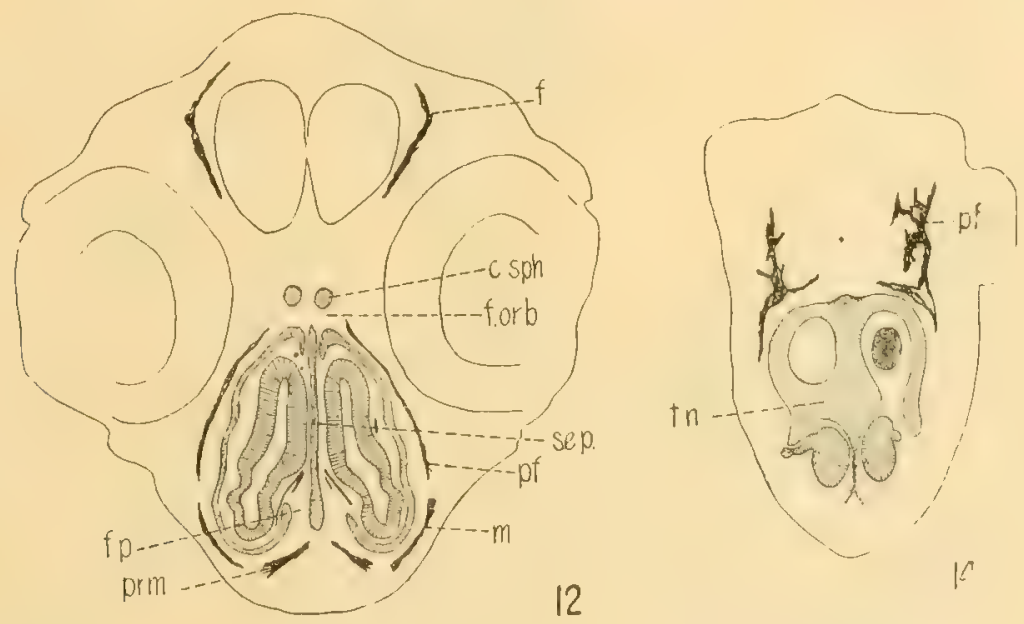

Fig. 11 Cross section through the ethmoid region a few sections in front of the preceding figure, showing the separation of the capsular wall dorsally from the septum, the thickening of the paries nasi to form a rudimentary concha, and the fusion of the planum nasi and cartilago paraseptalis with the septum posterior to the foramen praepalatinum which is seen in the following figure. $\times 15$.

Fig. 12 Cross section a short distance in front of the preceding figure, showing the foramen praepalatinum (f.p.) and the commissura spheno-ethmoidalis (c.sph.). $\times 15$.

Fig. 13 Cross section a short distance in front of the preceding figure showing the crista longitudinalis septi (c.l.), the pila supraglandularis (p.sg.), and the lamina terminalis anterior (l.t.a.). $\times \mathbf{1 5}$.

Fig. 14 Cross section through the extreme anterior end of the olfactory capsule of the same embryo, showing the glandula nasalis externa situated ventral to the cavity of the capsule. $\times 15$. 

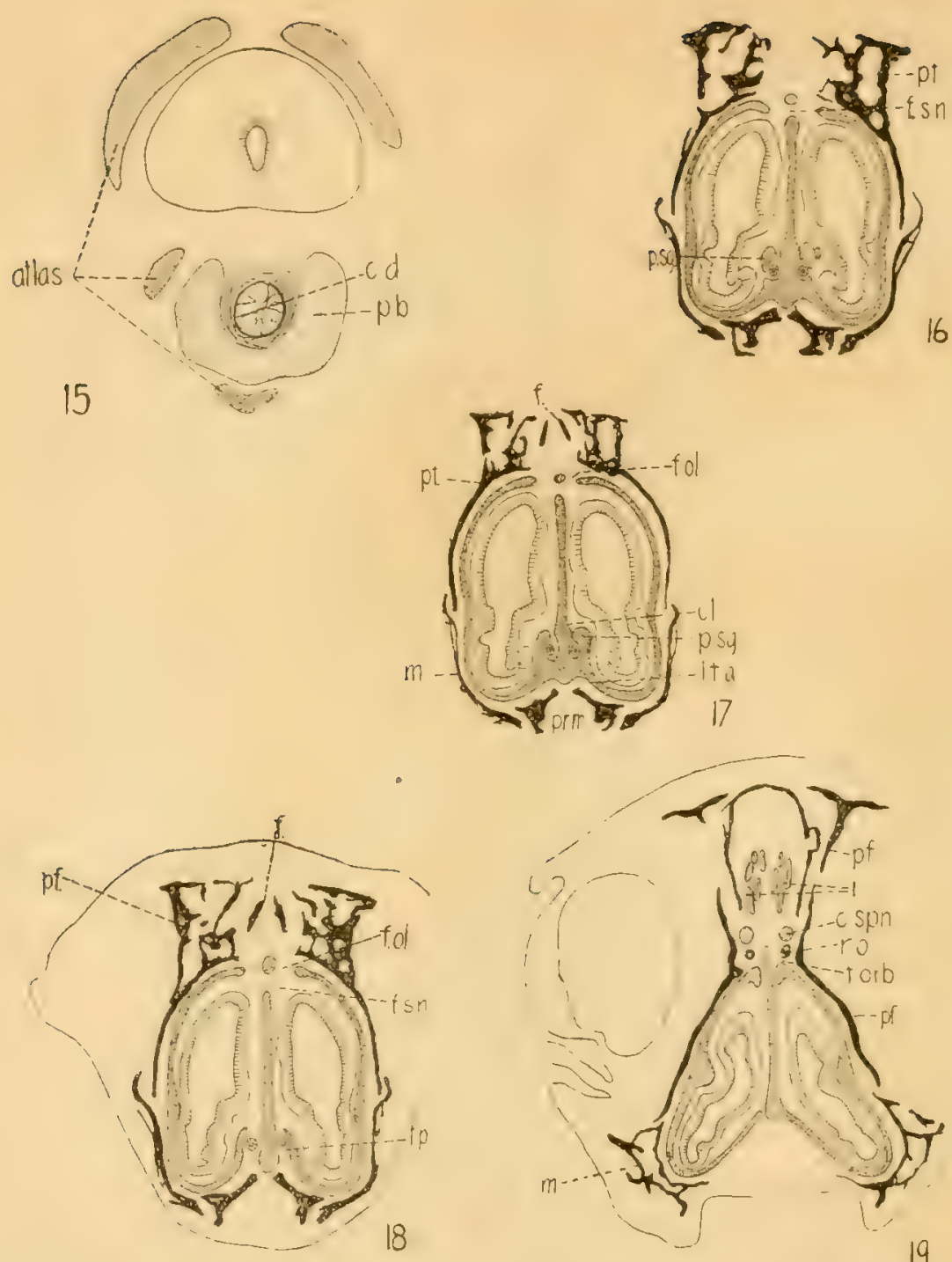

Fig. 15 Cross section through the extreme posterior end of the occipital condyle of an embryo slightly younger than that represented in the preceding figures, showing the chorda dorsalis (c.d.) incompletely surrounded by the occipital condyle which is here hypochordal in position. $\times 15$.

Figs. 16 to 19 A series of four cross sections through the ethmoidal region of an embryo having a carapace $13.5 \mathrm{~mm}$. Iong. The series is from anterior to posterior. In figure 16, on the right side, a cartilaginous nodule is lying in contact by its median surface with the pila supraglandularis $(p . s g$.$) . In figure 17$ the pila supraglandularis has extended ventrally and fused with the lamina terminalis anterior (l.t.a.). The thickening of the paries nasi to form a concha is greatest in figure $19 . \times 15$. 

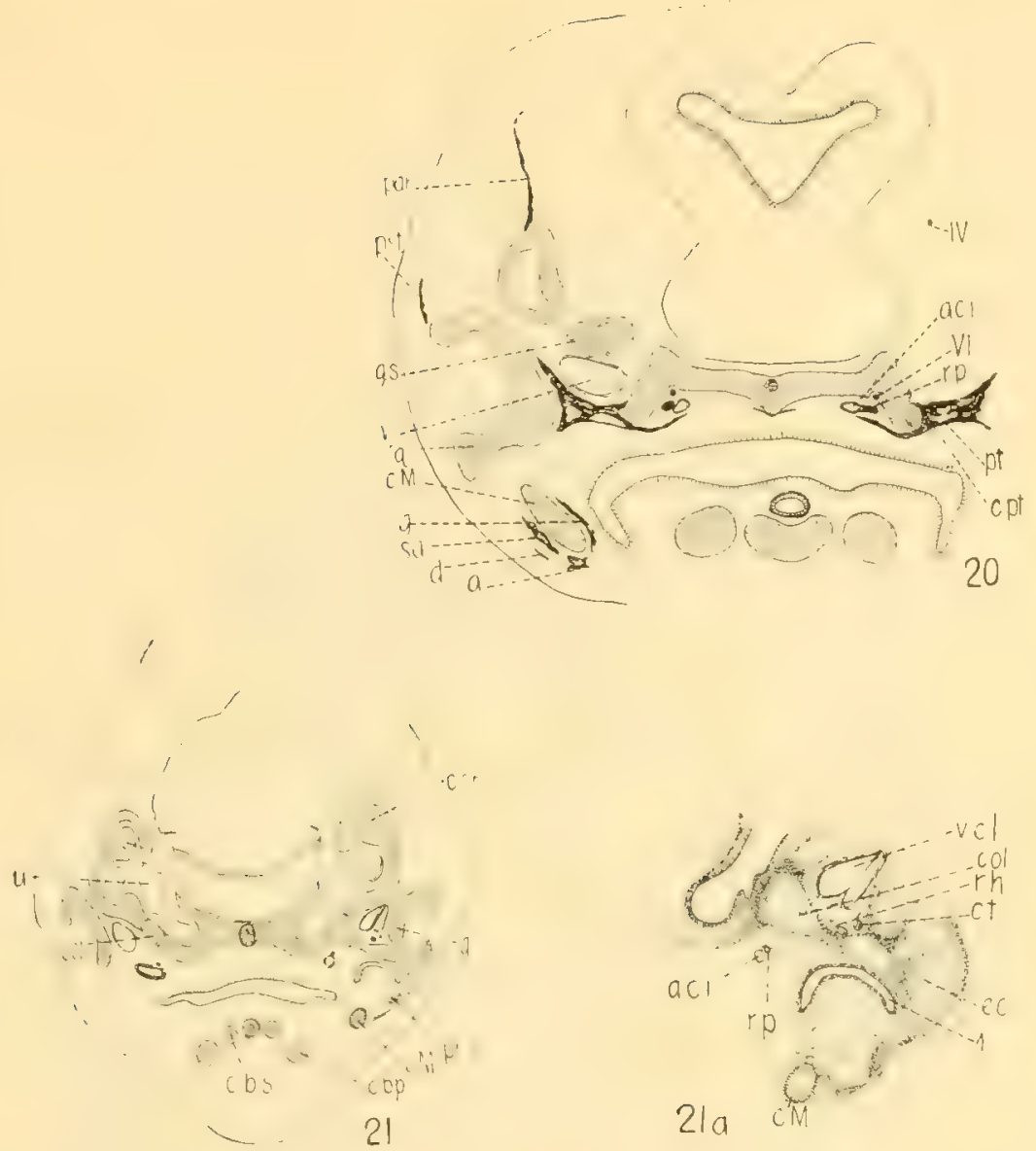

Fig. 20 Cross section through the posterior portion of the orbito-temporal region of an embryo having a carapace $13.5 \mathrm{~mm}$. long, showing the pterygoideum (pt.) extending medially beneath the arteria carotis interna (a.c.i.) and the ramus palatinus $n$. facialis $\left(r \cdot p_{.}\right)$to form the sulcus cavernosus of the adult pterygoideum. A thin osseous lamella may also be seen along the ventral crest of the planum basale which extends further forward and fuses with the parasphenoideum in the region of the fenestra hypophyseos. $\times 15$.

Fig. 21 Cross section through the otic region of an embryo having a carapace length of $7 \mathrm{~mm}$. showing the columella auris (col.) in its relation to the first visceral cleft $(1)$ to the ramus hyomandibularis $n$. facialis $(r, h$.$) , and to the chorda$ tympani $\left(c_{0} t_{0}\right)$. The processus interhyalis $\left(p r_{0} i_{-}\right)$in its relation to the cartilago Meckelii $(c .1 \%$. ) is shown. $\times 15$.

Fig. 21 a A portion of figure 21 more highly magnified. $\times 35$. 


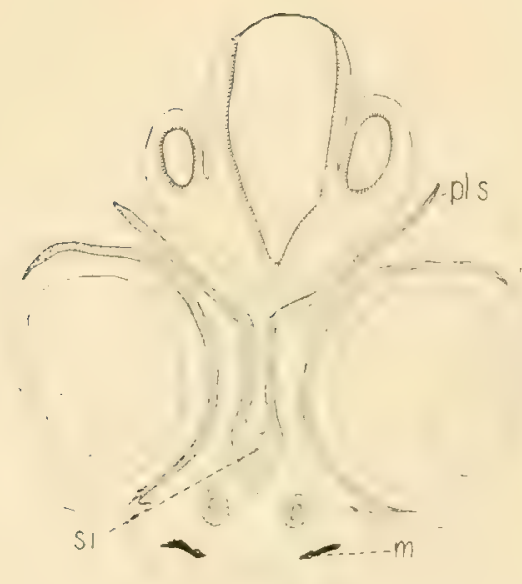

23

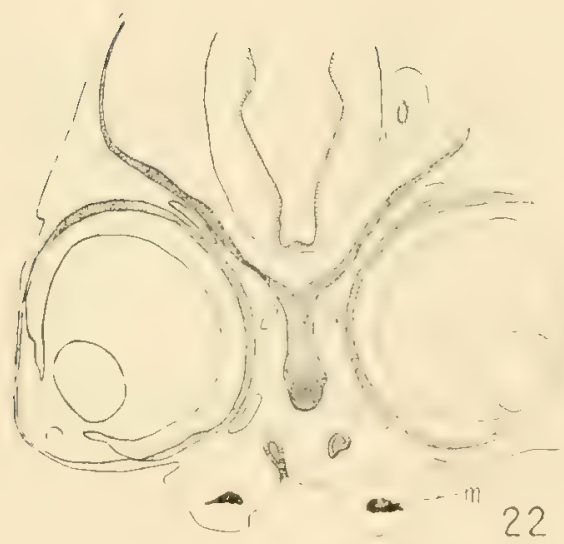

Fig. 22 Cross section through the anterior part of the orbito-temporal region of an embryo having a carapace $7 \mathrm{~mm}$. long, showing the septum interorbitalc much thicker from side to side than in an older embryo, $\times 15$.

Fig. 23 Cross section through the same embryo as the preceding, somewhat further anterior than the previous figure, showing the septum interorbitale $(s, i$. made up of two parallel plates which later become pressed together on the middle line. $\times 15$. 


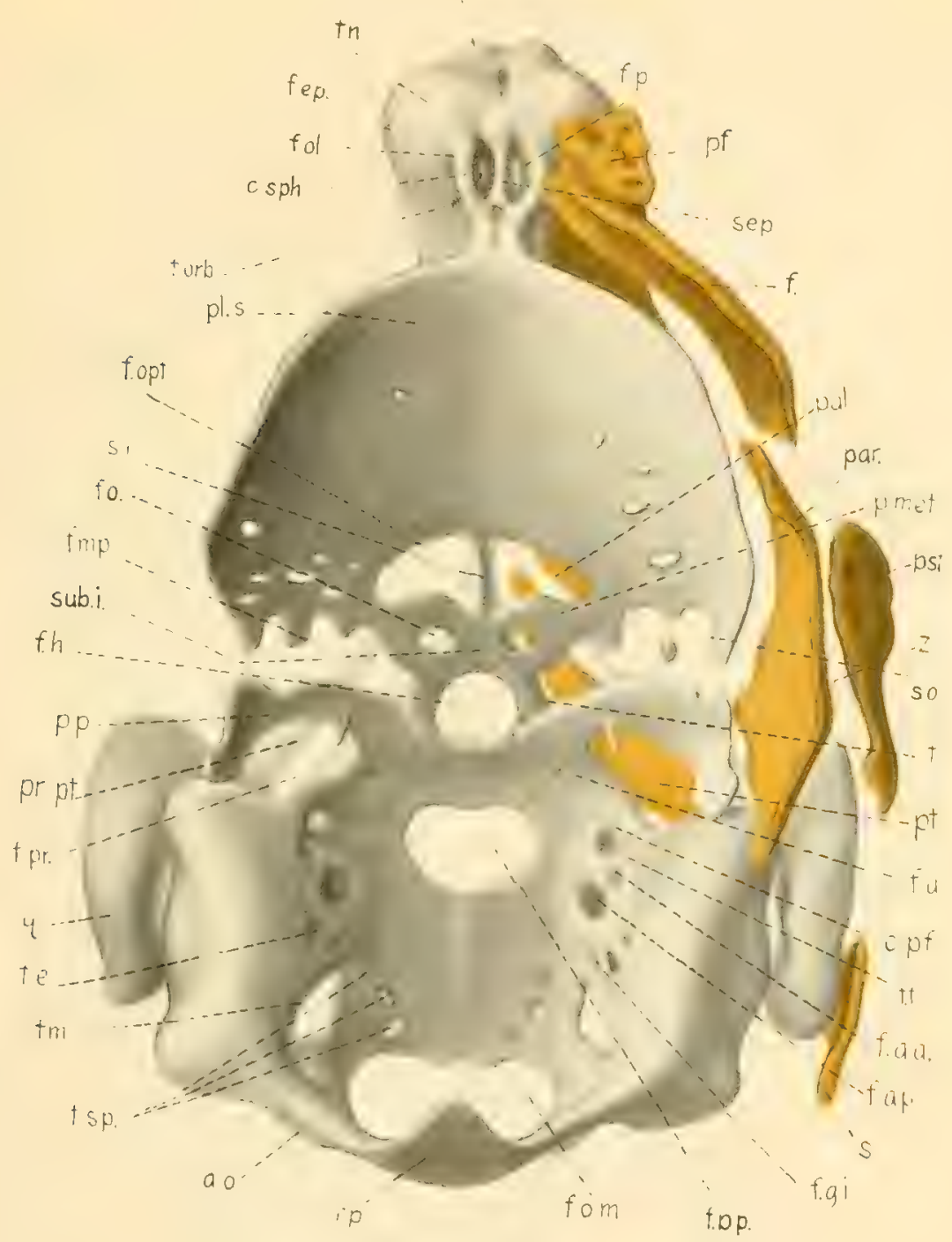

24

EXPLANATION (IF FIGIRH

24 Dorsal view of a model of the chomdroctunium of un embryo hatving a curtpace length of $11 \mathrm{~mm}$. The membrane bones of the right side only are represented. $\times 20$ 


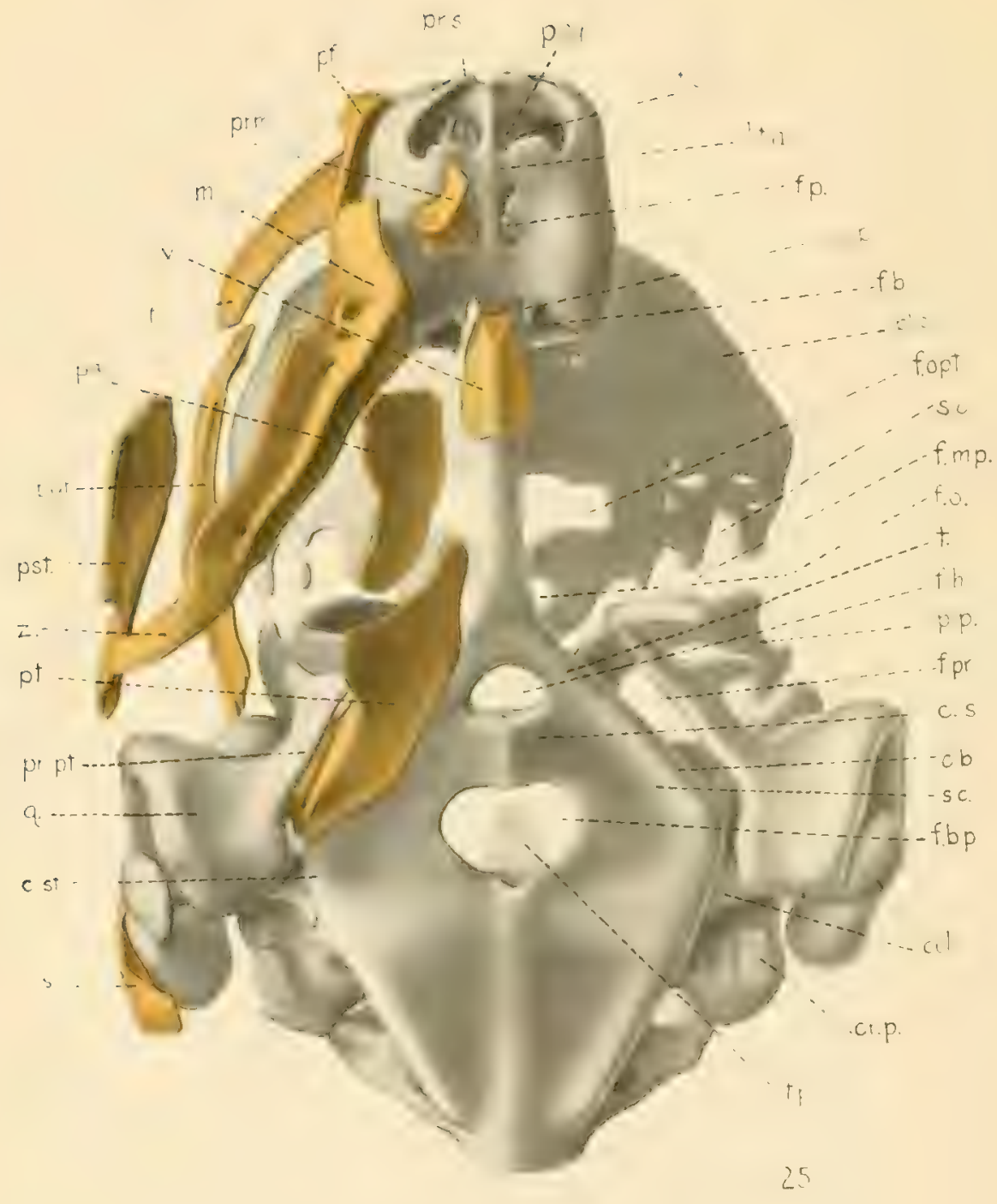

EXIIANATION OF FIGITH:

25 Ventral view of the same model. $\times 20$

776 


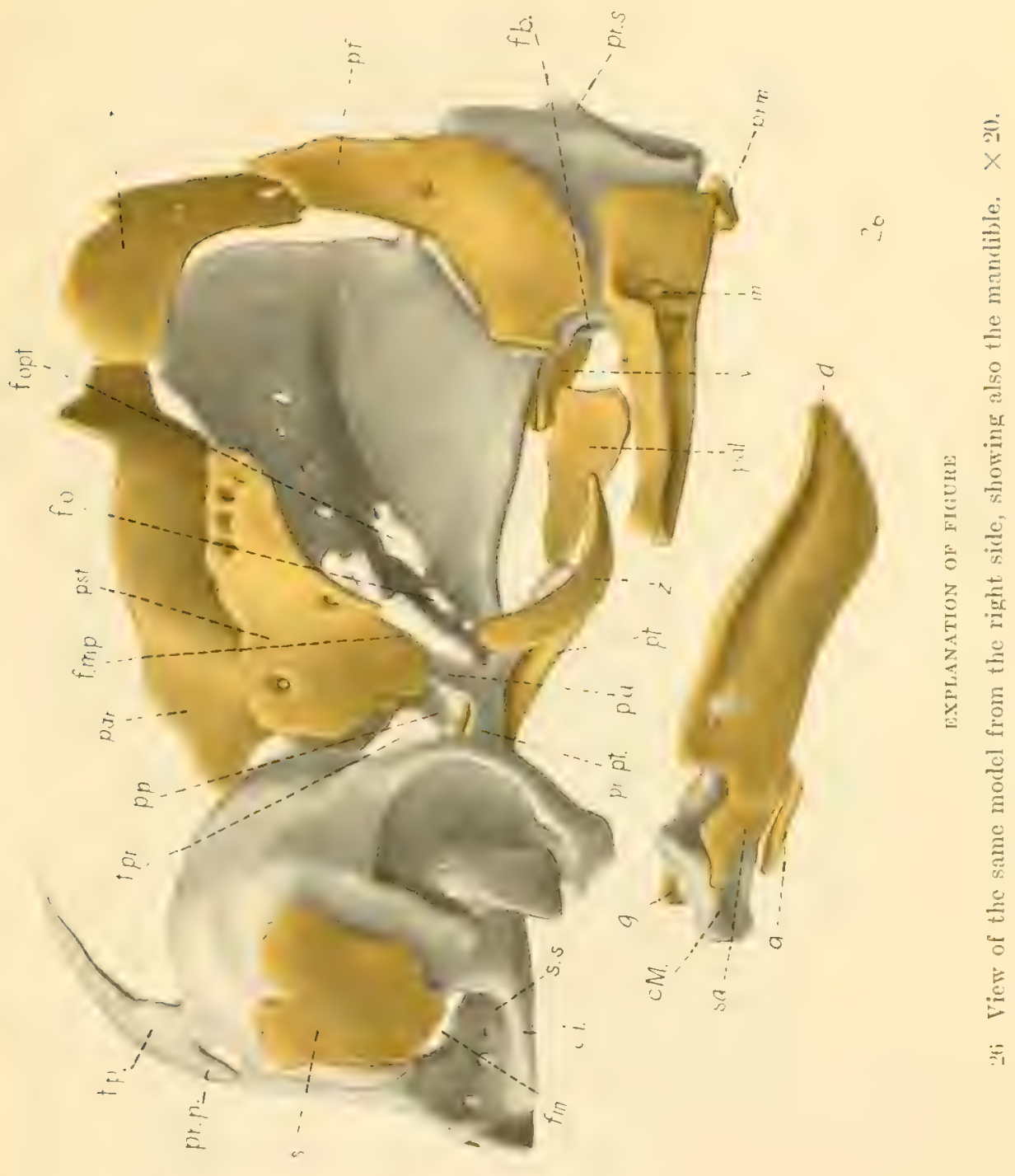




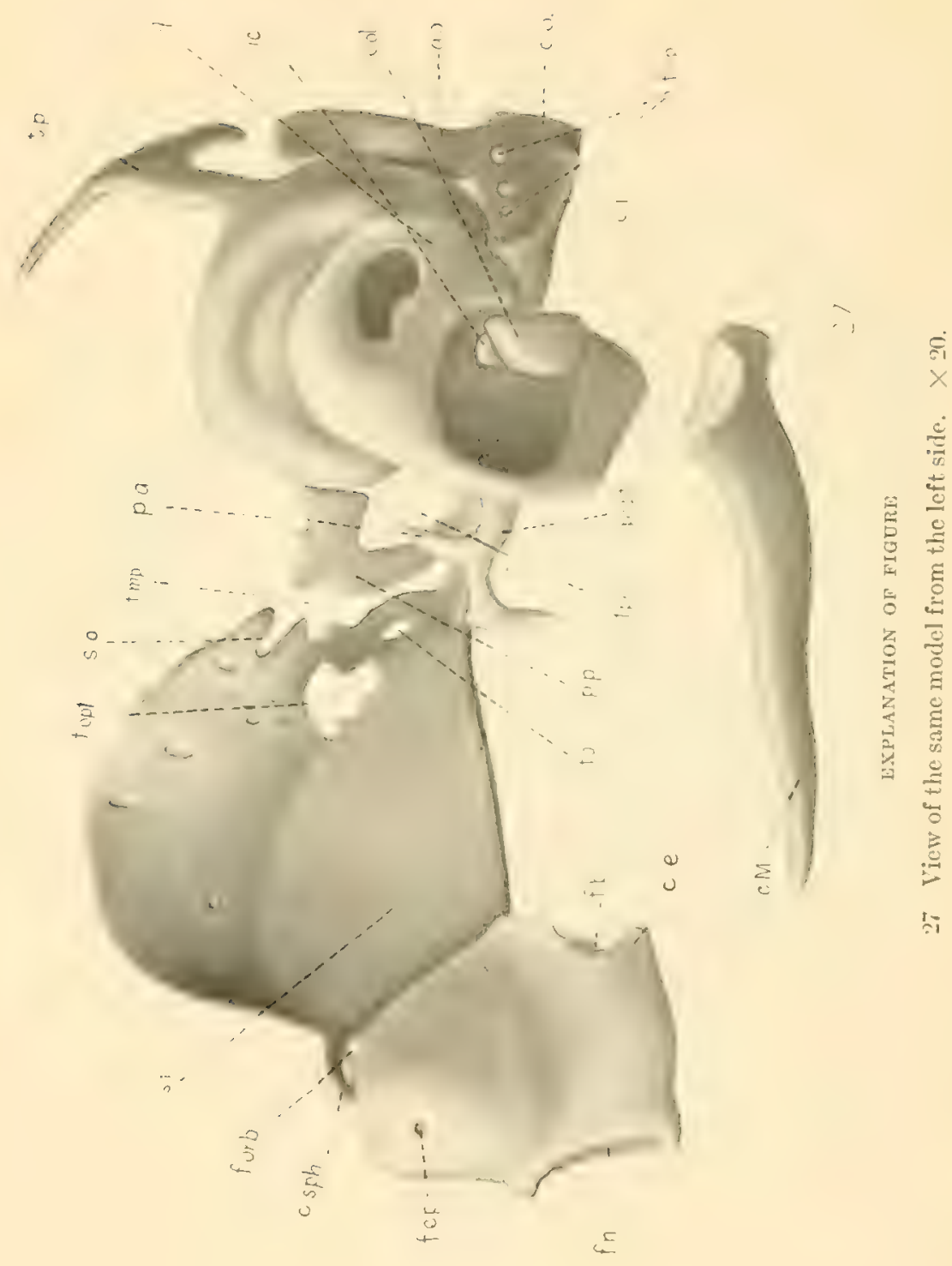



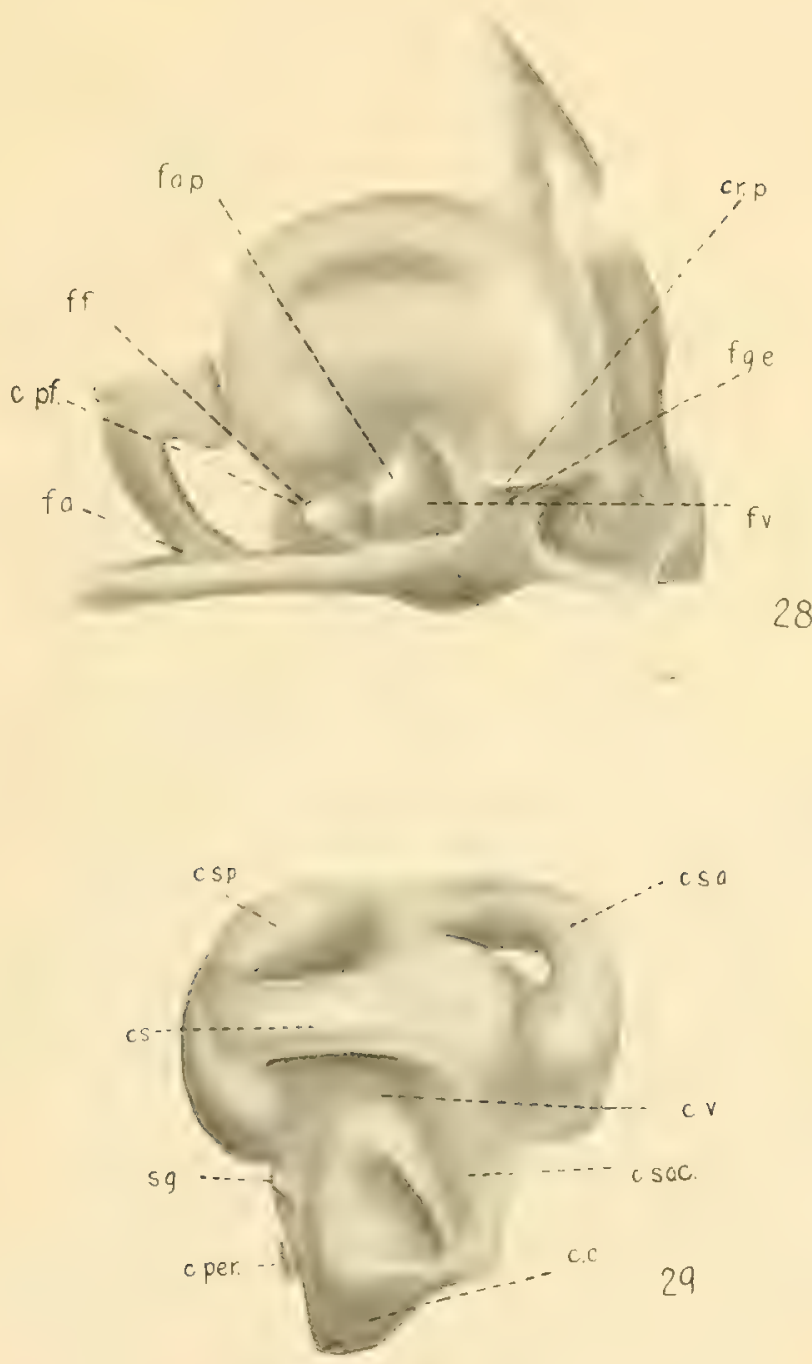

EXPLANATION OF FIGURES

28 View from left side of the same model showing the occipital and otic regions only, with the palatoquadratum removed in order to expose the lateral surface of the otic eapsule. $\times 20$.

29 Lateral view of a model of the cavity of the right otic capsule of the same embryo as the above. $\times 24$. 

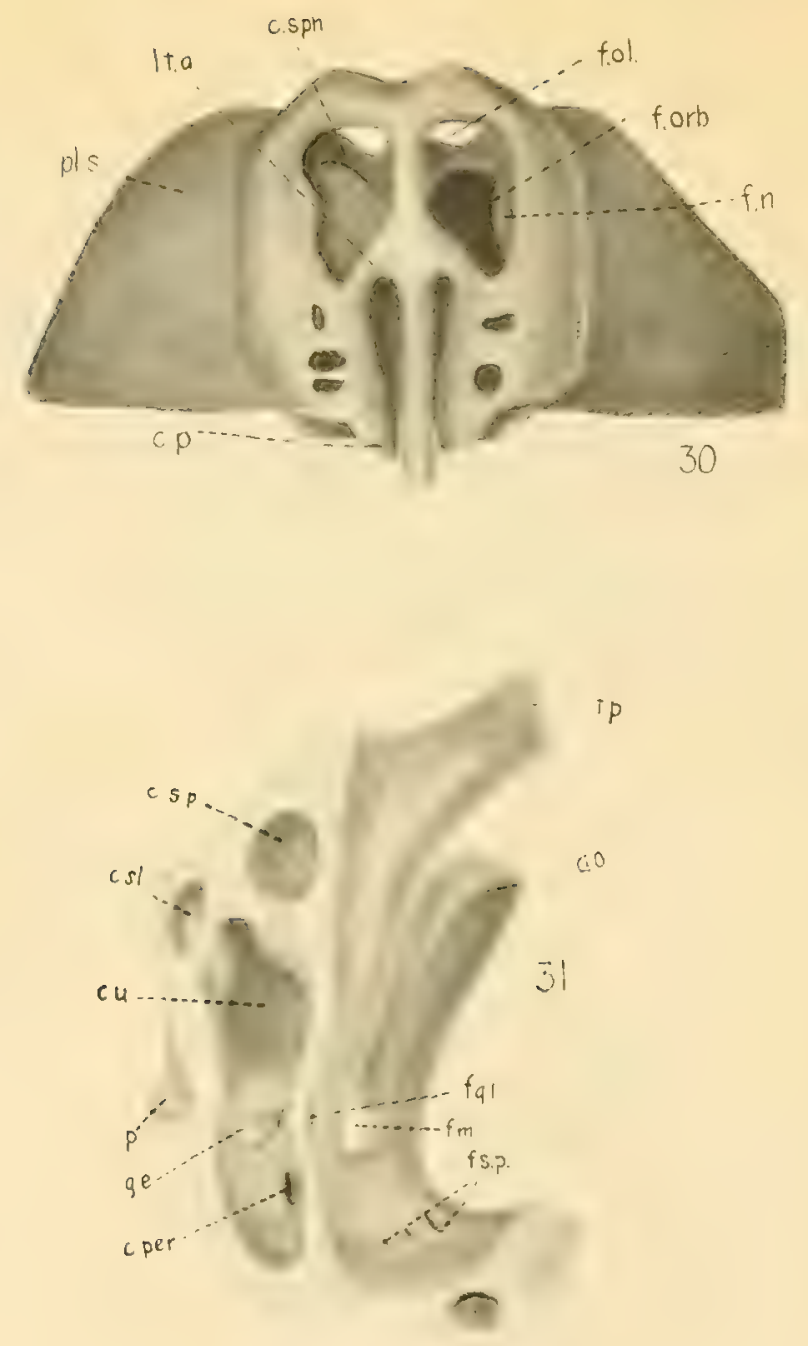

FXPTANATION OF FIGTHES

30 Ventral view of the olfactory capsule of an embryo having a carapace length of $7 \mathrm{~mm}$. showing the cartilago paraseptalis (c.p.) separated from the septum nasi as far anterior as the lamina terminalis anterior (l.t.r.) and consequently the foramen pracpalatinum not enclosed posteriorly. $\times 20$.

31 Posterior portion of the right otic capsule viewed from in front and slightly from the median line, showing especially the groove in which the $n$. glossopharyngeus passes through the capsule between the formen glossopharyngei internum $(f . g . i$.$) and the formen glossopharyngei externum (f.g.e.), and also showing the$ opening of the canalis perilymphaticus (c.per.) into the cochlear cavity. $\times 24$. 



\title{
THE JOURNAL OF MORPHOLOGY
}

\author{
VOLUME 23, NUMBER 4, DECEMBER 20, 1912
}

\section{CONTENTS}

\section{Robert Matheson}

The structure and metamorphosis of the fore-gut of Corydalis cornutus L. From the Entomological Laboratory, Cornell University. Twenty-nine figures..................

W. M. Smallwood and Elizabeth G. Clark

Chromodoris zebra Heilprin, a distinct species. From the Bermuda Biological Station for Research and from the Zoological Laboratory, Syracuse University. Six figures..............

S. W. Williston

Primitive reptiles. From the Paleontological Laboratory, the University of Chicago. One figure................... 637

\section{Gary N. Calkins}

The paedogamous conjugation of Blepharisma undulans St. From the Department of Zoology, Columbia University. Twenty-five figures ................................. 667

B. W. Kunkel

The development of the skull of Emys lutaria. From the Anatomisches Institut, Freiburg i. B., and the Sheffield Biological Laboratory of Yale University. Thirty-one figures......... 693 


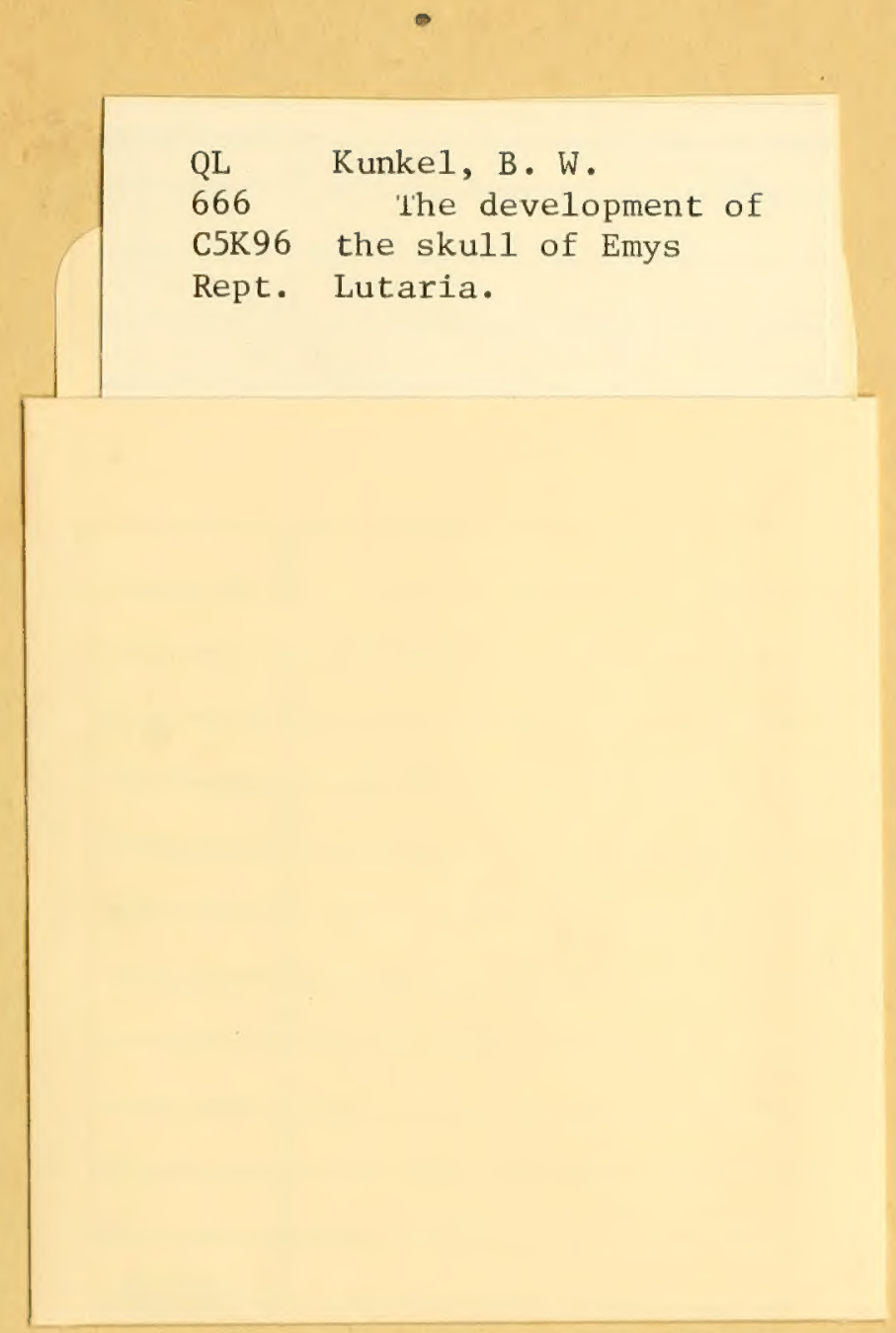




\section{C-

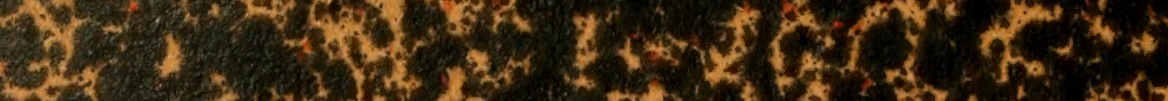

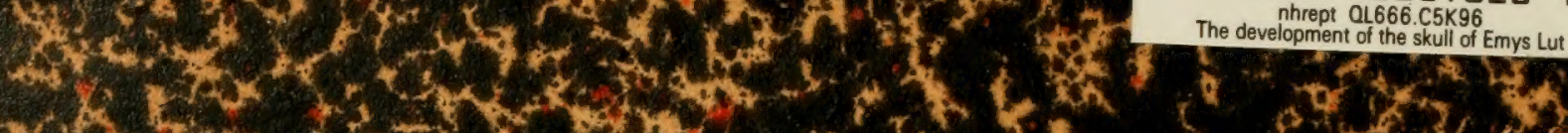

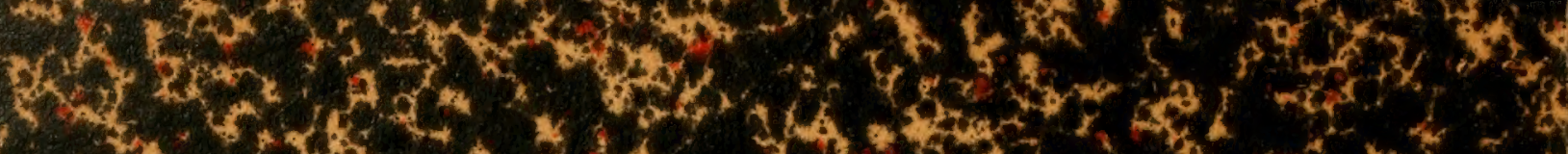
$x+2 x, 3,2,1$

-

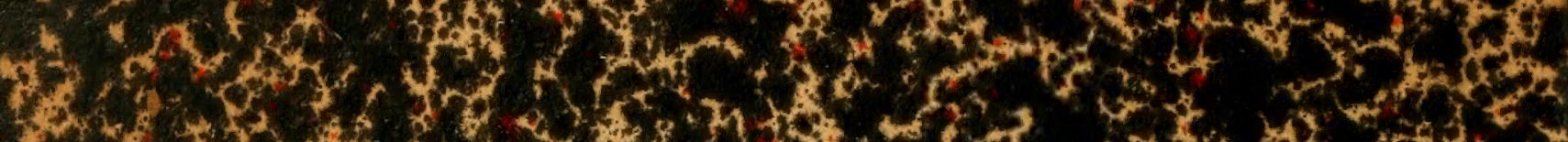

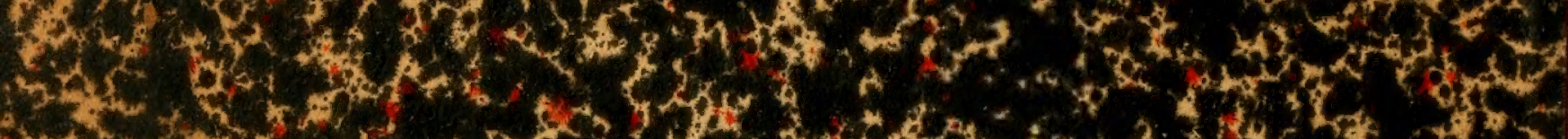

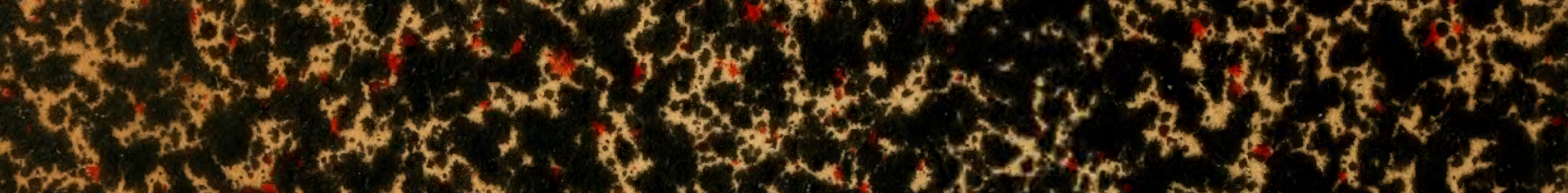

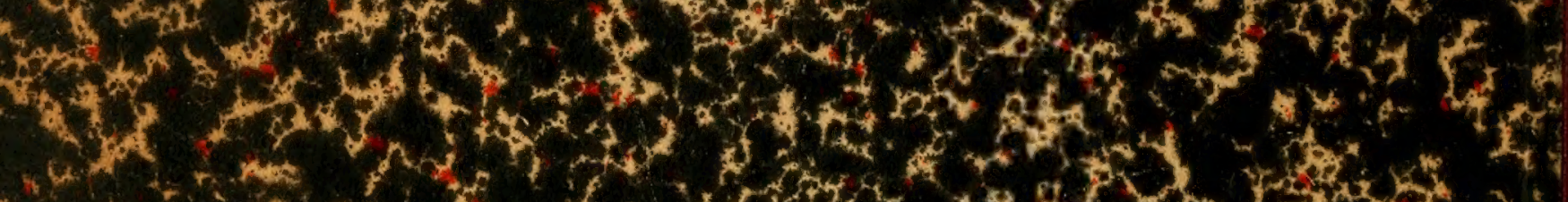
(n)

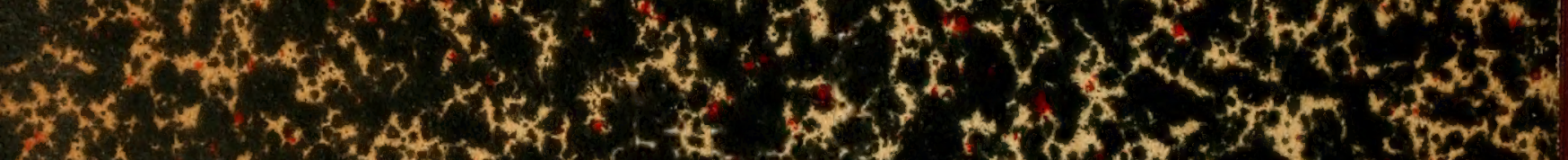

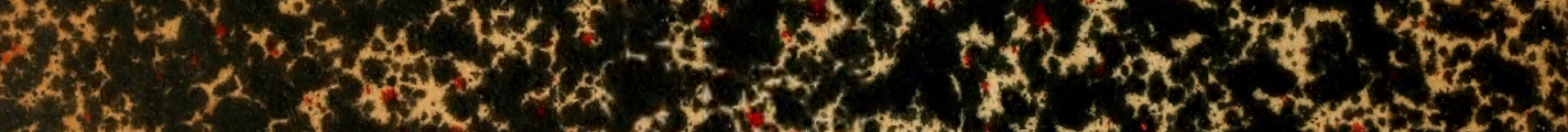

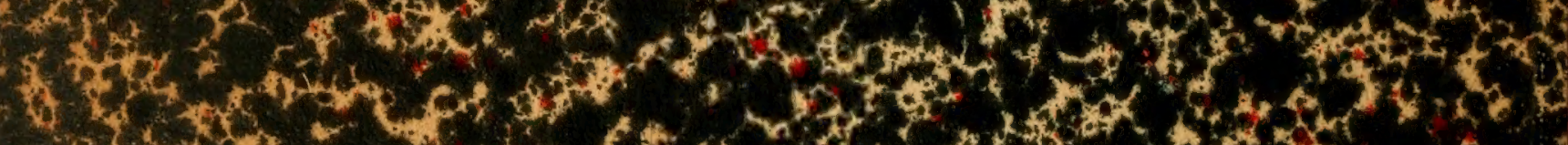

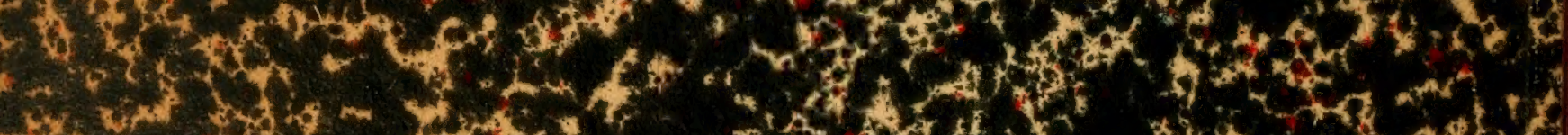
wit

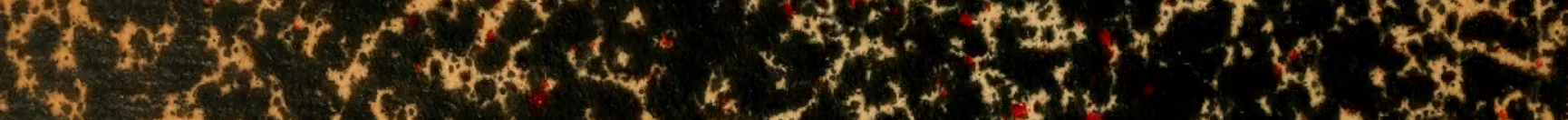

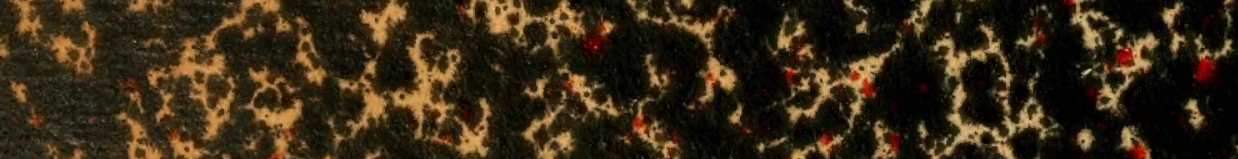

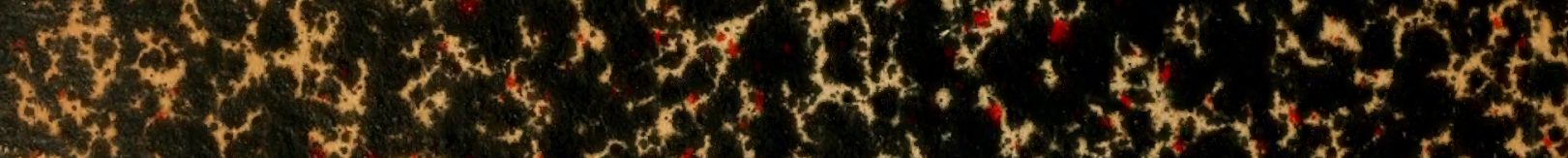

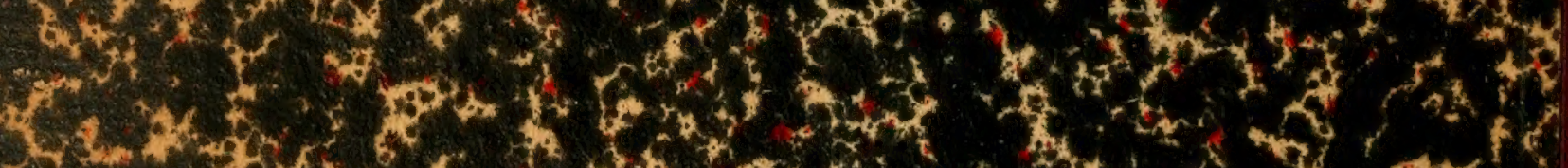
(x)

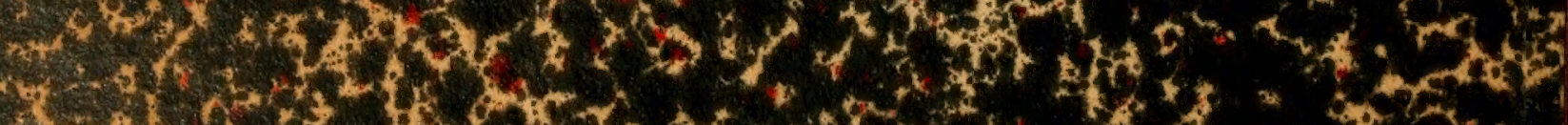

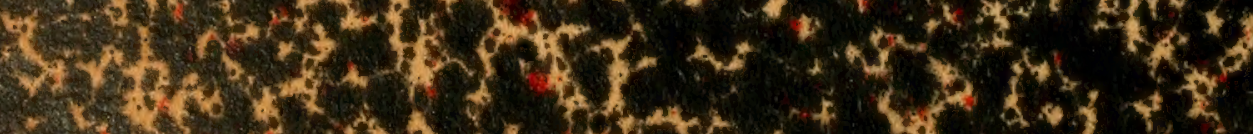
7. 